\title{
Development of Scaling Prediction Tools for Solar Hot Water Systems \\ Part B - Development of an Improved Calcium Carbonate Scaling Rate Model - An Experimental and Analytical Investigation
}

\section{Dissertation Proposal Prepared for:}

Dr. G.C. Vliet, Dept. of Mechanical Eng., Advisor

Dr. D.F. Lawler, Dept. of Civil Eng., Advisor

Dr. J.W. Barnes, Operations Research and Industrial Eng.

Dr. O.A. Ezekoye, Dept. of Mechanical Eng.

Dr. H.M. Liljestrand, Dept. of Civil Eng.

February 6, 1998

$$
\text { Derek Baker }
$$

The University of Texas at Austin

The Department of Mechanical Engineering

\author{
Prepared for the: \\ National Renewable Energy Laboratory \\ and the \\ United States Department of Energy
}

Sept. 22, 1999

Contract Number: DE-FG36-94 G010034 


\section{Foreward}

Contract DE-FG36-94 G010034 began in September 1996 and had an original ending date of August 31, 1997. However, there was a no-cost extension to March 8, 1998.

A Preliminary Final Report, "Validation of SOLSCALE: Software to Predict Scaling in Solar Hot Water Systems", referred to here as Part A, was submitted to NREL/DOE October 8, 1997. The final reporting for this contract consists of that Preliminary Final Report (Part A) and the dissertation proposal of Mr. Baker (February 6, 1998) which is Part B of this final submission. Rather than reproducing the earlier Preliminary Final Report in this final submission, it stands on its own as Part A and the content of this final submission is the dissertation proposal of Mr. Baker, designated Part B. 


\section{DISCLAIMER}

This report was prepared as an account of work sponsored by an agency of the United States Government. Neither the United States Government nor any agency thereof, nor any of their employees, make any warranty, express or implied, or assumes any legal liability or responsibility for the accuracy, completeness, or usefulness of any information, apparatus, product, or process disclosed, or represents that its use would not infringe privately owned rights. Reference herein to any specific commercial product, process, or service by trade name, trademark, manufacturer, or otherwise does not necessarily constitute or imply its endorsement, recommendation, or favoring by the United States Government or any agency thereof. The views and opinions of authors expressed herein do not necessarily state or reflect those of the United States Government or any agency thereof. 


\section{DISCLAIMER}

Portions of this document may be illegible in electronic image products. Images are produced from the best available original document. 


\section{Table of Contents}

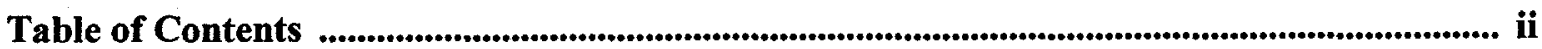

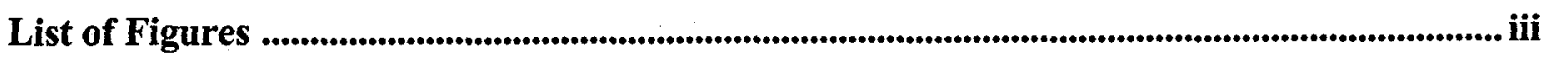

List of Tables

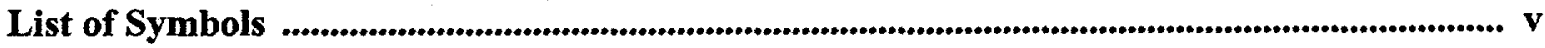

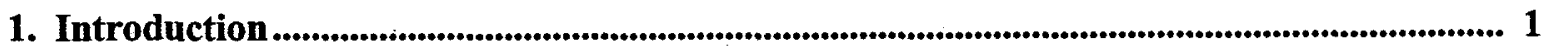

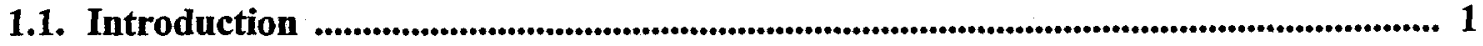

1.2. Examples of the Adverse Affects of Scaling..................................................................... 1

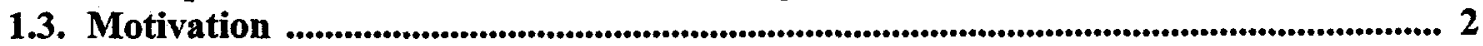

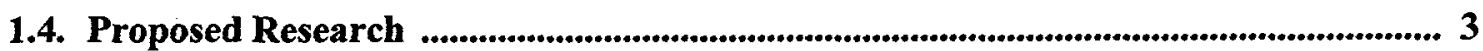

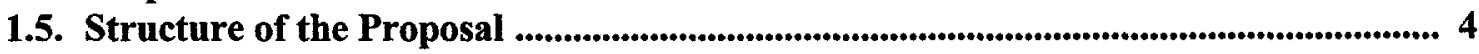

2. Background Information and Literature Review ..........................................................5

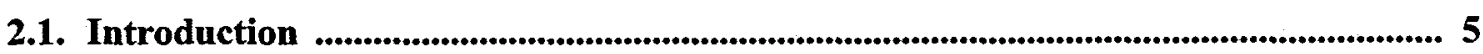

2.2. Scaling and its Relation to Fouling ........................................................................... 5

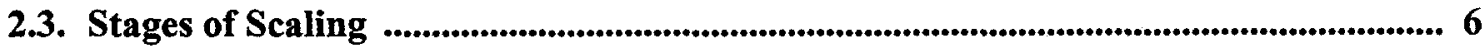

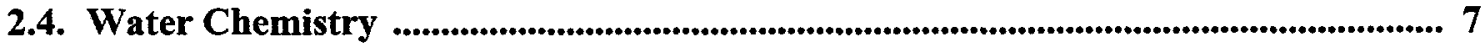

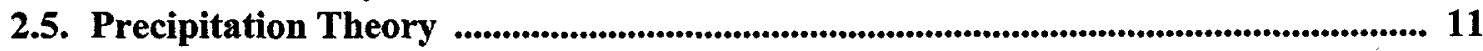

2.6. Parameters Influencing Calcium Carbonate Scaling Rates ....................................... 17

2.7. Review of Scaling Rate Models ............................................................................. 28

2.8. Experimental Scaling Data Compiled from the Literature......................................... 34

2.9. Review of Previous Experimental Set-ups ....................................................................... 40

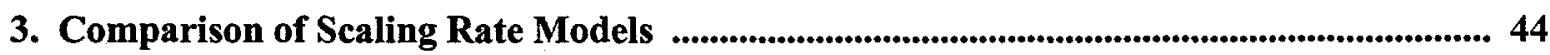

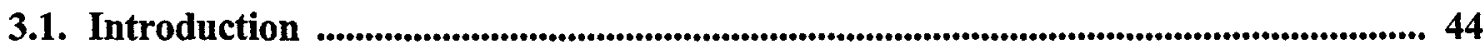

3.2. Empirical Constants Used in the Models ............................................................ 44

3.3. Data Used in the Comparison.................................................................................... 45

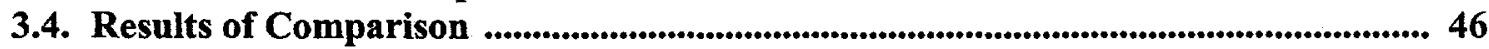

3.5. Semi-Empirical Scaling Rate Model Developed ............................................................. 53

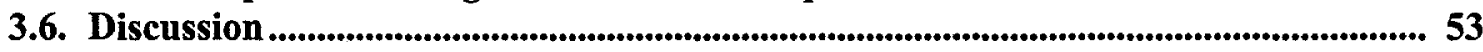

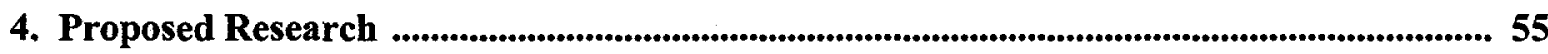

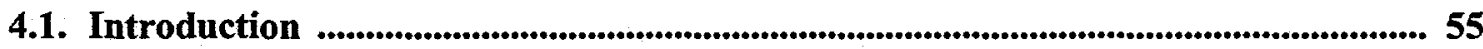

4.2. Proposed Research ........................................................................................................ 56

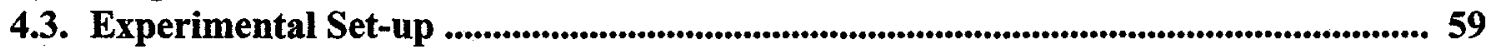

4.4. Applied Research on Scaling .............................................................................................62 62

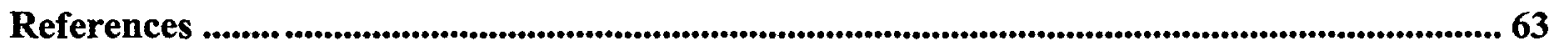

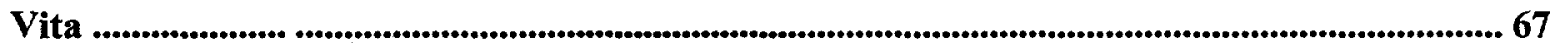




\section{List of Figures}

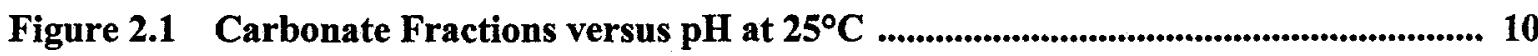

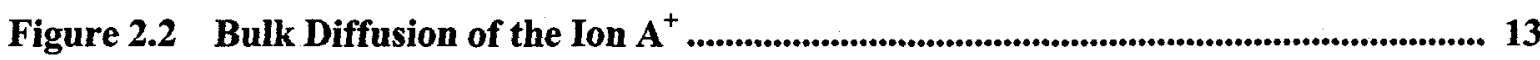

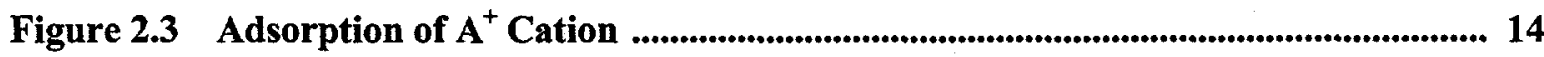

Figure 2.4 Surface Diffusion and Integration ................................................................................ 15

Figure 3.1 Measured and Predicted Scaling Rates versus Reynolds Number Dalas Surface Model ..............................................................................................4 47

Figure 3.2 Predicted/Measured Scaling Rate versus Surface Temperature Baker Diffusion Model $(\mathbf{f}=\mathbf{0 . 6})$

Figure 3.3 Predicted/Measured Scaling Rate versus Bulk Temperature Baker Combined Model $\left(E=43 \mathrm{~kJ} / \mathrm{mole}, A=5 \times 10^{7}\right)$ Hasson (1968) Data Only

Figure 3.4 Predicted/Measured Scaling Rate versus Bulk Temperature Baker Combined Model $\left(E=43 \mathrm{~kJ} / \mathrm{mole}, A=5 \times 10^{7}\right)$

Watkinson (1983) Data 50

Figure 3.5 Predicted/Measured Scaling Rate versus Bulk Temperature Baker Combined Model ( $\left.E=43 \mathrm{~kJ} / \mathrm{mole}, A=5 \times 10^{7}\right)$

All Data 51

Figure 3.6 Predicted/Measured Scaling Rate versus Bulk Temperature Baker Diffusion Model $(f=0.6)$ 52

Figure 3.7 Predicted/Measured Scaling Rates versus Bulk Temperature Corrected Baker Diffusion Model 53

Figure 4.1 Initial Experimental Set-up 60

Figure 4.2 Cross Sectional View of the Heated Portion of the Test Section 61 


\section{List of Tables}

Table 2.1 Summary of Experimental Conditions and Important Conclusions for Scaling Rate Experiments 18

Table 2.2 Summary of Experimental Conditions and Important Conclusions for Main Crystal Growth Experiments 18

Table 2.3 Experiment Type and Calcium Carbonate Properties for Several Useful Data Sets

Table 2.4 Compilation of Calcium Carbonate Scaling Rate Data (Parts A, B and C) 37

Table 3.1 Model Comparison Results 46

Table 4.1 Phases of Research and Major Tasks to be Completed 57 


\section{List of Symbols}

[] Denotes concentrations

- Indicates the constant has been modified based on activity coefficients

PKINK Crystal kink density

$\checkmark \quad$ Jumping frequency

A Pre-exponential constant

$\mathrm{C}_{\mathrm{T}}$ Total carbonate: $\mathrm{C}_{\mathrm{T}}=\left[\mathrm{H}_{2} \mathrm{CO}_{3}{ }^{*}\right]+\left[\mathrm{HCO}_{3}{ }^{-}\right]+\left[\mathrm{CO}_{3}{ }^{2-}\right]$

E Activation Energy

f Correction factor

$f \quad$ Activity coefficient

$\mathrm{h}_{\mathrm{D}} \quad$ Diffusion coefficient

$\mathrm{H}_{2} \mathrm{CO}_{3}$ * Hypothetical species representing carbonic acid $\left(\mathrm{H}_{2} \mathrm{CO}_{3}\right)$ and dissolved carbon dioxide

$\mathrm{k}_{\mathrm{r}} \quad$ Rate constant

$\mathrm{k}_{\mathrm{AD}} \quad$ Adsorption rate constant

$k_{B} \quad$ Boltzmann's constant

$\mathrm{K}_{\mathrm{AD}} \quad$ Linear adsorption equilibrium constant $\left(\mathrm{K}_{\mathrm{AD}}=[]_{\mathrm{AD}} /[]_{\mathrm{i}}\right)$

$\mathrm{K}_{\mathrm{W}} \quad$ Water equilibrium constant

$\mathrm{K}_{1} \quad$ First disassociation constant for the carbonate system

$\mathrm{K}_{2} \quad$ Second disassociation constant for the carbonate system

R Universal Gas Constant

$\mathrm{T}$ Temperature in Kelvin

\section{Subscripts}

A $\quad \mathrm{A}^{+}$cation of the hypothetical scaling salt $\mathrm{AB}$

$A B \quad H y p o t h e t i c a l$ scaling salt composed of $\mathrm{A}^{+}$and $\mathrm{B}^{-}$ions

AD Adsorption or Adsorption layer conditions

B Bulk conditions or $\mathrm{B}^{-}$anion of the hypothetical scaling salt $\mathrm{AB}$

Dis Disintegration

Ds Desorption

EQ Equilibrium conditions

I Interface conditions

INT Integration

PPT Precipitation 


\section{Chapter 1}

\section{Introduction}

\subsection{Introduction}

Scaling is a common problem in situations where water is heated and where hot water is used. Scaling is caused by dissolved salts precipitating on surfaces. In industrial situations scaling often occurs from cooling water, while in domestic situations scaling often occurs in water heaters and hot water pipes. In situations where the scaling occurs on a heat transfer surface, the scaling increases the surface's heat transfer resistance and results in efficiency losses. In all situations where scaling occurs, it can cause reliability problems due to clogged pipes and premature failures. Based on a comparison of experimentally measured scaling rates and scaling rates predicted by models, the fundamental mechanisms by which scaling occurs are not well understood. This lack of knowledge limits the proactive treatment of scaling problems and makes design and operating decisions based on scaling theory difficult. The purpose of the proposed research is to extend the knowledge on the fundamental mechanisms of scaling. The proposed research will consist of conducting experiments under a variety of scaling conditions and then developing improved scaling rate models based on first principles and validated by the experimental results.

\subsection{Examples of the Adverse Affects of Scaling}

Recently in Austin, hot water pipes in multi-family residences were completely clogged with calcium carbonate scale, leaving the residences without hot water and resulting in legal action. Perhaps more common is the scaling that occurs in residential hot water heaters, leading to premature failures in the case of electric heaters and efficiency losses in the case of gas and oil heaters. Another problem in the residential sector is scaling in solar hot water collectors, which in all cases leads to efficiency losses and in certain cases leads to catastrophic failures due to freeze damage.

Scaling is common in industrial and commercial processes involving cooling water. Typically, chemical inhibitors are added to the cooling water to reduce the scaling rate and the surfaces are cleaned periodically to remove scale build-up. Scaling still occurs, though, and results in efficiency losses and increased maintenance costs. Scaling is a common problem in the petroleum industry, in cooling towers, and in condensers in electric power plants. 


\subsection{Motivation}

The author has been developing software to predict calcium carbonate scaling rates in solar hot water systems over the last three years (Vliet, Lawler, and Baker, 1995, 1997; and Baker, 1996a, 1996b). In the past, solar contractors primarily reacted to scaling problems in existing systems, since they had no way of knowing a priori if a system would scale. This lack of knowledge has led to reliability problems and costly repairs. In fact, many solar hot water systems are no longer operational due to scale build-up. The purpose of the software is to allow installers to predict during the design stage if a system will have a scaling problem. This prediction will allow measures to be taken proactively to reduce the amount of scaling and/or its consequences, making the installed systems more reliable.

Currently, the Lower Colorado River Authority (LCRA) adds chemical inhibitors to the cooling water used in the condensers of its electric power plants to reduce scaling. The amount of inhibitor added is based on the observed scaling rate during periodic inspections. If an increase in the scaling rate is noticed, the chemical addition is increased by $10 \%$. Likewise, if scaling is not observed, the chemical addition may be decreased by $10 \%$. Although the exact chemical used to inhibit scaling was not identified, the return of the cooling water with the added chemical to the cooling lake evidently is not controlled by the EPA. Due to efficiency, maintenance and potential environmental concerns, the LCRA and the American Public Power Association (APPA) recently awarded a scholarship to the author to develop software to predict scaling rates in electric power plants.

All of the scaling rate models found in the literature were reviewed and compared, with the review and comparison of the models being included in Chapters 2 and 3, respectively. Based on the comparison of the models, in which predicted scaling rates were compared to experimentally measured scaling rates, there are fundamental problems with all the scaling rate models. The most striking result from this comparison is that the experimentally measured scaling rates appear to have a large bulk temperature dependency that is neither captured in any of the models nor suggested by the current scaling theory. An additional concern is that most of the experiments on which these models are based used carefully prepared waters with high saturations to achieve simple water chemistries, pure calcium carbonate scale, and short run times. These simple and controlled conditions do not appear to be representative of the scaling conditions in most residential, commercial, and industrial situations. Texas waters, for example, often have high magnesium concentrations, and magnesium ions are believed to influence calcium carbonate precipitation. Industrial scales often contain several species in addition to 
calcium carbonate, and, relative to pure calcium carbonate scale, tend to be more susceptible to removal mechanisms caused by fluid shear forces. Little research has been performed to determine the applicability of scaling rate models developed under these controlled conditions to situations outside the laboratory. Also, all of the scaling rate models are based on mass deposition rates, while most of the scaling rate experiments measure heat transfer fouling rates. It seems possible that a scale's porosity, and therefore its effective density and thermal conductivity, may vary with the scaling conditions. However, there has been little research trying to directly correlate mass deposition rates with heat transfer fouling rates under varying conditions.

\subsection{Proposed Research}

The objectives of the research are as follows:

1. To generate a theoretical understanding of the factors that influence scaling rates, and to express that understanding in a mathematical model.

2. To test, experimentally, the most important variables the influence scaling rates, specifically water chemistry, bulk temperature, flow velocity, surface temperature, and scale quality.

3. To test the validity of the mathematical model with the experimental results.

Initially, pure calcium carbonate scaling will be investigated, which is the dominant scale in most domestic situations and in many industrial and commercial situations. This research will focus on understanding the effects of bulk temperature on scaling rates and correlating mass deposition rates with heat transfer fouling rates. These experiments will be performed under carefully controlled laboratory conditions and the knowledge gained will provide a framework for later, more complicated scaling experiments.

Once sufficient experience has been gained on designing scaling experiments, several long-term scaling experiments will be initiated using uncontrolled water, such as City of Austin tap water and/or cooling water from electric power plants. These waters have a lower supersaturation level and more complex chemistry than the prepared waters. The focus of these experiments will be on assessing the applicability of the laboratory results to more typical scaling conditions. These results may also suggest the direction for later research.

After the.calcium carbonate scaling experiments are completed, experiments on scaling from water with significant calcium and magnesium concentrations will be conducted. It is thought that these conditions should more closely approximate those in many industrial and 
commercial settings, and those for much of the domestic water in Texas, which tend to have higher magnesium concentrations than in other parts of the United States. The focus of these experiments will be on understanding the influence significant concentrations of magnesium and calcium ions have on scaling rates and the quality of scale deposited. None of the previous work on scaling has considered the effect of magnesium on scaling.

Other experimental conditions will probably also be investigated based on the results of these experiments. Scaling rate models will be developed based on first principles and validated using the experimental results.

\subsection{Structure of the Proposal}

Chapter 2 contains background information to assist in understanding this research and also contains the literature review. The chapter is organized so that the information can easily be assimilated and then applied with respect to designing scaling rate experiments and models. The third chapter is a comparison of proposed scaling rate models using experimental scaling rates compiled from the literature. This chapter highlights the differences between the rates predicted by the models and those measured experimentally, these differences providing the motivation for this research. The final chapter outlines the proposed research, which is divided into five experimental phases. The proposed experimental design for the first phase of the research is included and subsequent experimental designs will be based on the results and experiences from the previous phases of the research. 


\section{Chapter 2}

\section{Background Information and Literature Review}

\subsection{Introduction}

This chapter provides the background information that is considered essential to understanding this research and contains the literature review. It is proposed to initially investigate calcium carbonate scaling only. Later experiments will include magnesium ions in the bulk and scales containing both calcium and magnesium may result. The water chemistry overview and much of the literature review focuses on calcium carbonate scaling, both for simplicity and because calcium carbonate has been studied much more extensively.

Scaling is just one type of fouling, and this introductory section is followed by a section providing an overview of how scaling fits into the larger category of fouling. This is followed by a section discussing the stages of scaling and the relavance of each stage to the proposed research. The next section is on water chemistry and is intended for readers who may have a strong background in heat transfer but who have not had much experience with the water chemistry involved in calcium carbonate precipitation. This is followed by a section on precipitation theory as it applies to scaling in general and calcium carbonate scaling in particular. The heart of the literature review is found in the next four sections. The first of these discusses the parameters that have been shown in the literature to exert a large influence on calcium carbonate precipitation rates. This knowledge is critical in designing experiments, intrepretting results and developing scaling rate models. Next is a review of previously proposed calcium carbonate scaling rates models, which includes three models that were developed previously by the present author. Experimental data from calcium carbonate scaling and precipitation experiments compiled from the literature is then presented. This compiled data is used in the following chapter to compare the reviewed scaling rate models and elucidate some of their weaknesses. The chapter concludes with a review of experimental set-ups used in previous scaling experiments, which will form the starting point for the proposed experimental design

\subsection{Scaling and its Relation to Fouling}

Scaling is a broad field and is contained in the even broader field of fouling, which includes any mechanism that leads to degradation of a surface. There have been numerous general reviews of the fouling literature (Taborek et al., 1972a, 1972b; Somerscale and Knudsen, 1981; Epstein, 1981a, 1981b, 1983, and 1988; and Hasson, 1981b) and the authors have generally classified fouling into six basic categories: scaling, particulate fouling, chemical 
reaction fouling, corrosion fouling, biofouling, and freeze fouling. A short description of each type of fouling follows (Epstein 1981a, 1981b, and 1983):

(1) Scaling (also called Precipitation Fouling and Crystallization Fouling): The precipitation of inverse solubility salts (such as $\mathrm{CaCO}_{3}, \mathrm{CaSO}_{4}, \mathrm{Ca}_{3}\left(\mathrm{PO}_{4}\right)_{2}, \mathrm{CaSiO}_{3}$ $, \mathrm{Ca}(\mathrm{OH})_{2}, \mathrm{Mg}(\mathrm{OH})_{2}, \mathrm{MgSiO}_{3}, \mathrm{Na}_{2} \mathrm{SO}_{4}, \mathrm{Li}_{2} \mathrm{SO}_{4}$, and $\mathrm{Li}_{2} \mathrm{CO}_{3}$ in water) onto heated surfaces.

(2) Particulate Fouling: The accumulation on surfaces of finely dissolved solids suspended in the process fluid.

(3) Chemical Reaction Fouling: Deposits formed by chemical reactions at the heat transfer surface in which the surface material itself is not a reactant. Polymerization, cracking and coking of hydrocarbons are prime examples.

(4) Corrosion Fouling: The heat transfer surface itself reacts to produce corrosion products which foul the surface and may foster the attachment of other potential fouling materials.

(5) Biofouling: The attachment of macro-organisms (macro-biofouling) and/or microorganisms (micro-biofouling or microbial fouling) to a heat transfer surface, along with the adherent slimes often generated by the latter.

(6) Freezing Fouls (also called Solidification Fouling): The solidification of a pure liquid or constituents of a liquid solution onto a sub-cooled transfer surface.

For this research it is perhaps most important to distinguish between scaling and particulate fouling, since both can be caused by the precipitation of scaling salts. Scaling occurs when these scaling salts precipitate directly on a heated surface, while particulate fouling occurs when these scaling salts precipitate in the bulk and then attach to the heat transfer surface.

\subsection{Stages of Scaling}

There are four basic stages in scaling: nucleation, growth, removal, and, aging. Scaling occurs because the elevated temperature of the water at the heat transfer surface increases the water's supersaturation with respect to a scaling salt and therefore the driving force for precipitation. Scaling initially occurs as nucleation on the bare heat transfer surface. After nucleation occurs, the scaling salts precipitate preferentially at these nucleated sites instead of on the bare heat transfer surface, in a process termed growth. The scale grows from these nucleation sites, becoming thicker and covering more of the heat transfer surface. The rate of scale growth is typically much faster than nucleation. If the resulting scale is sufficiently loose 
and/or the fluid shear forces sufficiently large, the scale can be torn from the surface and entrained in the fluid bulk in a process termed removal. The removal rate is greatest for scales composed of more than one scaling salt and/or if more than one fouling mechanism is present, but is negligible for scales composed $90+\%$ of calcium carbonate. If the initial phase to precipitate is not the most thermodynamically stable solid phase, aging may occur where the solid changes from one solid phase into a more thermodynamically stable phase. The proposed research will focus on measuring and modeling scale growth rates, although it will be necessary to account for the other stages in the experimental design, interpretation of measured rates, and modeling.

\subsection{Water Chemistry}

The water chemistry involved for different precipitation processes varies greatly. For simplicity and brevity, this section only addresses the water chemistry that is considered essential to understanding calcium carbonate scaling.

The calcium carbonate precipitation reaction is typically written as

$$
\mathrm{Ca}^{2+}+\mathrm{CO}_{3}^{2-} \rightarrow \mathrm{CaCO}_{3}
$$

with water chemistry having a large influence on this reaction through the carbonate ion, $\mathrm{CO}_{3}{ }^{2-}$. Water consists of water molecules, hydrogen cations, and hydroxide anions that are present in concentrations that satisfy the following equilibrium relationship

$$
\mathbf{K}^{\prime} \mathbf{W}=\frac{\left[\mathbf{H}^{+}\right]\left[\mathrm{OH}^{-}\right]}{\left[\mathrm{H}_{2} \mathbf{O}\right]}
$$

where $\mathrm{K}^{\prime} \mathrm{w}$ is the water equilibrium constant. Here, as throughout this proposal, the prime , ', on the equilibrium constant means that it has been modified based on activity coefficients and the brackets, [ ], indicate concentrations. Reactions between water molecules, hydrogen ions, and hydroxide ions occur are so rapid that equilibrium among these species can always be assumed. Additionally, the concentration of water molecules is always assumed to be $1.0\left(\left[\mathrm{H}_{2} \mathrm{O}\right]=1\right)$. The master variable in water chemistry is $\mathrm{pH}$, which is defined as

$$
\mathbf{p H}=-\log _{10}\left(f_{\mathbf{H}}\left[\mathbf{H}^{+}\right]\right)
$$

where $f_{\mathrm{H}}$ is hydrogen's activity coefficient.

Water is a highly polar molecule with the negative charge being densely concentrated in the oxygen atom while the positive charge is spread much less densely between the two hydrogen atoms. This strong polarity allows water to neutralize the ionic bonds in solid scaling salts, 
dissolving the scaling salt into cations and anions. The cations tend to be single atoms with a relatively high positive charge density, while the anions tend to be molecules that are larger than the cations and have a relatively low negative charge density. The differences in the charge densities of the water molecules and ions result in the cations normally having $4-6$ waters of hydration, and the anions typically having $0-2$ waters of hydration. Water will tend to dissolve a scaling salt until saturation is reached, at which point the water and solid scaling salt are in equilibrium. Equilibrium conditions with respect to calcium carbonate are defined as follows:

$$
K_{S, C a C O 3}^{\prime}=\frac{\left[\mathrm{Ca}^{2+}\right]\left[\mathrm{CO}_{3}^{2-}\right]}{\left[\mathrm{CaCO}_{3}\right]}
$$

where $\mathrm{K}_{\mathrm{S}, \mathrm{CaCO} 3}$ is the solubility product of calcium carbonate. The denominator in this expression is the concentration of solid calcium carbonate and is always assumed to be 1.0. By convention, equilibrium expressions are normally written as $\mathrm{K}_{\mathrm{s}, \mathrm{CaCO} 3}=\left[\mathrm{Ca}^{2+}\right]\left[\mathrm{CO}_{3}{ }^{2-}\right]$ with the denominator being left out. Calcium carbonate has the potential to precipitate when the product of the calcium and carbonate ion concentrations exceeds the solubility product. Since calcium carbonate precipitation involves not only the carbonate anion, $\mathrm{CO}_{3}{ }^{2-}$, but also the entire carbonate acid-base system (referred to herein as the carbonate system), some knowledge of the carbonate system is necessary to understand calcium carbonate precipitation.

The carbonate system consists of the following species and reactions for the special case when the water is closed to the atmosphere (i.e., there is no transfer of carbon dioxide between the water and the air), these being the conditions of interest to this research:

$$
\begin{aligned}
& \mathrm{CO}_{2, \mathrm{AQ}}+\mathrm{H}_{2} \mathrm{O} \leftrightarrow \mathrm{H}_{2} \mathrm{CO}_{3} \\
& \mathrm{H}_{2} \mathrm{CO}_{3} \leftrightarrow \mathrm{HCO}_{3}^{-}+\mathrm{H}^{+} \\
& \mathrm{HCO}_{3}^{-} \leftrightarrow \mathrm{CO}_{3}^{2-}+\mathrm{H}^{+}
\end{aligned}
$$

Here $\mathrm{CO}_{2, \mathrm{AQ}}$ is dissolved carbon dioxide, $\mathrm{H}_{2} \mathrm{CO}_{3}$ is carbonic acid, and $\mathrm{HCO}_{3}{ }^{-}$is bicarbonate. Reactions 2.6 and 2.7 involve a hydrogen ion and are fast enough compared to most other reactions that they can be considered to be at equilibrium. Although reaction 2.5 is slower than reactions 2.6 and 2.7 (Snoeyink and Jenkins, 1980), as will be shown later the concentrations of dissolved carbon dioxide and carbonic acid should be small enough at the $\mathrm{pHs}$ of interest that any error in assuming equilibrium conditions for this reaction should be negligible. Since it can be difficult to distinguish between dissolved carbon dioxide and carbonic acid in solution, the two species are often lumped together and referred to as $\mathrm{H}_{2} \mathrm{CO}_{3}{ }^{*}$, called carbonic acid herein. The resulting equilibrium conditions for the carbonate system are 


$$
\begin{aligned}
\mathrm{K}_{1}^{\prime} & =\frac{\left[\mathrm{HCO}_{3}^{-}\right]\left[\mathrm{H}^{+}\right]}{\left[\mathrm{H}_{2} \mathrm{CO}_{3}^{*}\right]} \\
\mathrm{K}_{2}^{\prime} & =\frac{\left[\mathrm{CO}_{3}^{2-}\right]\left[\mathrm{H}^{+}\right]}{\left[\mathrm{HCO}_{3}^{-}\right]}
\end{aligned}
$$

where $\mathrm{K}_{1}^{\prime}$ and $\mathrm{K}_{2}^{\prime}$ are the first and second disassociation constants for carbonic acid.

As will be explained later, it is often beneficial to think of these species' concentrations as fractions of the total carbonate system concentration. This is commonly done by referring to the total carbonate concentration $\left(\mathrm{C}_{\mathrm{T}}\right)$ in solution

$$
\mathrm{C}_{\mathrm{T}}=\left[\mathrm{H}_{2} \mathrm{CO}_{3}^{*}\right]+\left[\mathrm{HCO}_{3}^{-}\right]+\left[\mathrm{CO}_{3}^{2-}\right]
$$

and the fraction of total carbonate existing as each species $\left(\propto_{0}, \propto_{1}\right.$, and $\left.\propto_{2}\right)$

$$
\begin{aligned}
& \alpha_{0}=\frac{\left[\mathrm{H}_{2} \mathrm{CO}_{3}^{*}\right]}{\mathrm{C}_{\mathrm{T}}} \\
& \alpha_{1}=\frac{\left[\mathrm{HCO}_{3}^{-}\right]}{\mathrm{C}_{\mathrm{T}}} \\
& \alpha_{2}=\frac{\left[\mathrm{CO}_{3}^{2-}\right]}{\mathrm{C}_{\mathrm{T}}}
\end{aligned}
$$

Thus, the condition for calcium carbonate equilibrium can be rewritten as $\mathrm{K}_{\mathrm{S}, \mathrm{CaCO} 3}=\propto_{2} \mathrm{C}_{\mathrm{T}}\left[\mathrm{Ca}^{2+}\right]$. The fractions $\propto_{0}, \propto_{1}$, and $\propto_{2}$ are mainly functions of $\mathrm{pH}$ but are also slight functions of temperature, with the sum of the fractions always equaling 1. Figure 2.1 is a graph of the carbonate fractions versus $\mathrm{pH}$. 


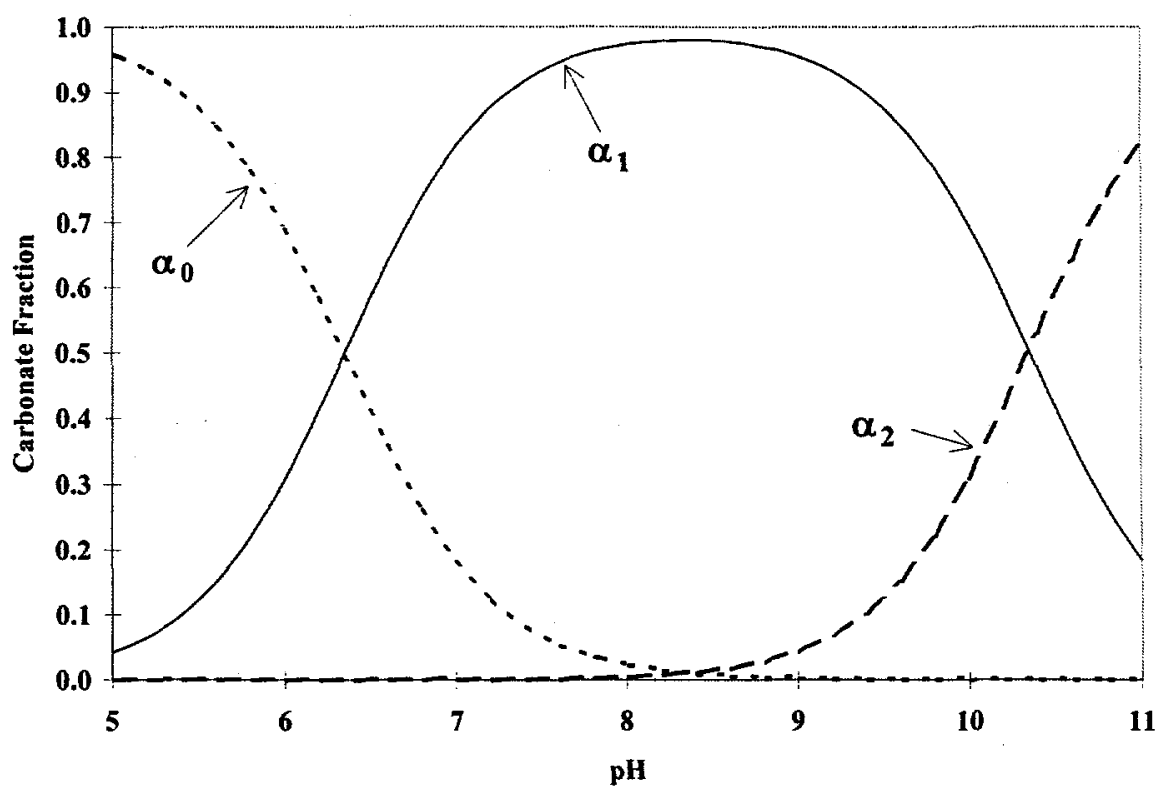

Figure 2.1: Carbonate Fractions versus pH at $25^{\circ} \mathrm{C}$

As can be seen in Figure 2.1, most of the carbonate system exists as bicarbonate, $\alpha_{1} \mathrm{C}_{\mathrm{T}}$, throughout most of the range of $\mathrm{pHs}$ found in most domestic waters $(6<\mathrm{pH}<10)$. For a constant total carbonate concentration, the fraction existing as carbonate, $\alpha_{2}$, increases with $\mathrm{pH}$. It is important to recognize several points about how the carbonate system influences calcium carbonate precipitation. Equilibrium with respect to calcium carbonate is defined by the product of the calcium and carbonate ion concentrations, and not in terms of the total carbonate concentration. Thus a water initially under saturated with respect to calcium carbonate may become supersaturated if its $\mathrm{pH}$ is raised, due to the increasing fraction of the carbonate system existing as carbonate. Additionally, as calcium carbonate precipitation occurs, the carbonate concentration is replenished by the disassociation of carbonic acid and bicarbonate into carbonate. Therefore, calcium carbonate precipitation decreases the concentration of the entire carbonate system, and not just the carbonate species. Also, due to the disassociation of carbonic acid and bicarbonate during precipitation, the $\mathrm{pH}$ of the solution decreases. Thus equilibrium conditions are reached through precipitation not only due to the decrease in the calcium and total carbonate concentrations, but also due to the decreasing fraction of the carbonate system existing as carbonate due to the decreasing $\mathrm{pH}$. All precipitation rate models assume that the precipitation rate is some function of the water's deviation from equilibrium conditions. Equilibrium conditions with respect to calcium carbonate can be calculated if the water's initial 
$\mathrm{pH}$ and total carbonate and calcium concentrations are known. This solution can be found in the literature (Baker, 1996a; Snoeyink and Jenkins, 1990; Loewenthal and Marais, 1976).

It should be noted that the above discussion neglects the presence of the complexes $\mathrm{CaHCO}_{3}{ }^{+}, \mathrm{CaCO}_{3}{ }^{\circ}$, and $\mathrm{CaOH}^{+}$, which are species normally present in small enough concentrations relative to the total carbonate and calcium ion concentrations that they are generally neglected. Inclusion of these complexes in a discussion of the importance of the carbonate system on calcium carbonate scaling makes the discussion significantly more complex while adding very little insight. Baker (1996a) presented a model for calcium carbonate precipitation that included these complexes and it was significantly more complicated than the model that neglected these complexes. It was decided that the increased complexity of the model with complexes was not warranted. This decision may need to be reevaluated for this work.

More detailed explanations of water chemistry can be found in the literature (Baker, 1996a; Snoeyink and Jenkins, 1990).

\subsection{Precipitation Theory}

This section is based on the two articles: Electrolyte Crystal Growth Kinetics (Nielsen and Toft, 1984) and Electrolyte Crystal Growth Mechanisms (Nielsen, 1984), called herein the kinetics and mechanisms articles, respectively. The mechanisms article appears to be an update of the book The Kinetics of Precipitation (Nielsen, 1964). The articles are particularly important from a conceptual standpoint, since they explain the theory behind each mechanism in the precipitation process and derive equations to model precipitation rates applicable when each mechanism is rate limiting. However, although the final rate equations are very elegant which is conceptually useful, the validity of applying most of the final rate equations to actual scaling systems appears questionable due to many of the simplifying assumptions made. From other more recent but more applied articles reviewed, there does appear to be some advances made in the field since 1984, although it also appears that there are not any more recent publications that are nearly as comprehensive on precipitation theory as these two articles. This is an area where further literature review is needed to help bridge the apparent gap between theory and practice.

The overall scaling rate can be thought of as the rate at which the reacting ions move from the fluid bulk into the scale's crystal lattice on the heat transfer surface. The mechanisms by which this occurs include diffusion from the bulk to the solid-liquid interface, adsorption from the interface into an adsorption layer, diffusion across the adsorption layer, and then either integration into a crystal kink, termed surface integration herein, or nucleation on top of the 
surface to form a new kink, termed surface nucleation herein. In the two papers these mechanisms are assumed to occur independently but at the same rate for each of the precipitating species; i.e., for the electrolyte $\mathrm{AB}$, the $\mathrm{A}^{+}$ion proceeds through the bulk diffusion, adsorption, and adsorption layer diffusion mechanisms as an ion and without ever interacting with a $\mathrm{B}^{-}$ion. Then either surface integration occurs and the adsorbed $\mathrm{A}^{+}$ion attaches to $\mathrm{B}$ atom in the crystal lattice, or surface nucleation occurs and the adsorbed $\mathrm{A}^{+}$ion reacts with an adsorbed $\mathrm{B}^{-}$ion to form a new kink. Since for a given ion either surface integration or surface nucleation can occur, the mechanism with the smaller resistance is the one most likely to occur and is said to dominate. Based on a literature review, which is discussed more in the next chapter, it appears that for calcium carbonate the surface integration mechanism dominates over the surface nucleation mechanism (Nancollas and Reddy, 1971; Reddy and Nancollas, 1971; Wiechers et al., 1975; Kralj et al., 1990; Christoffersen and Christoffersen, 1990; Weijden et al., 1997). For this reason and for brevity (surface nucleation is a much more complex process than surface integration), only bulk diffusion, adsorption, and surface integration are discussed in greater detail here.

For simplicity and generality, this section utilizes the hypothetical scaling salt $\mathrm{AB}$ and does not discuss calcium carbonate precipitation in particular. The hypothetical scaling salt $A B$ dissolves in water to form the ions $\mathrm{A}^{+}$and $\mathrm{B}^{-}$, and these ions do not undergo further reactions in the water. For precipitation of the scaling salt $\mathrm{AB}$ when a single mechanism is rate limiting, the elegance of the final rate equations stems from the fact that they are only a function of constants and the nondimensional saturation ratio, $S_{R}$.

$$
S_{R}=\left(\frac{\left[A^{+}\right]_{B}\left[B^{-}\right]_{B}}{K_{S, A B}}\right)^{1 / 2}
$$

\subsubsection{Diffusion}

Initially the precipitating ions are hydrated in the bulk solution and diffuse (with their hydration shells) independently to the solid-liquid interface. For the hypothetical scaling salt $\mathrm{AB}$, the bulk diffusion of the $\mathrm{A}^{+}$cation is shown conceptually in Figure 2.2, where the $\mathrm{A}^{+}$cation is assumed to have 4 waters of hydration (recognizing that the hydration shell would look different in three dimensions, but is shown as it is for simplicity). 


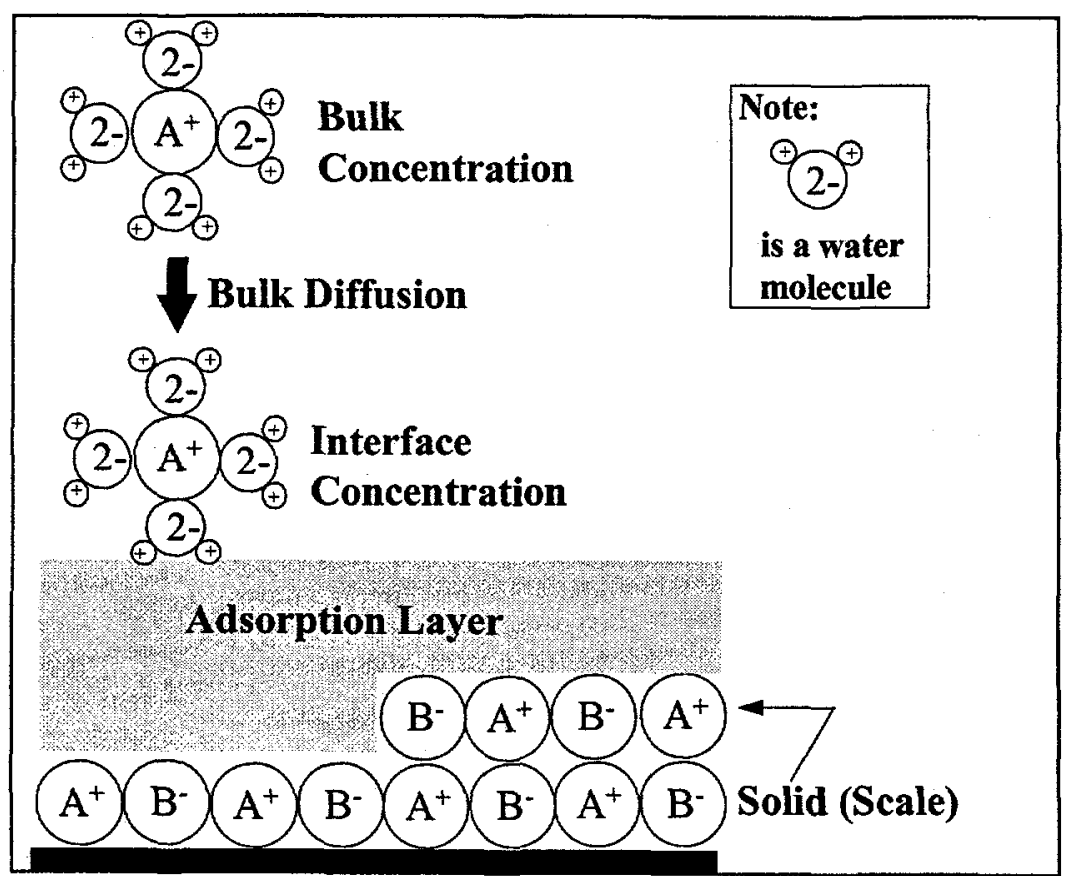

Figure 2.2: Bulk Diffusion of the Ion $\mathrm{A}^{+}$

The bulk diffusion of the $\mathrm{B}^{-}$anion would be represented in an analogous manner except it would only have $0-2$ water(s) of hydration, these being attached through a water's hydrogen atom instead of through its oxygen atom. The diffusion rate for each of the ions equals the overall precipitation rate $(w)$. For the hypothetical scaling salt $\mathrm{AB}$ the diffusion rate can be represented as

$$
\mathbf{w}=\mathbf{h}_{\mathbf{D}, \mathbf{A}+}\left(\left[\mathbf{A}^{+}\right]_{\mathbf{B}}-\left[\mathbf{A}^{+}\right]_{\mathbf{I}}\right)=\mathbf{h}_{\mathbf{D}, \mathbf{B}-}\left(\left[\mathbf{B}^{-}\right]_{\mathbf{B}}-\left[\mathbf{B}^{-}\right]_{\mathbf{I}}\right)
$$

where $h_{D}$ is the diffusion coefficient for each ion, and the subscripts ${ }_{B}$ and ${ }_{I}$ represent bulk and interface conditions, respectively. For the condition when diffusion is rate limiting, $\left[\mathrm{A}^{+}\right]_{\mathrm{B}}=\left[\mathrm{B}^{-}\right.$ ]$_{B}$, and $h_{D, A+}=h_{D, B}$, this equation can be simplified to the conceptually elegant

$$
\mathbf{w}=k_{1}(S-1)
$$

\subsubsection{Adsorption}

Once the precipitating ions reach the solid-liquid interface they jump with their hydration shells into an adsorption layer. This is shown conceptually in Figure 2.3 for the $\mathrm{A}^{+}$cation, with the $\mathrm{B}^{+}$anion going through an analogous process. 


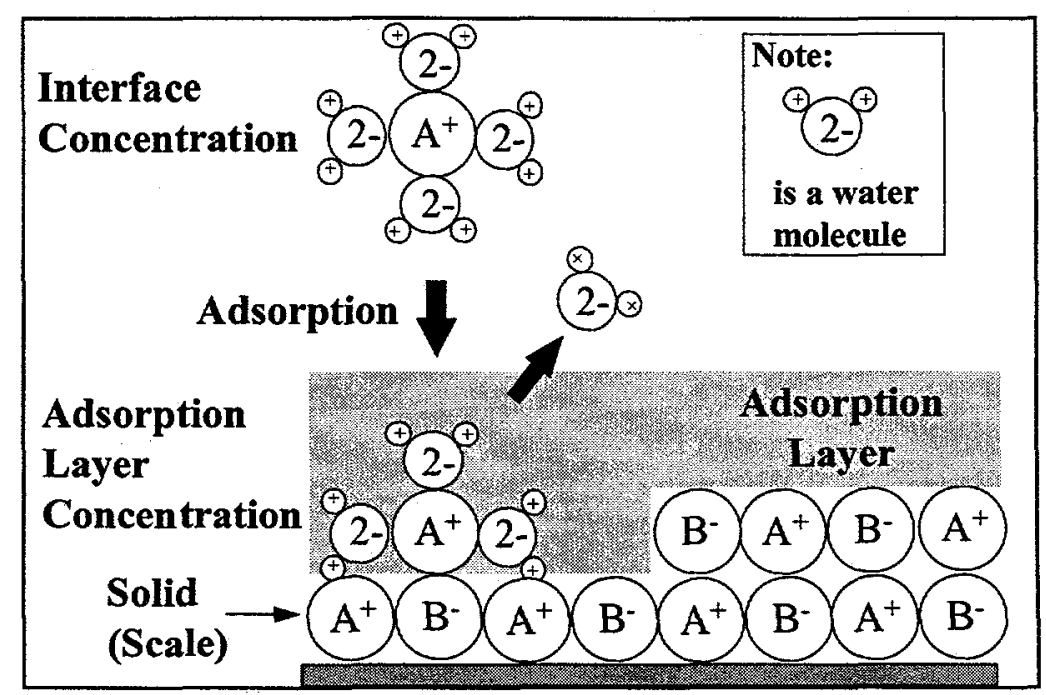

Figure 2.3: Adsorption of $\mathrm{A}^{+}$Cation

The net rate of adsorption must equal the rate of precipitation, and the mechanism paper suggests modeling the adsorption rate for the $\mathrm{A}^{+}$cation using the following first order rate equation

$$
\mathbf{w}=\mathbf{C o n s t a n t}\left(\mathbf{v}_{\mathrm{AD}}\left[\mathbf{A}^{+}\right]_{\mathrm{I}}-\mathbf{v}_{\mathrm{DS}}\left[\mathbf{A}^{+}\right]_{\mathrm{AD}}\right)
$$

where the constant accounts for geometric effects, $v_{\mathrm{AD}}$ and $v_{\mathrm{DS}}$ are the jumping frequencies into and out of the adsorption layer, and the subscript ${ }_{A D}$ refers to adsorption layer conditions. For the condition when adsorption is rate limiting and applying several assumptions including electroneutrality in the adsorption layer and the preferntial adsorption of the precipitating ions (the Paneth-Hahn-Fajan rule), equation 2.17 can be simplified back to the conceptually elegant equation 2.16

$$
\mathbf{w}=k_{1}\left(S_{R}-1\right)
$$

It is interesting to note that based on equation 2.16 , the scaling rate should be a linear function of the saturation ratio when either bulk diffusion or adsorption is rate limiting.

Although not discussed in either paper, it is conceptualized that adsorption differs from integration only in the number of bonds that are formed with the crystal lattice. For adsorption, only one bond is formed between the adsorbed ion and the crystal lattice, and the adsorbed ion can then diffuse across the adsorption layer and integrate into the crystal lattice at a kink, where it is locked into place. A crystal kink, then, is a site where an adsorbed ion can form multiple bonds with the crystal lattice. Both papers assume that the adsorbed ions retain all of their waters of hydration during adsorption. However, it seems possible that the ions would give up 
one or more of their water's of hydration during the adsorption process, as shown in Figure 2.3, in favor of forming an adsorption bond with the solid crystal.

\subsubsection{Surface Diffusion and Integration}

According to the mechanisms paper, once the reacting ions are in the adsorption layer, they diffuse in their hydration shells across the crystal lattice surface and then simultaneously dehydrate and integrate into the crystal lattice structure at a kink. This is shown conceptually in Figure 2.4 for the $\mathrm{A}^{+}$cation, with the $\mathrm{B}^{+}$anion going through an analogous process.

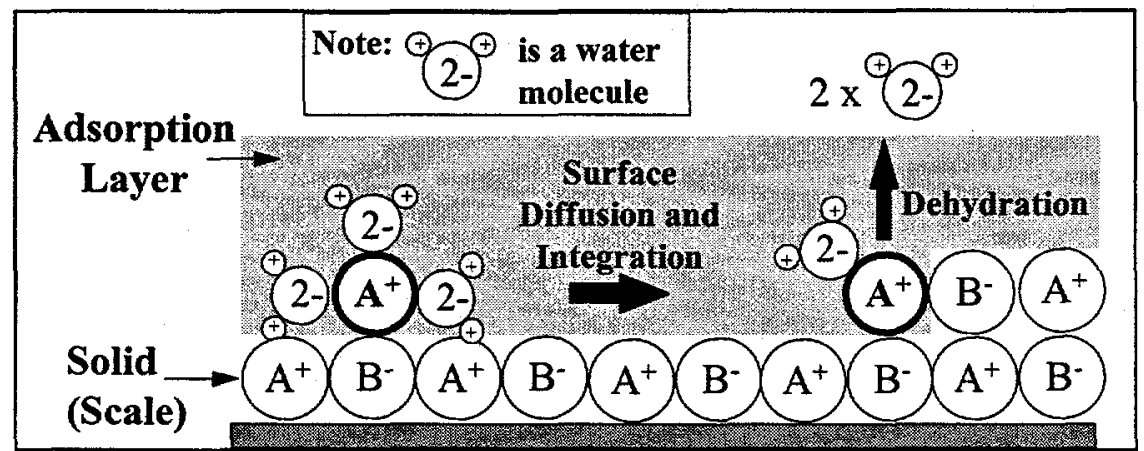

Figure 2.4: Surface Diffusion and Integration

According to the mechanisms paper, the rate of integration is a function of the concentration of the integrating ions in the adsorption layer and the kink density. The kink density is also a function of the ion concentrations in the adsorption layer:

$$
\rho_{\text {KINK }}=\text { Constant }\left(S_{R}-1\right)
$$

where $\rho_{\mathrm{KINK}}$ is the kink density. Thus, the greater the saturation ratio, the greater the number of kinks. The net rate of integration at a kink is the difference between the rates at which the precipitating ions jump from the adsorption layer into the crystal structure (integration) and the rate at the dissolving ions jump out of the crystal structure into the adsorption layer (disintegration).

$$
\left.\mathbf{w}\right|_{\text {KINK }}=\text { Constant }\left(v_{\text {INT, } A}\left[\mathbf{A}^{+}\right]_{\text {AD }}-v_{\text {DIS,A }}\left[\mathbf{A}^{+}\right]_{\text {SOLID }}\right)
$$

where the constant accounts for geometric effects and the subscripts ${ }_{\mathrm{INT}}$ and $\mathrm{DIS}_{\mathrm{S}}$ refer to integration and disintegration, respectively. For the case where surface integration is rate limiting and if several assumptions can be made, then equations 2.18 and 2.19 can be combined and simplified to give the conceptually elegant

$$
\mathbf{w}=\mathbf{k}_{2}\left(\mathbf{S}_{\mathrm{R}}-1\right)^{2}
$$


For this case, the scaling rate would follow a parabolic rate law with respect to the saturation ratio.

The mechanism paper assumes that there is no dehydration of the precipitating ions until integration occurs, at which point the ions completely dehydrates. For the cations, which are attached to the water molecules through the water's oxygen atom, during integration complete water molecules are either lost or are retained, the retained ions being integrated into the crystal lattice. For the anions, which are attached to the waters through the water's hydrogen atom, dehydration may consist of losing the entire water molecule or just a hydroxide, with the extra hydrogen entering the crystal lattice. The extra hydrogen atom is reasoned to be small enough that it can then leave the crystal later, which is why it is not seen in crystal structures.

\subsubsection{Precipitation Theory versus Practice}

The mechanisms article develops rate equations for the condition when each mechanism is rate limiting. These equations are derived based on the assumption that the ions proceed through each mechanism in a parallel, but somewhat independent, fashion and at the same rate. These derivation runs into problems when one tries to reconcile the bulk concentrations of the ions (which usually are not in the stoichiometric ratio of the precipitation reaction), with those in the solid (which are in the stoichiometric ratio of the precipitation reaction by definition); i.e., based on the proposed mechanism models, an ion in excess in the bulk should also be in excess in the solid, which is not possible. One possible way to reconcile these differences is to relax an assumption that the adsorption layer is electrically neutral. First, assume that the jumping frequencies into and out of the adsorption layer are initially equal for $\mathrm{A}^{+}$and $\mathrm{B}^{-}$; i.e., at equal interface concentrations, neither adsorbs preferentially. Next, assume that their can be a net charge in the adsorption layer, which means that the precipitating ion in excess at the interface will adsorb in greater quantities, resulting in a surface charge. A surface charge will result in a double-layer, increasing the concentration of the deficient ion at the surface. A net surface charge may also increase the jumping frequencies of the deficient ion into the adsorption layer and the excess ion out of the adsorption layer, and vice versa, due to electrostatic attraction and repulsion. The increase in the deficient ion's concentration at the interface, together with the changes in the jumping frequencies, could work as feedback mechanisms to move the adsorption layer toward (but not reach) electroneutrality and equal ion concentrations in the adsorption layer. Thus, although the ratio of the precipitating ions' concentrations in the bulk may not be in 
the stoichiometric ratio of the precipitation reaction, after each mechanism the actual concentration ratio will approach the stoichiometric ratio more closely.

Another possibility is that the deficient ion limits the precipitation rate. Under this scenario for the hypothetical scaling salt $\mathrm{AB}$, if $\mathrm{A}^{+}$is in excess in the bulk, then the crystal lattice kinks that require an $\mathrm{A}^{+}$cation will be filled relatively quickly because of the availability of $\mathrm{A}^{+}$ cations, while the kinks that require a $\mathrm{B}^{-}$anion will take a relatively longer time to fill due to the absence of $\mathrm{B}^{-}$ions. However, all the literature reviewed assumes that the rate is a function of the concentrations of both the precipitating ions, and not the deficient ion, and this seems to fit the experimental data well.

\subsection{Parameters Influencing Calcium Carbonate Scaling Rates}

This section is based on a literature review of both calcium carbonate scaling experiments and calcium carbonate crystal growth experiments, where the crystal growth experiments investigated calcium carbonate precipitation in a batch reactor. The influence of each parameter on calcium carbonate precipitation is discussed both in terms of scale quality and growth rate.

Since scaling is just a special type of precipitation where the precipitation occurs directly on a heated surface, the literature was reviewed to determine the parameters that influence calcium carbonate precipitation rates in general, and not just scaling rates. The literature reviewed can then be divided between experiments investigating calcium carbonate precipitating as scale on heated surfaces, termed scaling experiments herein, and those investigating calcium carbonate precipitating on crystals in the bulk using batch reactors, termed crystal growth experiments herein. On the whole, the scaling experiments tended to be more applied, while the crystal growth experiments tended to be more fundamental.

Table 2.1 is a summary of the experimental conditions and important conclusions from the scaling rate experiments, and Table 2.2 is a summary of the experimental conditions and important conclusions from the most applicable crystal growth experiments. 


\begin{tabular}{|c|c|c|c|c|c|c|c|}
\hline \multirow[b]{2}{*}{ Reference } & \multirow{2}{*}{$\begin{array}{l}\text { Velocity } \\
\mathrm{m} / \mathrm{s}\end{array}$} & \multirow[b]{2}{*}{$\operatorname{Re}$} & \multicolumn{2}{|c|}{ Temp $\left({ }^{\circ} \mathrm{C}\right)$} & \multicolumn{2}{|c|}{$\mathrm{S}_{\mathrm{R}}$} & \multirow[b]{2}{*}{ Comments } \\
\hline & & & Bulk & Surface & Bulk & Surface & \\
\hline Hasson et al. (1968) & $\begin{array}{l}0.25- \\
0.82\end{array}$ & $\begin{array}{l}9,500- \\
34,000\end{array}$ & $\begin{array}{c}39- \\
45\end{array}$ & $\begin{array}{c}68- \\
83\end{array}$ & $\begin{array}{c}1.1- \\
3.3\end{array}$ & $\begin{array}{c}1.8 \\
5.4\end{array}$ & $\begin{array}{l}\text { Surface resistance negligible } \\
\text { Scaling rate }=\text { diffusion rate }\end{array}$ \\
\hline $\begin{array}{l}\text { Morse and Knudsen } \\
\text { (1977) }\end{array}$ & 1.04 & 9,000 & 22 & $\begin{array}{r}65 \\
72\end{array}$ & $\begin{array}{l}2.6 \\
2.9\end{array}$ & $\begin{array}{l}4.1 \\
4.3\end{array}$ & \\
\hline Watkinson (1983) & 0.7 & 14,000 & $\begin{array}{c}25- \\
59\end{array}$ & 100 & $\begin{array}{l}1.9- \\
6.4\end{array}$ & $\begin{array}{l}4.8- \\
13.5\end{array}$ & Diffusion Controlled \\
\hline $\begin{array}{l}\text { Sheikholeslami and } \\
\text { Watkinson (1986) }\end{array}$ & $\begin{array}{c}0.3- \\
0.8\end{array}$ & $\begin{array}{l}6,000- \\
16,000\end{array}$ & $\begin{array}{l}25, \\
30\end{array}$ & 100 & $\begin{array}{c}2.4- \\
4.1\end{array}$ & $\begin{array}{l}5.7 \\
9.7\end{array}$ & $\begin{array}{l}\text { Copper surfaces diffusion controlled } \\
\text { Scaling rate decr. } w / \text { vel. for mild steel }\end{array}$ \\
\hline $\begin{array}{l}\text { Dalas and } \\
\text { Koutsoukos (1990) }\end{array}$ & 0.05 & 223 & 25 & $\begin{array}{c}50- \\
80\end{array}$ & $\begin{array}{c}2.4- \\
4.4\end{array}$ & $\begin{array}{c}2.9- \\
7.8\end{array}$ & \\
\hline $\begin{array}{l}\text { Andritsos et al. } \\
\text { (1997) }\end{array}$ & $\begin{array}{l}0.4- \\
2.35\end{array}$ & $\begin{array}{l}3,000- \\
30,000\end{array}$ & $\begin{array}{l}15- \\
55\end{array}$ & $\begin{array}{l}\text { Same } \\
\text { as } \\
\text { Bulk }\end{array}$ & $\begin{array}{c}3.5- \\
20\end{array}$ & $\begin{array}{l}\text { Same } \\
\text { as } \\
\text { Bulk }\end{array}$ & $\begin{array}{l}\text { Equal bulk and surf Temps } \\
\text { For } S_{R}<2.8 \text {, surface controlled } \\
\text { For } S_{R}>2.8 \text {, diffusion controlled }\end{array}$ \\
\hline
\end{tabular}

Table 2.1: Summary of Experimental Conditions and Important Conclusions for Scaling Rate Experiments

\begin{tabular}{|c|c|c|c|c|c|c|}
\hline Reference & Phase & $\begin{array}{c}\text { Seed } \\
\text { Crystals } \\
\end{array}$ & $\begin{array}{c}\text { Temp. } \\
\left({ }^{\circ} \mathrm{C}\right)\end{array}$ & $\mathrm{pH}$ & $S_{R}$ & Comments \\
\hline $\begin{array}{l}\text { Nancollas and Reddy } \\
\text { (1971) }\end{array}$ & Calcite & Yes & 25 & NA & NA & $\begin{array}{l}\text { Precip. rates independent of stirring rate } \\
\text { Good agreement modeling rates using } S_{\text {DIFF }}\end{array}$ \\
\hline $\begin{array}{l}\text { Reddy and Nancollas } \\
\text { (1971) }\end{array}$ & Calcite & Yes & $\begin{array}{c}10,25 \\
40\end{array}$ & 8.6 & $2.5-5.7$ & $\begin{array}{l}\text { Noticed initial surge in precipitation rates and crystal surface roughening } \\
\text { - Explained as heterogeneous nucleation } \\
\text { - Low conc. w/ high seed densities did not have this surge and had smooth crystals } \\
\text { Good agreement modeling rates using } S_{\mathrm{DiF}} \\
\text { Notes activation energy }=16 \mathrm{~kJ} / \mathrm{mole} \text { typical for diffusion control }\end{array}$ \\
\hline Wiechers et al. (1974) & $\begin{array}{l}\text { NA } \\
\text { Probably } \\
\text { Calcite }\end{array}$ & Yes & $\begin{array}{c}10,20 \\
25,30 \\
40\end{array}$ & 9.5 & $7.4-17$ & $\begin{array}{l}\mathrm{Na} \text { and } \mathrm{Cl} \text { ion pairing assumed negligible } \\
\text { Initial surge in precipitation rates for low seed densities } \\
\text { - Explained as heterogeneous nucleation in the bulk }\end{array}$ \\
\hline Kralj et al. (1990) & Vaterite & No & $11-42$ & $9.3-9.9$ & NA & $\begin{array}{l}\text { Rates much smaller than theoretical diffusion rates, therefore diffusion not limiting } \\
\text { Good agreement modeling rates using }\left(\mathrm{S}_{\mathrm{R}}-1\right)^{2} \text {, therefore integration limiting } \\
\text { Reasoned heterogeneous nucleation occurred since the number of particles didn't } \\
\text { increase with increasing } \mathrm{S}_{\mathrm{R}} \\
\text { Based on activation energy, more than one water leaves the } \mathrm{Ca}^{2+} \text { ion during integration }\end{array}$ \\
\hline $\begin{array}{l}\text { Christoffersen and } \\
\text { Christoffersen (1990) }\end{array}$ & Calcite & Yes & 37 & $8.3-10$ & $1.5-10$ & 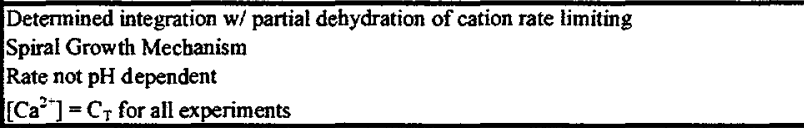 \\
\hline $\begin{array}{l}\text { Kralj et al. (1994) } \\
\text { *Dissolution Exp }\end{array}$ & Vaterite & NA & 20 & 10 & NA & $\begin{array}{l}\text { Diffusion rate limiting } \mathrm{w} / \text { activation energy of } 24.4 \mathrm{~kJ} / \mathrm{mole} \\
\text { Calcite characterized by a single crystal and vaterite by spherulites }\end{array}$ \\
\hline Tai and Chen (1995) & Calcite & Some & 30 & $8.5-10$ & $2.5-5.7$ & $\begin{array}{l}\text { Based on this experiment and other crystal growth literature } \\
\text { For } S_{R}>8 \text { vaterite formed } \\
\text { For } 4<S_{R}<8 \text { aragonite formed } \\
\text { Fot } 2<S_{R}<4 \text { calcite formed. }\end{array}$ \\
\hline $\begin{array}{l}\text { Gomez-Morales et al. } \\
\text { (1996) }\end{array}$ & Vaterite & No & NA & $8-10$ & $3.6-11$ & $\begin{array}{l}\text { pH meter better than calcium meter due to scaling formation on calcium meter } \\
\text { Heterogeneous nucleation occurred }\end{array}$ \\
\hline Weijden et al. (1997) & Calcite & Yes & 22 & NA & $1.3-3.3$ & $\begin{array}{l}\text { Potassium does not incorporate as easily as sodium into the } \mathrm{CaCO}_{3} \text { crystal. } \\
\text { However, thought sodium would not affect } \mathrm{CaCO}_{3} \text { growth rates. } \\
\text { Calcium electrode more sensitive to sodium than potassium } \\
\text { No growth for } \mathrm{S}_{\mathrm{R}}<1.3 \\
\text { Spiral growth controlled by surface integration } \\
\text { At constant } \mathrm{S}_{\mathrm{R}} \text {, rate increases w/ higher } \mathrm{Ct}\left(\left[\mathrm{Ca}^{2+}\right]=\text { const and lower } \mathrm{pH}\right) \\
\text { Concluded } \mathrm{HCO}_{3}{ }^{2-} \text {.impt. in predicting rates at moderate } \mathrm{pHs}\end{array}$ \\
\hline
\end{tabular}

NA $=$ Not Available or Not App licable

Table 2.2: Summary of Experimental Conditions and Important Conclusions for Main Crystal Growth Experiments 


\subsubsection{Calcium and Carbonate Ion Concentrations}

The degree to which a water is supersaturated with respect to calcium carbonate provides the basic driving force for precipitation and is the most important parameter in any precipitation rate model. A water's supersaturation is defined using some comparison between current and equilibrium ion concentrations. The three measures of supersaturation most often used in modeling are the saturation ratio $\left(\mathrm{S}_{\mathrm{R}}\right)$, saturation difference $\left(\mathrm{S}_{\mathrm{DIFF}}\right)$, and absolute saturation $\left(\mathrm{S}_{\mathrm{ABS}}\right)$.

$$
\begin{aligned}
& S_{R}=\left(\frac{\left[\mathrm{Ca}^{2+}\right]_{\mathrm{B}}\left[\mathrm{CO}_{3}^{2-}\right]_{\mathrm{B}}}{\mathrm{K}_{\mathrm{S}}^{\prime}}\right)^{1 / 2} \\
& \mathrm{~S}_{\mathrm{DIFF}}=\left[\mathrm{Ca}^{2+}\right]_{\mathrm{B}}\left[\mathrm{CO}_{3}^{2-}\right]_{\mathrm{B}}-\mathrm{K}_{\mathrm{S}}^{\prime} \\
& \mathrm{S}_{\mathrm{ABS}}=\left[\mathrm{Ca}^{2+}\right]_{\mathrm{B}}-\left[\mathrm{Ca}^{2+}\right]_{\mathrm{EQ}}=\mathrm{C}_{\mathrm{T}, \mathrm{B}}-\mathrm{C}_{\mathrm{T}, \mathrm{EQ}}=\mathrm{CaCO}_{3, \mathrm{PPT}}
\end{aligned}
$$

There are a few important differences to note between these different representations. The saturation ratio and saturation difference are functions of the calcium and carbonate ion concentrations, while the absolute saturation is a function of either the calcium ion concentration or the total carbonate concentration. Additionally, the absolute supersaturation can also be defined as the amount of calcium carbonate precipitation that is necessary to achieve equilibrium. Because calcium carbonate precipitation results in a decrease in $\mathrm{pH}$ and total carbonate concentration (and not just the carbonate ion concentration), there is no direct relationship between the saturation difference and the amount of calcium carbonate precipitation necessary to achieve equilibrium.

Most precipitation rate models only model the rate of the limiting mechanism(s). As was suggested in Section 3, the manner in which the precipitation rate varies with the ion concentrations can indicate if one mechanism is rate limiting. Precipitation rates that vary linearly with the absolute saturation are most likely controlled by either bulk diffusion or adsorption, with bulk diffusion control being distinguished for scaling by the rate having a large Reynolds number dependency in the turbulent regime. Conversely, the saturation difference in the past and a parabolic form of the saturation ratio more recently, $\left(\mathrm{S}_{\mathrm{R}}-1\right)^{2}$, have both been used to successfully model scaling rates that are surface controlled. It is important to note that the rate limiting mechanism may change under different conditions. In general, at high degrees of supersaturation, precipitation rates tend to be diffusion controlled, while at lower degrees of 
supersaturation precipitation rates tend to be surface controlled (Nielsen, 1964). It also seems possible that scaling rates may be diffusion controlled at low Reynolds Number, where diffusional resistance is large relative to the surface resistance, but surface controlled at high Reynolds Numbers, where the diffusional resistance is small relative to the surface resistance.

The rate limiting mechanism for calcium carbonate precipitation determined from scaling and crystal growth experiments tends to be conflicting, the scaling experiments tending to indicate diffusion control and the crystal growth experiments tending to indicate surface integration control. The results for scaling and crystal growth experiments are summarized separately.

\subsubsection{Scaling Rate Experiments}

In scaling rate experiments, scaling rates are measured after nucleation has occurred over the entire heat transfer surface, when precipitation is occurring on deposited calcium carbonate scale and not on the bare heat transfer surface. All the experiments for scaling rates on copper heat transfer surfaces under turbulent conditions found diffusion to be rate limiting (Hasson et al., 1968; Watkinson, 1983; and Sheikholeslami and Watkinson, 1986). For this case, the scaling rate can be modeled as the bulk diffusion rate of the precipitating ions from the bulk to the interface, using the absolute saturation

$$
\mathbf{w}=\mathbf{h}_{\mathrm{D}}\left(\left[\mathrm{Ca}^{2+}\right]_{\mathrm{B}}-\left[\mathrm{Ca}^{2+}\right]_{\mathrm{EQ}}\right)=\mathbf{h}_{\mathrm{D}} \mathbf{S}_{\mathrm{ABS}}
$$

For non-copper heat transfer surfaces, the results are less conclusive. For mild steel heat transfer surfaces, the scaling rate initially increased with increasing velocity, reached a maximum, and then decreased with further increases in velocity (Sheikholeslami and Watkinson, 1986). For these experiments, Sheikholeslami and Watkinson described their scale as "not being fragile", inferring that significant removal due to fluid shear was unlikely. They were unable to explain these scaling rate differences for the different heat transfer surfaces. Ishiguro et al. (1993) investigated scaling on gold, stainless steel, and nickel and found the rates to be surface controlled. For isothermal conditions (i.e., the bulk and surface temperatures are the same) Andritsos et al. (1997) found scaling rates on 304 and 316L stainless steel to be surface controlled for saturation ratios less than 2.8 and diffusion controlled for saturation ratios greater than 2.8. An adequate explanation for the scaling rate's dependence on the heat transfer surface material has not been found in the literature. 


\subsubsection{Crystal Growth Experiments}

The earliest literature classified the precipitation rate as either diffusion or surface controlled, with surface control including the adsorption, surface integration, and surface nucleation mechanisms. The first three experimenters (Nancollas and Reddy, 1971; Reddy and Nancollas, 1971; and Wiechers et al., 1975) classified the precipitation rate as surface controlled based on its independence from the stirring rate. They found good agreement when they modeled the precipitation rate using the saturation difference

$$
\mathrm{w}=\mathrm{k}_{\mathrm{r}}\left(\left[\mathrm{Ca}^{2+}\right]_{\mathrm{B}}\left[\mathrm{CO}_{3}^{2-}\right]_{\mathrm{B}}-\mathrm{K}_{\mathrm{S}}^{\prime}\right)=\mathrm{k}_{\mathrm{r}} \mathrm{S}_{\mathrm{DIFF}}
$$

where $k_{r}$ is a rate constant. Their conclusion that the rate is surface controlled was later critiqued because the diffusion rate to crystals smaller than about $5 \mu \mathrm{m}$ (depending on the density of the crystal) is independent of the stirring rate (Nielsen, 1984) and the crystals in their experiments were about $10 \mu \mathrm{m}$. However, diffusion controlled precipitation should follow a first-order rate law based on the absolute saturation, and not a second-order rate law based on the saturation difference, such as was found for these experiments. Thus, the order of the reaction suggests that surface integration is rate limiting.

Kralj et al. (1990) found that diffusion exerted only a 1 to $10 \%$ influence on the precipitation rate for temperatures between 11 and $40^{\circ} \mathrm{C}$ based on theoretical diffusion rates, and that the reaction was surface integration limited based on good agreement with the parabolic rate equation 2.20

$$
\mathbf{w}=\mathbf{k}_{\mathrm{R}}\left(\mathrm{S}_{\mathrm{R}}-1\right)^{2}
$$

Christoffersen and Christoffersen (1990) when plotting $\log (w)$ versus $\log \left(\mathrm{S}_{R}-1\right)$ found a slope of $1.8 \pm 0.1$. Although this slope is close to the slope of 2 for equation 2.20 , they found better agreement when plotting $\log (w)$ versus $\log \left[S^{1 / 2}(S-1) \ln S\right]$, resulting in slopes of $0.95 \pm 0.04$ and $0.97 \pm 0.05$ for their two sets of data. They indicated that this suggests spiral growth with integration limiting, which they modeled as

$$
w=S_{R}^{1 / 2}\left(S_{R}-1\right) \ln S_{R}
$$

Most recently, Weijden et al. (1997) obtained similar results to Christoffersen and Christoffersen (1990), finding slopes between 1.8 and 2 when plotting $\log (w)$ versus $\log \left(S_{R}-1\right)$. This led them also to conclude that spiral growth was occurring with integration rate limiting. 
The only researchers who found diffusional resistances important on calcium carbonate crystal growth were Roques and Girou (1974), and it is unclear how their experimental conditions differed that would lead to this result.

The precipitation reaction for calcium carbonate is typically written as a function of the calcium and carbonate ion concentrations, and not on the total carbonate concentration. Weijden et al. (1997) found that for a constant carbonate ion concentration, the crystal growth rate for calcium carbonate increased with increasing total carbonate concentration. However, they were unable to quantify the crystal growth rate's dependence on the total carbonate concentration.

\subsubsection{Removal Rates}

The shear forces from the flowing water can result in scale being torn away from the surface and entrained in the bulk water. Experiments investigating scale growth and models predicting fouling rates based on scale growth models can be confounded if removal rates become significant. Most previous scaling experiments have focused on scaling that is $90+\%$ pure calcium carbonate, which results in a very tenacious and strong scale where removal rates are negligible (Taborek et al., 1972a and 1972b; Morse and Knudsen, 1977; Watkinson, 1983; Sheikholeslami and Watkinson, 1986; Andritsos et al., 1997). However, if the scale consists of more than one scaling salt or if in addition to scaling, particulate fouling is present, a much looser foulant is deposited and removal rates must be accounted for (Taborek et al., 1972a; Morse and Knudsen, 1977; Epstein, 1981a). Although removal rates are not the focus of the proposed experiments, if significant they must be accounted for.

\subsubsection{Temperature}

It is generally accepted that scaling of inverse solubility salts (salts with decreasing solubility with increasing temperature ) occurs on heat transfer surfaces due to the surface's higher temperatures relative to the fluid bulk. The increased temperature increases the water's supersaturation at the surface and hence increases the driving force for precipitation. The generally accepted scaling model assumes that the precipitating ions first diffuse from the bulk to the heat transfer surface and then precipitate on the surface, suggesting that scaling rates should have a large surface temperature dependency if a surface mechanism is rate limiting. Additionally, this also suggests that the only influence of the bulk temperature should be on the diffusion rate.

In scaling rate experiments, temperature dependent mechanisms occurring on the heat transfer surface can be differentiated from those occurring in the fluid bulk, since these 
temperatures can be varied independently. For these experiments, the different influences of surface and bulk temperatures on scaling rates are discussed below. For the one set of scaling experiments where the bulk and the surface were at equal temperatures (Andritsos et al., 1997) and therefore their effects could not be separated, a large temperature dependency was found. For the crystal growth experiments, which appeared to be surface and not diffusion controlled, the researchers who varied the temperature between runs (Reddy and Nancollas, 1971; Wiechers et al., 1974; Kralj et al., 1990) found a large temperature dependency on the precipitation rate for temperatures between 10 and $50^{\circ} \mathrm{C}$.

\subsubsection{Surface Temperature}

Of the three investigations of scaling on copper heat transfer surfaces (Hasson et al., 1968; Watkinson, 1983; and Sheikholeslami and Watkinson, 1986), only Hasson et al. varied the surface temperature between runs. They found that the scaling rate's dependence on the surface temperature was small relative to its dependence on the Reynolds number. Dalas and Koutsoukos (1990) investigated scaling on borosilicate glass, stainless steel, and aluminum heat transfer surfaces. They did find a surface temperature dependency on the scaling rate, but since the influence of diffusion was not investigated the relative magnitudes of the diffusion and surface resistances were not compared. Vliet et al. (1997) found that the experimental scaling rates of Dalas and Koutsoukos conformed well to diffusion controlled growth. Ishiguro et al. (1993) investigated scaling on gold, stainless steel, and nickel under turbulent conditions and found the rates to depend on the surface temperature but not on the Reynolds number, suggesting that for these conditions the surface resistances are much higher than diffusional resistances.

\subsubsection{Bulk Temperature}

Bulk temperature has not previously been identified as being important in modeling calcium carbonate precipitation rates. Therefore its affect on scaling rates has not been investigated in most scaling rate experiments (Hasson et al., 1968; Watkinson and Martinez, 1975; Morse and Knudsen, 1977; Sheikholeslami and Watkinson, 1986; Dalas and Koutsoukos, 1990; Ishiguro et al., 1993; and Andritsos et al., 1997). Watkinson (1983) ran most of his experiments at a bulk temperature of $25^{\circ} \mathrm{C}$, but had two runs at 37 and $59^{\circ} \mathrm{C}$, respectively. While the surface conditions for these two runs were similar to those for the other runs, the scaling rates were significantly higher, with that for the $59^{\circ} \mathrm{C}$ run being almost an order of magnitude larger than for the other runs. As will be shown in more detail later in this chapter, it appears that bulk 
temperature has a more significant affect on the scaling rates for the experiments of Hasson et al. (1968), Watkinson (1983), and Sheikholeslami and Watkinson (1986) than surface temperature.

\subsubsection{Velocity}

Velocity appears to not only affect the scaling rate by influencing the diffusional rate in the turbulent regime and the removal rates, discussed in Sections 4.1 and 4.2, respectively, but also by influencing the quality of the scale formed.

Sheikholeslami and Watkinson (1986) found the scale on a heated copper surface to be more porous and less tenacious at lower velocities $(0.3 \mathrm{~m} / \mathrm{s})$ than at higher velocities $(0.5$ and 0.7 $\mathrm{m} / \mathrm{s}$ ). This is significant in terms of scale remediation because the expected benefit of higher velocities leading to higher fluid shear forces and therefore greater removal rates may be offset by a stronger scale forming. Keysar et al. (1994) report that higher velocities result in smoother scale surfaces on metallic surfaces.

\subsubsection{Bulk versus Surface Precipitation}

By definition, scaling is surface precipitation. Most scaling experiments are designed to avoid particulate fouling, which is the deposition of suspended solids from the fluid bulk onto surfaces and can be caused by bulk precipitation. Researchers have concluded that bulk precipitation did not occur in most of the previous scaling experiments (Hasson et al., 1968; Morse and Knudsen, 1977; Sheikholeslami and Watkinson, 1986; Dalas and Koutsoukos, 1990; Ishiguro et al., 1993; and Andritsos et al., 1997), based on either the stability of the bulk water over time, the use of a filter to remove suspended solids, or the absence of a loose foulant, the loose foulant being indictative of particulate fouling and hence bulk precipitation.

However, it seems reasonable that the larger the solids being deposited, the looser the resulting foulant, and that if sufficiently small solids are being deposited, especially if this is combined with scaling, then a foulant that is strong enough to resist removal mechanisms may result. Thus the correlation between a loose foulant and bulk precipitation may not be strict. There is also some ambiguity in the term bulk precipitation, since calcium carbonate can exist in a continuum of sizes from a "dissolved" complex $\left(\mathrm{CaCO}_{3}{ }^{\circ}\right)$ up through macroscopically visible crystals. How many calcium carbonate molecules must be bonded together before bulk precipitation is said to occur? One might use the same criteria used to distinguish between suspended and dissolved solids in water, which is the size of the solid. Suspended solids are defined as those that are collected by a filter, while the dissolved solids are those that pass through the filter. This definition is not concise, though, since it depends on the pore size of the 
filter used. Roughly, filter pore sizes are typically on the order of $0.5 \mu \mathrm{m}$. These means approximately that dissolved particles can have diameters up to 1,000 times larger than a water molecule or, equivalently, have the volume of $10^{9}$ water molecules.

Typically bulk precipitation starts as heterogeneous nucleation on foreign solids in the bulk, the foreign solids providing an advantageous nucleation site. Bulk precipitation starting from homogeneous nucleation (where there is no foreign solid to initiate precipitation) is so rare due to impurities in water, that even under laboratory conditions heterogeneous nucleation is believed to have occurred for experiments meant to study homogeneous nucleation (Kralj et al., 1990; Gomez-Morales et al., 1996). Additionally, heterogeneous nucleation may occur when there is insufficient crystal surface area to support a certain growth rate; i.e., in crystal growth experiments, heterogeneous nucleation occurred for experiments with low seed crystal density and high saturation levels (Reddy and Nancollas, 1971; Wiechers et al., 1974). This suggests that heterogeneous nucleation and bulk precipitation may be more important in scaling experiments with large water volume to heat transfer area ratios. The possibilities of bulk precipitation occurring in scaling experiments will be discussed more at the end of this chapter.

\subsubsection{Surface Nucleation}

The nucleation rate on a heat transfer surface should at least be a function of the surface material, roughness, cleanliness and temperature, and the water's flow characteristics and degree of supersaturation. In general, the nucleation rate is much slower than the subsequent growth rate. For the experiments of Dalas and Koutsoukos (1990), no nucleation occurred until the surface temperature was increased above the bulk temperature, and the rate of nucleation increased with further increases in surface temperature. Surface temperature may be more important in controlling the nucleation rate than the subsequent growth rate, since during precipitation one would expect surface resistances to be much higher for nucleation than subsequent scale growth. Additionally, not only may the resistances of the mechanisms be different for nucleation and growth, the dominant mechanisms occurring may also be different. It seems reasonable that for similar scale growth rates under different experimental conditions the nucleation time may vary considerably, this being particularly likely if surface temperature has a much larger affect on nucleation rates than on growth rates. This would have implications for scaling inhibition in industry and in design of scaling rate experiments, since experimental time may be lost waiting for nucleation to occur. 


\subsubsection{Precipitating Phase}

The three solid phases of calcium carbonate, in order of increasing solubility, are calcite, aragonite, and vaterite, with calcite being the most thermodynamically stable phase. The predominate phase to precipitate depends on the supersaturation conditions and foreign cations and impurities present (Baker and Judd, 1996c; Franke and Mersmann, 1995; Roques and Girou, 1974). The greater the supersaturation, the more likely a higher solubility phase will initially form; i.e., vaterite forms at high supersaturation levels, aragonite at moderate, and calcite at low. If the initially precipitated phase is not calcite, the precipitated phase should age into calcite as the water approaches equilibrium. For calcium carbonate, aging occurs by the simulataneous dissolution of the higher solubility phase and the precipitation of the lower solubility phase, and thus cannot occur in the absence of water.

Aragonite is often called a soft scale and may be more susceptible to removal mechanisms due to fluid shear forces than calcite, which is often described as being hard and tenacious (Baker and Judd, 1996c). Inhibiting the aging of aragonite into calcite may be one way to reduce the consequences of scaling if shear forces are large enough to induce aragonite scale removal.

All three solid phases have been observed in scaling experiments. It is interesting to note that Dalas and Koutsoukos (1990) found vaterite to be the initial phase to precipitate and that it converted quickly and directly into calcite without first forming aragonite; in fact, they did not observe aragonite in any of their experiments. The water in their experiments had degrees of supersaturation of similar magnitude to other scaling experiments where the calcite and aragonite phases were reported. It was not clear how long the calcium carbonate aged in the other experiments before the phase was determined and if the time was sufficient to allow aging to occur.

In a crystal growth experiment, an unstable calcium carbonate precursor was formed at high saturation levels $\left(\mathrm{S}_{\mathrm{R}}>12\right)$, which the authors hypothesized might by $\mathrm{CaCO}_{3} \cdot 6 \mathrm{H}_{2} \mathrm{O}$ (Nielsen and Toft, 1984). This phase has not been reported elsewhere in the literature reviewed. Due to the high saturation levels necessary to achieve this precursor, it is thought that it should not form under most scaling conditions.

\subsubsection{Foreign Ions}

The effect of 34 additives on calcite growth were studied in a batch reactor, including the effect of metal cations, polyphosphates and other anions and organic compounds, and it was 
found that most additives reduced calcite's growth rate (Meyer, 1984). Specifically, iron was the most effective inhibitor. Magnesium, which is present with calcium in many hard waters and will be included in the later portions of the proposed experiments, was also found to be an inhibitor. Other experiments have shown that the presence of iron compounds in water slows the growth of calcium carbonate (some researchers indicating the calcite phase specifically), and that it also slows the transformation of aragonite into calcite. However, Baker and Judd (1996c) found the growth of aragonite to be unaffected by iron compounds. Magnesium has also been found to change the dominant precipitated phase from calcite to aragonite (Roques and Girou, 1974; and Baker and Judd, 1996c).

\subsubsection{Surface Roughness}

Keysar et al. (1994) investigated the effect of surface roughness on calcium carbonate scale (forming as calcite) on an unheated mild steel pipe. They found that nucleation tends to occur on roughness peaks and not roughness troughs, and that the deposits on smooth surfaces $(\mathrm{Ra}=0.1-0.15 \mu \mathrm{m})$ were three to four times more porous and up to 30 times less adhesive than those on rough surfaces $(\mathrm{Ra}=18-24 \mu \mathrm{m})$. They postulated that this occurred because the rougher surface produced a greater number of nucleation sites, and the resulting crystals then grew together enhancing adhesion through mechanical interlocking and forming a more compact, less porous, scale. They also found that the initial surface roughness propagated with the scale growth, meaning that rougher surfaces produced rougher scales.

\subsubsection{Heat Transfer Material}

After nucleation most of the scaling occurs as growth on the existing scale and not as new crystals nucleating on the bare heat transfer surface. Because of this, one would expect the heat transfer material to affect scale nucleation rates but not scale growth rates. The idea of scale growth rates being unaffected by surface material is supported by Suitor et al. (1977) in their literature review, Dalas and Koutsoukos (1990), who researched scaling on stainless steel, aluminum, and borosilicate glass, and Ishiguro et al. (1993), who researched scaling on stainless steel, gold, and nickel, and found scale growth rates to be unaffected by the surface material. Contrarily, Sheikholeslami and Watkinson (1986) found differences in scale growth rates for copper and mild steel heat transfer surfaces. The reason for these differences is not known. 


\subsection{Review of Scaling Rate Models}

Several scaling rate models have been proposed in the literature (Hasson et al., 1968; Hasson et al., 1978; Dalas and Koutsoukos, 1990; and Chan and Ghassemi, 1991a, 1991b) and each has been validated using portions of the experimental data available in the literature (Hasson et al., 1968; Hasson et al., 1978; Watkinson, 1983; Sheikholeslami and Watkinson, 1986; Dalas and Koutsoukos, 1990; and Chan and Ghassemi, 1991a, 1991b). However, the model developed by Hasson et al. (1978) is the only model that has been validated using data from more than one set of experiments, and even it has not been validated using all of the data available in the literature. Also, there has not been a direct comparison of the models except for Chan and Ghassemi's (1991b) comparison of their model and Hasson et al.'s model (1978), and this comparison appears to have some inconsistencies.

Six calcium carbonate scaling rate models are reviewed here and any validation performed for a model discussed. The models are classified according to the assumed rate controlling mechanism and labeled as either a diffusion, surface, or combined model. The "diffusion models" assume that the diffusion resistance is much greater than the surface reaction resistance. They assume that a significant concentration gradient exists between the bulk and interface, and they model the water at the interface as being at equilibrium with the solid. The "surface models" assume that the surface reaction resistance is much greater than the diffusion resistance and model the bulk and interface water concentrations as being equal. The "combined models" assume that the diffusion resistance is of the same order of magnitude as the surface reaction resistance. These models are basically a combination of the diffusion and surface models and assume that although there is a significant concentration gradient between the bulk and interface, the interface concentration cannot be assumed to be at equilibrium.

\subsubsection{Hasson Diffusion Model}

The model proposed by Hasson et al. (1968) is called herein the Hasson Diffusion Model and it assumes that diffusion is the rate controlling mechanism. The model also assumes that the carbonate concentration can be neglected relative to the bicarbonate concentration (i.e., $\left[\mathrm{HCO}_{3}{ }^{-}\right]$ $>>\left[\mathrm{CO}_{3}{ }^{2}\right]$ ), which should be valid for most waters. The model is based on the following overall reactions at the interface:

$$
\begin{aligned}
& 2 \mathrm{HCO}_{3}^{-} \longrightarrow \mathrm{CO}_{3}^{2-}+\mathrm{H}_{2} \mathrm{CO}_{3}^{*} \\
& \mathrm{Ca}^{2+}+\mathrm{CO}_{3}^{2-} \longrightarrow \mathrm{CaCO}_{3, \text { SOLID }}
\end{aligned}
$$


These surface reactions result in two bicarbonate ions and one calcium ion diffusing to the interface and reacting to form one solid calcium carbonate molecule and one carbonic acid molecule, with the carbonic acid diffusing back to the bulk. This can be represented as

$$
\begin{aligned}
& w=\frac{1}{2} h_{\mathrm{D} \mathrm{Ca}^{2+}}\left\{\left[\mathrm{HCO}_{3}^{-}\right]_{\mathrm{B}}-\left[\mathrm{HCO}_{3}^{-}\right]_{\mathrm{I}}\right\} \\
& \mathbf{w}=\mathrm{h}_{\mathrm{D}, \mathrm{Ca}^{2+}}\left\{\left[\mathrm{Ca}^{2+}\right]_{\mathrm{B}}-\left[\mathrm{Ca}^{2+}\right]_{\mathrm{I}}\right\} \\
& \mathbf{w}=\mathrm{h}_{\mathrm{D}, \mathrm{H}_{2} \mathrm{CO}_{3}}\left\{\left[\mathrm{H}_{2} \mathrm{CO}_{3}^{*}\right]_{\mathrm{I}}-\left[\mathrm{H}_{2} \mathrm{CO}_{3}^{*}\right]_{\mathrm{B}}\right\}
\end{aligned}
$$

where $h_{D, C a 2+}$ is the diffusion coefficient for the calcium and carbonate ions (assumed equal) and $\mathrm{h}_{\mathrm{D}, \mathrm{H} 2 \mathrm{CO} 3}$ is the diffusion coefficient for the carbonic acid. This three equations can be combined and simplified assuming equilibrium acid-base chemistry to arrive at the final form of the rate equation.

$$
\begin{aligned}
& {\left[\mathrm{H}_{2} \mathrm{CO}_{3}^{*}\right]_{\mathrm{B}}+\frac{\mathrm{w}}{\mathrm{h}_{\mathrm{D}, \mathrm{H}_{2} \mathrm{CO}_{3}}}} \\
& \quad=\frac{\mathrm{K}_{2}^{\prime}}{\mathrm{K}_{1}^{\prime} \mathrm{K}_{\mathrm{S}}^{\prime}}\left(\left[\mathrm{HCO}_{3}^{-}\right]_{\mathrm{B}}-\frac{2 \mathrm{w}}{\mathrm{h}_{\mathrm{D}, \mathrm{Ca}^{2+}}}\right)^{2}\left(\left[\mathrm{Ca}^{2-}\right]_{\mathrm{B}}-\frac{\mathrm{w}}{\mathrm{h}_{\mathrm{D}, \mathrm{Ca}^{2+}}}\right)
\end{aligned}
$$

Although the equation cannot be solved explicitly for the scaling rate, $w$, it is simple in that all of the surface concentrations have been eliminated. One possible limitation is its assumption that the bulk carbonate concentration can be neglected relative to the bulk bicarbonate concentration. This may result in significant errors for bulk pHs above approximately 9.5 at $25^{\circ} \mathrm{C}$, although $\mathrm{pHs}$ this high are rarely (but occasionally) found in municipal waters.

Hasson et al. (1968) compared their model with data they had collected and found that predicted rates matched measured rates within a factor of approximately 2 .

\subsubsection{Hasson Combined Model}

The subsequent model developed by Hasson et al. (1978) is called herein the Hasson Combined Model and it assumes that the diffusion and surface reaction resistances are of the same order of magnitude. It is an extension of the Hasson Diffusion Model and includes the rate of the surface reaction to form calcium carbonate using equation 2.25 .

$$
w=k_{R}\left(\left[\mathrm{Ca}^{2+}\right]_{i}\left[\mathrm{CO}_{3}^{2-}\right]_{i}-K_{S P}^{\prime}\right)=k_{R} S_{\text {DIFF }}
$$


The final form of the equation was obtained by combining the rate equations $2.25,2.28,2.29$ and 2.30 and simplifying based on equilibrium acid-base chemistry.

$$
\begin{gathered}
\left.\frac{\mathrm{K}_{1}^{\prime}}{4 \mathrm{~K}_{2}^{\prime}}\left\{\frac{\mathrm{w}}{\mathrm{k}_{\mathrm{R}}\left[\mathrm{Ca}^{2+}\right]_{\mathrm{B}}^{2}}+\frac{\mathrm{K}_{\mathrm{SP}}^{\prime}}{\left[\mathrm{Ca}^{2+}\right]_{\mathrm{B}}^{2}}\right\} \frac{\mathrm{w}}{\mathrm{h}_{\mathrm{D}}\left[\mathrm{Ca}^{2+}\right]_{\mathrm{B}}}+\frac{\left[\mathrm{H}_{2} \mathrm{CO}_{3}^{*}\right]_{\mathrm{B}}}{\left[\mathrm{Ca}^{2+}\right]_{\mathrm{B}}}\right\} \\
=\left\{1-\frac{\mathrm{w}}{\mathrm{h}_{\mathrm{D}}\left[\mathrm{Ca}^{2+}\right]_{\mathrm{B}}}\right\}\left\{\frac{\frac{1}{2}\left[\mathrm{HCO}_{3}^{-}\right]_{\mathrm{B}}}{\left[\mathrm{Ca}^{2+}\right]_{\mathrm{B}}}-\frac{\mathrm{w}}{\mathrm{h}_{\mathrm{D}}\left[\mathrm{Ca}^{2+}\right]_{\mathrm{B}}}\right\}^{2}
\end{gathered}
$$

In this model the diffusivities of carbonic acid, bicarbonate, and the calcium ion were all assumed equal, resulting in $\mathrm{h}_{\mathrm{D}, \mathrm{H} 2 \mathrm{CO} 3}=h_{\mathrm{D}, \mathrm{Ca} 2+}=h_{\mathrm{D}}$.

Hasson et al. (1978) also developed a rate equation for high $\mathrm{pH}$ waters, where the bicarbonate concentration can be neglected relative to carbonate concentration. This equation might be applicable for waters with $\mathrm{pHs}$ greater than approximately 11.5 . This is greater than the $\mathrm{pH}$ expected for all potable water's and therefore is not included here; interested readers are referred to Hasson et al. (1978) for details.

Hasson's Combined Model was first compared by Hasson et al. (1978) to the data of Morse and Knudsen (1977) for runs 28 and 29. It was found that the model gave predictions of the correct order of magnitude. Watkinson (1983) tested the model against his experimental data, which all had a surface temperature of $100^{\circ} \mathrm{C}$. He found good agreement except for runs with extremely large scaling rates, which differed from the other runs mainly by their elevated bulk temperatures. Sheikholeslami and Watkinson (1986) compared their experimental data to the model and found good agreement for copper heat transfer surfaces but not for mild steel heat transfer surfaces, where the model's trends did not match the experimental trends.

It appears that the above validations did not really test the efficacy of adding the surface reaction rate (equation 2.25) to the Hasson Diffusion Model, since the validation was not performed over a range of surface temperatures. Rather, including the surface reaction equation at a constant temperature merely resulted in a correction factor that served to lower the model's predictions. Hasson et al. 'validated' the model using two runs with surface temperatures of 65 and $71.5^{\circ} \mathrm{C}$, which resulted in surface rate constants that differed by less than $1 \%$. All of Watkinson's (1983) and Sheikholeslami and Watkinson's (1986) runs were at a constant surface temperature of approximately $100^{\circ} \mathrm{C}$, resulting in a constant surface rate constant for all runs. And although the surface temperatures for the runs used in the validation by Hasson were 
different from that used by Watkinson and Sheikholeslami and Watkinson, it appears that they used different Arrenhius pre-exponential constants.

It is interesting to note that the Hasson Diffusion Model was initially formulated to include the surface reaction (Hasson et al., 1968). However, they found the scaling rate had a very weak dependency on surface temperature and their experiments suggested that the scaling rate was diffusion controlled. This resulted in their proposed diffusion model, which gave good agreement with their measured scaling rates over a range of surface temperatures.

\subsubsection{Dalas Interface Model}

The model developed by Dalas and Koutsoukos (1990) is called herein the Dalas Surface Model. Based on their experiments at a single Reynolds Number in the laminar range, they found calcium carbonate scaling to be surface diffusion controlled (the diffusion of the ions across the surface of the crystal as they integrate into the crystal structure). They then proposed the following scaling rate model

$$
w=A \sigma_{v}{ }^{5 / 6} \exp \left(\frac{-B}{\sigma_{v}}\right)
$$

where $\mathrm{A}$ is a constant whose value was not given in the paper. The variables $\sigma_{\mathrm{v}}$ and $\mathrm{B}$ are defined as

$$
\begin{aligned}
& \sigma_{v}=\left\{\frac{\left[\mathrm{Ca}^{2+}\right]_{\mathrm{B}}\left[\mathrm{CO}_{3}^{2-}\right]_{\mathrm{B}}}{\mathrm{K}_{\mathrm{S}, \mathrm{CaCO}}^{\prime}}\right\}^{\frac{1}{2}}-1 \\
& \mathrm{~B}=\frac{\pi}{3} \gamma \mathrm{a}^{2} \mathrm{k}_{\mathrm{b}} \mathrm{T}
\end{aligned}
$$

where $\gamma$ is the surface energy, a is a step constant equal to $3 \AA$, and $k_{b}$ is Boltzmann's constant. A plot of surface energy for vaterite forming on 316 stainless steel versus temperature was given in their paper, which was reported to apply equally well for borosilicate glass and aluminum. In the next chapter where the models are compared, a best fit line was applied to this plot and the resulting equation was used to estimate surface energy for all heat transfer surfaces:

$$
\gamma\left[\mathrm{mJ}^{-1} \mathrm{~m}^{-2}\right]=0.0425 \mathrm{~T}^{2}-3.255 \mathrm{~T}+134.45 \quad\left[\mathrm{~T} \mathrm{in}^{\circ} \mathrm{C}\right]
$$

Dalas and Koutsoukos compared their scaling rate model to their experimental data and found good agreement. Their data, though, was all for one Reynolds Number and the importance 
of bulk diffusion on the scaling rate was not tested. Additionally, the constant $\mathrm{A}$ is empirical and therefore could serve as a correction factor.

\subsubsection{Chan and Ghassemi (1991a and 1991b)}

Chan and Ghassemi proposed two scaling rate models based on the work of Hasson et al. (1968) and Hasson et al. (1978). The models are much more numerically intensive than the other models and predict scaling rates as a function of time and location, accounting for changing pipe size with time due to scale build-up and differences in scaling rates along the pipe due to different temperatures and flow conditions. Unfortunately, the models appear to stress the numerical problem at the expense of the chemical problem.

The first model they proposed (1991a) assumed the surface reaction rate could be modeled as

$$
\mathrm{w}=\mathrm{k}_{\mathrm{r}}\left\{\left[\mathrm{Ca}^{2+}\right]_{\mathrm{i}}-\left[\mathrm{Ca}^{2+}\right]_{\mathrm{EQ}}\right\}^{2}
$$

This form of the surface rate equation was not found elsewhere in the literature. It was also assumed that the equilibrium calcium ion concentration equaled the square root of the solubility product $\left(\left[\mathrm{Ca}^{2+}\right]_{\mathrm{EQ}}=\left(\mathrm{K}_{\mathrm{SP}}\right)^{1 / 2}\right)$. A justification for this assumption was not given. For most waters $\left[\mathrm{Ca}^{2+}\right]_{\mathrm{EQ}} \gg\left[\mathrm{CO}_{3}{ }^{2-}\right]_{\mathrm{EQ}}$ and consequently $\left[\mathrm{Ca}^{2+}\right]_{\mathrm{EQ}} \gg\left\{\mathrm{K}_{\mathrm{SP}}\right)^{1 / 2}$ and the assumption seems to be erroneous. By modeling the surface reaction rate using equation 2.37 and assuming $\left[\mathrm{Ca}^{2+}\right]_{\mathrm{EQ}}=$ $\left(\mathrm{K}_{\mathrm{SP}}\right)^{1 / 2}$ they were able to develop their model considering only the calcium concentration; i.e., the carbonate system was neglected completely. The surface reaction was matched with the forward diffusion of calcium. When the model's predictions were compared to falling film scaling rates (Hasson and Pearl, 1981a) limited success was found.

As an improvement to their first model they proposed a second model (1991b) where equation 2.25 was used to model the surface reaction rate:

$$
w=k_{R}\left(\left[\mathrm{Ca}^{2+}\right]_{i}\left[\mathrm{CO}_{3}^{2-}\right]_{i}-K_{S P}^{\prime}\right)=k_{R} S_{\text {DIFF }}
$$

Equation 2.25 was matched with the forward diffusion of carbonate and calcium ions. However, it appears that the carbonic acid and bicarbonate species were neglected altogether, which is particularly troublesome since for most waters the bicarbonate is the dominant species in the carbonate system. The model was compared to the Hasson Combined Model using Sheikholeslami and Watkinson's (1986) data. For the rate constant $k_{R}$ they chose the activation energy and Arrhenius pre-exponential constant to provide a best fit to the measured scaling rate 
data and found their model's predictions matched the measured rates much better than the Hasson Combined Model.

Some of the most dramatic differences between the predicted rates of Chan and Ghassemi's model and the Hasson Combined Model are for Sheikholeslami and Watkinson's run 38. Chan and Ghassemi report their model over predicts the rate by $20 \%$ while the Hasson Combined Model under predicts the rate by $85 \%$. This is in contrast to Sheikholeslami and Watkinson (1986) who report for the same run that the Hasson Combined Model over predicts the rate by $25 \%$. One possible reason for this discrepancy is that Chan and Ghassemi may have optimized the activation energy and Arrhenius pre-exponential constant to provide a best fit for their model only. Thus this could easily result in a different rate constant being used than the one Sheikholeslami and Watkinson used.

A further concern is their claim to have optimized the activation energy and Arrhenius pre-exponential constant to provide a best fit for the data. The activation energy accounts for the temperature dependency of the reaction, and since all of the experimental runs were at the same surface temperature, it is not clear how the activation energy was separated from the Arrhenius pre-exponential constant; i.e., for a constant surface temperature an infinite number of combinations of the activation energy and the Arrhenius pre-exponential constant will give the same rate constant.

Because of the models' numeric complexity, which do not seem warranted based on the current understanding of the controlling mechanisms of calcium carbonate scaling, and the questionable water chemistry assumptions that were made, Chan and Ghassemi's models were not considered further.

\subsubsection{Baker Diffusion Model}

The diffusion model developed by Baker (1996a) is called herein the Baker Diffusion Model. The model is based on the Hasson Diffusion Model with one modification. During the development of the Hasson Diffusion Model the assumption was made that the carbonate system is at equilibrium at the interface and that bicarbonate diffuses from the bulk to the interface and the carbonic acid diffuses from the interface to the bulk. By neglecting the carbonate concentration when calculating diffusion rates the resulting rate model can be formulated in terms of only bulk concentrations but may be limited to $\mathrm{pHs}$ below approximately 9.5 . The Baker Diffusion Model is based on the assumption that if the carbonate system were at true equilibrium at the surface, then there could not simultaneously be a deficiency of bicarbonate 
ions and an excess of carbonic acid at the interface, which is the condition required for the simultaneous forward diffusion of bicarbonate and the backward diffusion of carbonic acid. Instead, the Baker Diffusion Model assumes that there is a net deficiency of the carbonate system at the surface and that there is a resulting net diffusion of the carbonate system to the surface, with the net carbonate system diffusion rate being equal to the scaling rate. The diffusivities of all species are assumed equal and the surface is assumed to be at equilibrium conditions:

$$
\begin{aligned}
& w=h_{D}\left\{\left[\mathrm{Ca}^{2+}\right]_{B}-\left[\mathrm{Ca}^{2+}\right]_{I}\right\} \\
& w=h_{D}\left\{C_{T, B}-C_{T, I}\right\}
\end{aligned}
$$

The strength of the model is that it should apply at all pHs, but unlike the Hasson Diffusion Model it does require calculation of the interface concentrations, making the resulting model more complex. An equilibrium model described in Baker (1996a) was used to calculate the equilibrium interfacial concentrations.

\subsubsection{Baker Combined Model}

The Baker Combined Model extends the Baker Diffusion Model by integrating the surface reaction rate into the model. The model consists of the two diffusion equations 2.38 and 2.39 and the surface reaction equation 2.25. The equilibrium model described in Baker (1996a) was modified for this model to calculate the interfacial concentrations necessary for the rates of equation $2.25,2.38$, and 2.39 to be equal, which no represent calcium carbonate equilibrium concentrations.

\subsubsection{Dalas-Baker Combined Model}

As discussed in section 4.1.1. of this chapter, the scaling rate on copper surfaces appears to be diffusion controlled. However, the Dalas Surface Model, which was validated based on a single Reynolds Number, neglects the diffusion rate entirely. The Dalas-Baker Combined Model is identical to the Baker Combined Model except instead of modeling the surface reaction rate as equation 2.25 it is modeled as in the Dalas Surface Model, equation 2.33.

\subsection{Experimental Scaling Data Compiled from the Literature}

Table 2.3 presents information on the type of experiment, the substrate material, and the nature of the precipitated phase $\left(\mathrm{CaCO}_{3}\right)$ as compiled from 9 different papers. The experiment type refers to whether the experiment was performed in a batch reactor, a tube heat exchanger, or a falling film evaporator. The base material is the material on which the precipitation occurred: 
in crystal growth experiments this was seed crystals and in the tube heat exchangers and falling film evaporators this was the material of the heat transfer surface. The precipitated phase is the phase of calcium carbonate reported, which is either calcite, aragonite, or vaterite. Aging, the transformation of a solid from one phase into a more stable phase, was reported for one scaling experiment (Dalas and Koutsoukos, 1990). In the other experiments, however, it was not clear whether there was sufficient time for aging to occur before the phase was determined.

The density and thermal conductivity, which were either measured or calculated from measured data, exhibited some variation between experiments. This can probably be attributed to varying scale porosity. The activation energy and Arrhenius pre-exponential constant were calculated from measured data and exhibited significant variation. Some of the variation may be a result of these values being sensitive to experimental conditions and affected by the presence of impurities and foreign ions (Meyer, 1984).

\begin{tabular}{|l|ccc|cccc|}
\hline & $\begin{array}{c}\text { Experiment } \\
\text { Type }\end{array}$ & $\begin{array}{c}\text { Base } \\
\text { Mat'l }\end{array}$ & $\begin{array}{c}\text { Precip. } \\
\text { Phase }\end{array}$ & $\begin{array}{c}\text { Density } \\
\text { Reference }\end{array}$ & $\begin{array}{c}\text { Thermal } \\
\text { Conductivity } \\
\mathbf{W} / \mathbf{m} \cdot \mathbf{K}\end{array}$ & $\begin{array}{c}\text { Activation } \\
\text { Energy } \\
\mathbf{k J} / \mathbf{m o l e}\end{array}$ & $\begin{array}{c}\mathbf{A}^{\mathbf{1}} \\
\mathbf{m} \cdot \mathbf{l} / \mathbf{s}^{\prime} \cdot \mathbf{m o l e}\end{array}$ \\
\hline Hasson et al. (1968) & Heat Exchanger & $\mathrm{Cu}$ & - & 2,760 & $\mathbf{1 . 7}$ & - & - \\
Nancollas et al. (1971) & Batch & Seed & Calcite & - & - & 46.1 & - \\
Wiechers et al. (1975) & Batch & Seed & Calcite & - & - & 43.1 & - \\
Gazit et al. (1975) & Falling Film & $\mathrm{Al}$ & Aragonite & - & - & 86.7 & $6.67 \mathrm{E}+13$ \\
Hasson et al. (1981) & Falling Film & $\mathrm{Al}$ & Aragonite & 2,380 & - & 72.6 & $3.66 \mathrm{E}+10$ \\
\hline Watkinson (1983) & Heat Exchanger & $\mathrm{Cu}$ & - & 2,650 & 2.3 & - & - \\
Dalas et al. (1990) & Heat Exchanger & $\mathrm{Cu}, \mathrm{Al}, \mathrm{G}$ & Vaterite & - & - & 36 & - \\
Kralj et al. (1990) & Batch & Seed & Vaterite & - & - & 57.1 & - \\
Keysar et al. (1994) & Unheated pipe & $\mathrm{MS}$ & Calcite & 2,360 & - & - & - \\
\hline
\end{tabular}

Abbreviations: $\mathrm{Cu}=$ Copper; Seed $=$ Crystal Seed; $\mathrm{Al}=$ Aluminum; $\mathrm{G}=$ Borosilicate Glass; $\mathrm{MS}=$ Mild Steel

Superscripts: $\quad 1=$ Arrhenius Pre-Exponential Constant

$2=$ Vaterite precipitated initially but quickly transformed into calcite

\section{Table 2.3: Experiment Type and Calcium Carbonate Properties} for Several Useful Data Sets

Experimental conditions and measured scaling rates for calcium carbonate scaling on heat transfer surfaces were compiled from five papers and are presented in Table 2.4. The papers did not give the experimental conditions in a consistent form and some estimations were necessary to develop this table: Footnotes are used in the table to indicate which values were estimated or calculated and how this was done. Two experimental run designations are given, the first being the number given in the original paper, and the second being that assigned by the present authors, with the first letter indicating the principle author, a second letter indicating a sub-set of experiments, and the number indicating a unique experimental run. The material (Mat'l) of the heat transfer surface on which the scale forms is given, along with the bulk and 
surface temperatures. The convention used for the flow dimensions (ID and $\mathrm{OD}$ ) is that if the scaling occurred in the annulus the ID is the inside diameter of the outside tube and the OD is the outside diameter of the inside tube. If the scaling occurred in the tube, the $\mathrm{ID}$ is the inside diameter of the tube and the OD is left blank. The velocity $(\mathrm{Vel}), \mathrm{pH}$, total alkalinity $\left(\mathrm{Alk}_{\mathrm{T}}\right)$, dissolved calcium $\left(\mathrm{Ca}^{2+}\right)$, and total dissolved solids (TDS) are also listed. The scaling rate is given in terms of both mass flux $\left(\mathrm{mg} / \mathrm{s} \cdot \mathrm{m}^{2}\right.$ of $\left.\mathrm{CaCO}_{3}\right)$ and fouling resistance $\left(\mathrm{m}^{2} \cdot \mathrm{K} / \mathrm{kW}\right)$. 
Experimental Conditions

\begin{tabular}{|c|c|c|c|c|c|c|c|c|c|c|c|c|c|c|c|}
\hline \multirow{14}{*}{ 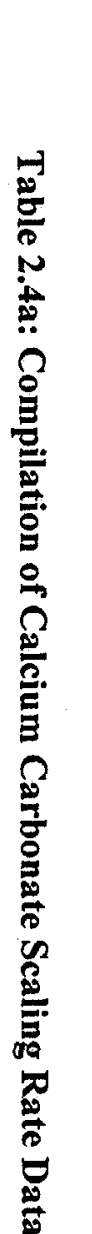 } & \multirow[b]{2}{*}{ Researchers } & \multirow{2}{*}{\multicolumn{2}{|c|}{$\begin{array}{l}\text { Exp. } \\
\text { Run }\end{array}$}} & \multirow[t]{2}{*}{ Mat'I } & \multicolumn{2}{|c|}{ Temp. } & \multicolumn{2}{|c|}{$\begin{array}{c}\text { Flow } \\
\text { Dimensions }\end{array}$} & \multirow[t]{2}{*}{ Vel. } & \multirow[t]{2}{*}{ pH } & \multirow{2}{*}{$\begin{array}{c}\mathrm{Alk}_{\mathrm{T}} \\
\mathrm{mg} / \mathrm{t} \\
\text { as } \\
\mathrm{CaCO}_{3}\end{array}$} & \multirow{2}{*}{$\begin{array}{c}\mathrm{Ca}^{2+} \\
\mathrm{mg} / \\
\text { as } \\
\mathrm{CaCO}_{3}\end{array}$} & \multirow{2}{*}{$\begin{array}{l}\text { TDS } \\
\mathrm{mg} / \mathrm{l}\end{array}$} & \multicolumn{2}{|c|}{ Scaling Rate } \\
\hline & & & & & $\begin{array}{l}\text { Bulk } \\
{ }^{\circ} \mathrm{C}\end{array}$ & $\begin{array}{l}\text { Surf } \\
{ }^{\circ} \mathrm{C}\end{array}$ & $\begin{array}{c}\text { Dime } \\
\text { ID }^{\prime} \\
\text { m }\end{array}$ & $\begin{array}{c}\text { nsions } \\
\text { OD' } \\
\text { m }\end{array}$ & & & & & & $\begin{array}{c}\text { Mass of } \\
\mathrm{CaCO}_{3} \\
\mathrm{mg} / \mathrm{s} \cdot \mathrm{m}^{2}\end{array}$ & $\begin{array}{c}\mathrm{R}_{\mathrm{f}} \\
10^{6} \\
\mathrm{~m}^{2} \cdot \mathrm{k} / \mathrm{kW}\end{array}$ \\
\hline & $\begin{array}{c}\text { Hasson ct al. } \\
\text { (1968) }\end{array}$ & $\begin{array}{c}\text { NA } \\
" \\
" \\
" \\
" \\
" \\
\end{array}$ & $\begin{array}{l}\text { IIV.I } \\
\text { IIV. } 2 \\
\text { HV. } \\
\text { HV. } \\
\text { HV. } \\
\text { HV. } 6 \\
\end{array}$ & $\begin{array}{l}\mathrm{Cu} \\
" \\
" \\
" \\
" \\
"\end{array}$ & $\begin{array}{c}45 \\
" \\
" \\
" \\
" \\
"\end{array}$ & $\begin{array}{c}75.8^{A} \\
" \\
" \\
" \\
" \\
\end{array}$ & $\begin{array}{c}0.0381 \\
" \\
" \\
" \\
" \\
" \\
\end{array}$ & $\begin{array}{c}0.0127 \\
" \\
" \\
" \\
" \\
\end{array}$ & $\begin{array}{l}0.25^{\mathrm{EI}} \\
0.36^{\mathrm{EI}} \\
0.48^{\mathrm{EI}} \\
0.59^{\mathrm{EI}} \\
0.71^{\mathrm{E}} \\
0.82^{\mathrm{EI}} \\
\end{array}$ & $\begin{array}{c}7.42^{\wedge} \\
" \\
" \\
" \\
" \\
\end{array}$ & $\begin{array}{c}325^{\wedge} \\
" \\
" \\
" \\
" \\
\end{array}$ & $\begin{array}{c}310^{4} \\
" \\
" \\
" \\
" \\
" \\
\end{array}$ & $\begin{array}{c}675^{A} \\
" ~ \\
" \\
" \\
" \\
" \\
\end{array}$ & $\begin{array}{c}9.44^{\mathrm{EI}} \\
11.11^{\mathrm{EI}} \\
12.50^{\mathrm{EI}} \\
14.72^{\mathrm{EI}} \\
17.50^{\mathrm{EI}} \\
20.56^{\mathrm{EI}}\end{array}$ & $\begin{array}{l}1.82 \mathrm{cl} \\
2.14 \mathrm{cl} \\
2.40 \mathrm{cl} \\
2.83 \mathrm{cl} \\
3.37 \mathrm{cl} \\
3.95 \mathrm{cl}\end{array}$ \\
\hline & & $\begin{array}{l}\text { " } \\
" \\
" \\
" \\
\end{array}$ & $\begin{array}{l}\text { HT.1 } \\
\text { HT.2 } \\
\text { HTT.3 } \\
\text { HT. } 4 \\
\text { HT. } .5 \\
\end{array}$ & $\begin{array}{l}\text { " } \\
" \\
" \\
"\end{array}$ & $\begin{array}{l}" \\
" \\
" \\
"\end{array}$ & $\begin{array}{r}67.5 \\
72.5 \\
73.5 \\
76.5 \\
81 \\
\end{array}$ & $\begin{array}{l}\text { " } \\
" \\
" \\
\end{array}$ & $\begin{array}{l}" \\
" \\
" \\
\end{array}$ & $\begin{array}{r}0.50 \\
" \\
" \\
" \\
" \\
\end{array}$ & $\begin{array}{l}n \\
" \\
" \\
" \\
\end{array}$ & $\begin{array}{l}" \\
" \\
" \\
"\end{array}$ & $\begin{array}{l}" \\
" \\
" \\
"\end{array}$ & $\begin{array}{l}" \\
" \\
" \\
"\end{array}$ & $\begin{array}{l}13.89^{\mathrm{EI}} \\
15.00^{\mathrm{EI}} \\
14.72^{\mathrm{EI}} \\
15.28^{\mathrm{EI}} \\
16.67^{\mathrm{EI}}\end{array}$ & $\begin{array}{l}2.67^{\mathrm{Cl}} \\
2.88^{\mathrm{Cl}} \\
2.83^{\mathrm{Cl}} \\
2.94^{\mathrm{Cl}} \\
3.21^{\mathrm{Cl}}\end{array}$ \\
\hline & & & $\begin{array}{l}\text { IIC.I } \\
\text { HC. } 2\end{array}$ & " & 39 & $\begin{array}{r}82.5 \\
n\end{array}$ & $"$ & " & $\begin{array}{r}0.26 \\
" ~\end{array}$ & $\begin{array}{c}7.65^{\wedge} \\
" ~\end{array}$ & $\begin{array}{l}130^{\mathrm{E} 2} \\
220^{\mathrm{E} 2}\end{array}$ & $\begin{array}{l}110^{\mathrm{E} 2} \\
330^{\mathrm{E} 2}\end{array}$ & $\begin{array}{l}320^{\mathrm{E} 2} \\
760^{\mathrm{E} 2}\end{array}$ & $\begin{array}{l}0.00^{\mathrm{EI}} \\
2.36^{\mathrm{EI}}\end{array}$ & $\begin{array}{l}0.00^{\mathrm{CT}} \\
0.45^{\mathrm{Cl}}\end{array}$ \\
\hline & & 45 & HC. 3 & $"$ & $"$ & $"$ & $"$ & $"$ & " & $"$ & $228^{\mathrm{E} 2}$ & $350^{E 2}$ & $800^{\mathrm{E} 2}$ & $2.50^{\mathrm{EI}}$ & $0.48^{\mathrm{Cl}}$ \\
\hline & & 38 & HC. 4 & $"$ & $"$ & " & $"$ & $"$ & $"$ & $"$ & $253^{\mathrm{E} 2}$ & $410^{\mathrm{E} 2}$ & $920^{\mathrm{E} 2}$ & $4.17^{\mathrm{E1}}$ & $0.80^{\mathrm{Cl}}$ \\
\hline & & 33 & IIC.5 & " & " & " & " & " & " & " & $271^{\mathrm{c}}$ & $455^{20}$ & $1010^{\mathrm{E} 2}$ & $3.75^{\mathrm{E1}}$ & $0.72^{\mathrm{Cl}}$ \\
\hline & & 34 & HC. 7 & $"$ & $"$ & " & " & $"$ & $"$ & 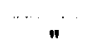 & $293 \mathrm{E} 2$ & $510^{\mathrm{E} 2}$ & $\mathrm{CO}^{\mathrm{E}}$ & $4.17^{\mathrm{E}}$ & $\begin{array}{l}0.80^{\mathrm{C}} \\
0.96^{\mathrm{Cl}}\end{array}$ \\
\hline & & 43 & HC. 8 & $"$ & " & $"$ & " & $"$ & $"$ & " & $"$ & $"$ & $"$ & $5.28^{\mathrm{El}}$ & $1.01^{\mathrm{Cl}}$ \\
\hline & & 36 & HC.9 & $"$ & " & $"$ & $"$ & $"$ & $"$ & $"$ & $298^{\mathrm{E} 2}$ & $520^{\mathrm{E} 2}$ & $1140^{\mathrm{E} 2}$ & $7.22^{\mathrm{EI}}$ & $1.39^{\mathrm{Cl}}$ \\
\hline & & 39 & HC. 10 & $"$ & " & $"$ & " & " & $"$ & $"$ & $310^{\mathrm{E} 2}$ & $550^{\mathrm{E} 2}$ & $1200^{\mathrm{E} 2}$ & $7.22^{\mathrm{EI}}$ & $1.39^{\mathrm{Cl}}$ \\
\hline & & 35 & IIC.11 & $"$ & $"$ & $"$ & $"$ & $"$ & $"$ & $"$ & $320^{\mathrm{E} 2}$ & $575^{\mathrm{E} 2}$ & $1250^{\mathrm{E} 2}$ & $5.83^{\mathrm{EI}}$ & $1.12^{\mathrm{Cl}}$ \\
\hline & & 40 & HC. 12 & $"$ & $"$ & $"$ & $"$ & $"$ & $"$ & $"$ & $"$ & $"$ & $"$ & $7.50^{\mathrm{EI}}$ & $1.44^{\mathrm{Cl}}$ \\
\hline
\end{tabular}

Abbreviations: $\mathrm{Cu}=$ Copper

Footnotes:

1: For scaling in annulus, ID is ID of outside tube and OD is OD of inner tube. For scaling in tube, ID is ID of the tube

$\Lambda: \Lambda$ verage value

$\mathrm{Cl}$ : Calculated based on a scale density of $2.600 \mathrm{~kg} / \mathrm{m}^{3}$. conductivity of $2 \mathrm{~W} / \mathrm{m} \cdot \mathrm{K}$ and either the mass or fouling resistance scaling rate.

El= Estimated from a graph data point.

1:2 = Estimated by varying total alkalanity, dissolved calcium, and TDS between the minimum and maximum values reported by the same proportion until their absolute supersaturation calculated using a calcite solubility product matched a graph data point. 


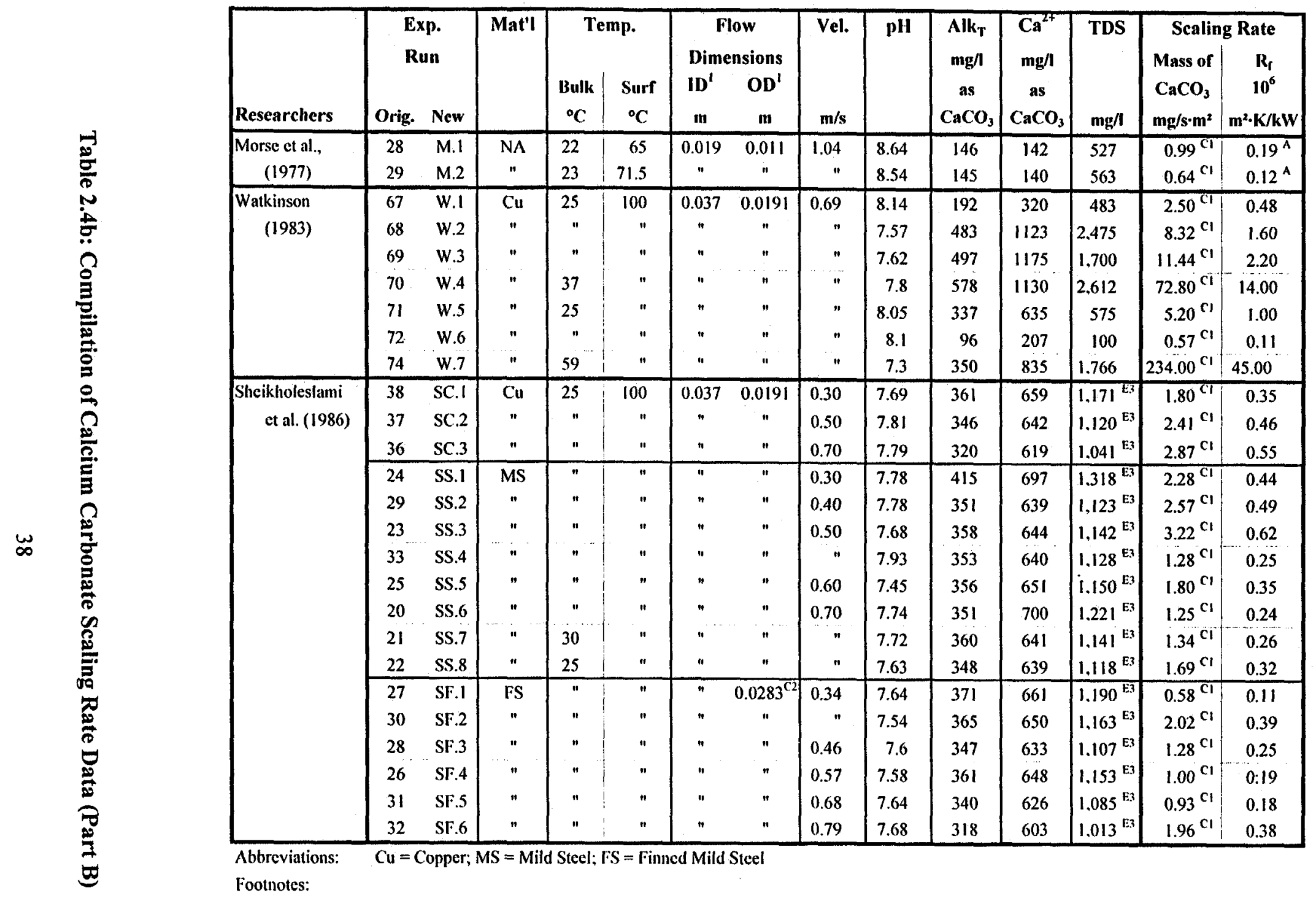

1: For scaling in annulus. ID is ID of outside lube and OD is OD of inner tube. For scaling in tube, ID is ID of the tube.

C1: Calculated based on a scale density of $2,600 \mathrm{~kg} / \mathrm{m}^{3}$. conductivity of $2 \mathrm{~W} / \mathrm{m} \cdot \mathrm{K}$ and the mass scaling rate.

C2: Calculated from OD = ID - Hydraulic Diameter, wilh hydraulic diameter given in the paper.

Li: Estimated based on TDS values for experiments with similar total alkalinities and dissolved calcium concentrations. 


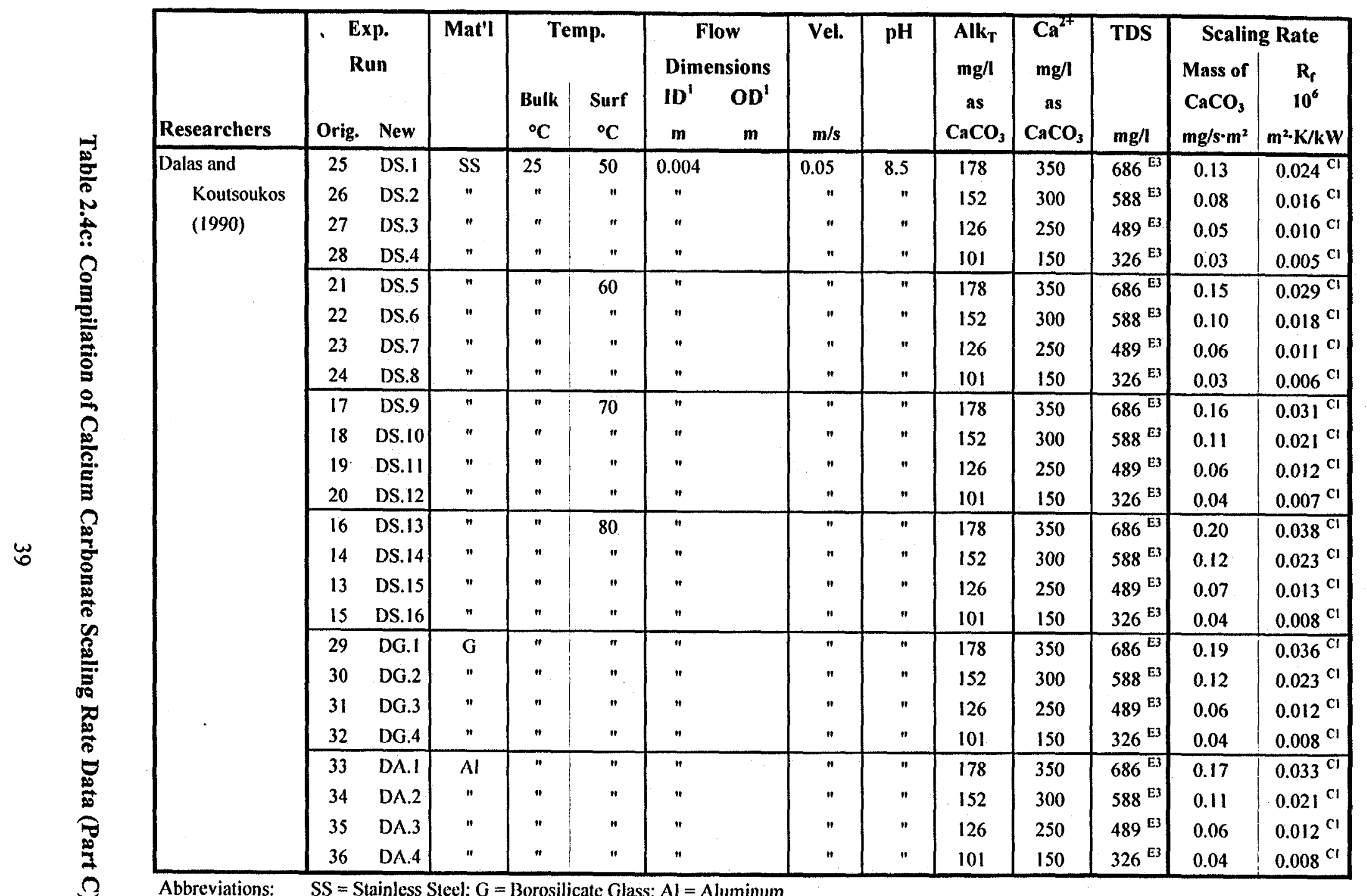
Footnotes:

1: For scaling in annulus, ID is ID of outside tube and OD is OD of inner tube. For scaling in tube, ID is ID of the tube.

$\mathrm{Cl}$ : Calculated based on a scale density of $2,600 \mathrm{~kg} / \mathrm{m}^{3}$. conductivity of $2 \mathrm{~W} / \mathrm{m} \cdot \mathrm{K}$ and the mass scaling rate.

E3: Estimated based on TDS values for experiments with similar total alkalinities and dissolved calcium concentrations. 


\subsection{Review of Previous Experimental Set-ups}

As an aid in designing the experimental set-up, a review of past experimental set-ups for scaling rate experiments is given here. The general experimental conditions are contained in Table 2.1 and conditions for individual runs are shown in Tables $2.4 \mathrm{a}-2.4 \mathrm{c}$. The experimental set-ups for these experiments are described below.

\subsubsection{Hasson et. al. (1968)}

Hasson et al. utilized a constant flux heat exchanger and measured the change in the temperature of the heat transfer surface with time. Assuming that changes in the convection coefficient are negligible as the scale is deposited and grows on the heat transfer surface, a constant heat flux means that the liquid-solid interface, where the scale is being deposited, should remain at a relatively constant temperature while the temperature at the heat transfer surface should increase with time due to the fouling. The scaling water was passed through the annulus of the heat exchanger, while the center section was heated using an electrical resistance heater. The outer pipe consisted of a thick-walled Perspex tube (38.1 $\mathrm{mm} \mathrm{ID)}$ ), allowing visual observation of the scale growth. The inner tube consisted of three pieces of copper tubing (12.7 $\mathrm{mm}$ OD) forming a $508 \mathrm{~mm}$ long unheated entry section (equal to 20 equivalent diameters), a $610 \mathrm{~mm}$ long heated test section, and an unheated exit section of unspecified length. To prevent conduction from the heated to the unheated sections, the tubes were joined using Textolite heatinsulating tubes of the same outside diameter. Two perforated Ebonite disks were located near the inlet and outlet to center the inner pipe and smooth the flow. Thermocouples were placed at 150,300 , and $450 \mathrm{~mm}$ from the beginning of the test section, representing 6,12 , and 18 equivalent diameters. The electrical element consisted of a $1-\mathrm{mm}$ coil-wound Nichrome wire inside a quartz tube, which provided electrical insulation from the copper tube. The element could supply up to $3.7 \mathrm{~kW}$ at full load using 220 volts. The rise in the bulk temperature across the heat exchanger was less than $3^{\circ} \mathrm{C}$, allowing a constant surface temperature to be assumed for the entire heat transfer surface.

Initially municipal water was used and either $\mathrm{CaCl}_{2}$ or $\mathrm{NaHCO}_{3}$ was added to the stream to increase the saturation, or the water stream was diluted with distilled water to lower the saturation. For the later experiments a $6 \mathrm{~m}^{3}$ storage tank was used and no make-up water was added during an experimental run.

Run times varied between 16 and 60 hours and nucleation was achieved within approximately 2 hours. 


\subsubsection{Watkinson (1983)}

The test section consisted of a $133 \mathrm{~cm}$ long copper tube $(1.91 \mathrm{~cm} \mathrm{OD)} \mathrm{mounted} \mathrm{inside} \mathrm{a}$ glass annulus $(3.72 \mathrm{~cm} \mathrm{ID})$. The scaling water flowed through the annulus and was heated by steam condensing on the inside of the tube. The steam pressure was adjusted so that a constant heat flux was maintained. The water entered the test section from a 140 liter tank. After leaving the test section the water was cooled in a second heat exchanger and then returned to the tank. The water was prepared by using $\mathrm{CaCl}_{2}$ and $\mathrm{NaHCO}_{3}$, and in some cases $\mathrm{NaOH}$ or $\mathrm{HCl}$. Run times varied between 5 and 70 hours

\subsubsection{Sheikholeslami and Watkinson (1986)}

The physical set-up is essentially the same as for Watkinson (1983) except that mild steel tubes were used in addition to copper, and make-up chemicals were added periodically to keep the water chemistry constant. Additionally, nitrogen was initially bubbled through the water to remove any oxygen to keep the mild steel from corroding, and the feed tank was blanketed in nitrogen. Run times were on the order of 70 hours.

\subsubsection{Dalas and Koutsoukos (1990)}

A double walled, water jacketed PYREX glass reactor was used to feed thermostatically constrolled water to the test sections. The feed tank was filled with $0.2 \mathrm{~L}$ of water, held at $25 \pm$ $0.1^{\circ} \mathrm{C}$, and there was little air space allowing minimal exchange of $\mathrm{CO}_{2}$. The water was prepared by simultaneously mixing equal volumes of calcium nitrate and sodium bicarbonate solutions. The $\mathrm{pH}$ of the solution was adjusted using a potassium hydroxide solution, and measured using a combination glass/saturated calomel electrode. After the water was prepared it was allowed to sit for 2 hours to verify its stability, and then circulated through the test specimen using a peristaltic pump. During a run, a pH drop as small as $0.003 \mathrm{pH}$ units triggered the addition of calcium nitrate, sodium bicarbonate and sodium carbonate titrant solutions from two mechanically coupled burettes of a modified automatic titrator, maintaining a constant water chemistry.

The test section consisted of $70 \mathrm{~mm}$ long tubes $(4 \mathrm{~mm} \mathrm{ID}$ ) of either aluminum, stainless steel, or borosilicate glass heated from the outside by a tubular heating mantel. The maximum heat flux used was $3.1 \mathrm{cal} / \mathrm{sec}$ and the temperature rise across the test specimen was never more than $2^{\circ} \mathrm{C}$. Upon exiting the test section the water was cooled by a condenser in which water at $25^{\circ} \mathrm{C}$ was circulating, and then returned to the feed tank. Prior to use the specimens were cleaned 
by ultrasonication for $30 \mathrm{~min}$. in doubly distilled acetone, and then dried at $100^{\circ} \mathrm{C}$ for 15 minutes.

Experiments were also run measuring the conductivity and calcium activity of the solutions over time periods exceeding the times of the individual runs to show that the solutions were stable and would not spontaneously precipitate. The constancy of the solution composition was verified by withdrawing samples from the main reactor, filtering through membrane filters, and analyzing the filtrates for calcium by atomic adsorption spectroscopy. The solid phases were examined by infra-red spectroscopy by scanning electron microscopy and by powder X-ray diffraction.

\subsubsection{Ishiguro et al. (1993)}

The water was prepared from deionized water with a conductivity of less than $0.2 \mu \mathrm{S} / \mathrm{cm}$ and was filtered with a $0.45 \mu \mathrm{m}$ mesh filter. Calcium chloride and sodium bicarbonate were then dissolved in the water. Atomic adsorption analysis was used to test for metal impurities such as $\mathrm{Fe}, \mathrm{Mg}$, and $\mathrm{Cu}$.

The test section had a rectangular cross-section $16 \mathrm{~mm}$ in width and $5 \mathrm{~mm}$ high and was $500 \mathrm{~mm}$ long. Nickel and stainless steel were added to the surface of a $10 \mathrm{~mm}$ wide copper block to form the heat transfer surface, with a heater being mounted at the bottom of the copper block. After each run the heat transfer surface was immersed in dilute hydrochloric acid to dissolve the deposited $\mathrm{CaCO}_{3}$, washed with water and ethanol, and reused. A camera mounted on a microscope was placed $350 \mathrm{~mm}$ downstream from the starting point of the test section and used to photograph the progress of the scaling. The rate of scaling was measured based on the temperature change at the surface of the copper block. Run times were on the order of 10 hours.

\subsubsection{Andritsos et al. (1996)}

These experiments were conducted under isothermal conditions, i.e., the bulk and surface temperatures were the same. The water was either drawn from the water main or a large tank, with the water in the tank being prepared by mixing softened water with calcium chloride. The drawn water was heated and then a sodium hydroxide solution was continuously added to the water stream, increasing the water's saturation by increasing its $\mathrm{pH}$.

The water flowed through a tube and the scale was deposited on semi-annular coupons made of stainless steel. The coupons were weighed before each run, and periodically during a run a pair of coupons would be removed and replaced with a clean pair. The removed coupons would be reweighed to determine the mass of scale deposited. Run times varied between 5 and 
20 hours. The deposits were characterized using powder X-ray diffraction and scanning electron microscopy, and the chemical composition was determined using atomic adsorption spectroscopy. 


\section{Chapter 3}

\section{Comparison of Scaling Rate Models}

\subsection{Introduction}

All the scaling rate models reviewed in Chapter 2 except for those by Chan and Ghassemi (1991a; 1991b) were compared using the compiled experimental rate data. The models were compared on the basis of the standard deviation of their error from the experimental data compiled from the literature. The error for each run was defined as

$$
\text { Error }=\frac{\text { Predicted Rate }- \text { Measured Rate }}{\text { Measured Rate }}
$$

and the standard deviation $(\sigma)$ was calculated for each model.

$$
\sigma=\left[\frac{\sum_{\text {Runs }} \text { Error }^{2}}{\text { Runs }}\right]^{\frac{1}{2}}
$$

To elucidate scaling rate dependencies that were not effectively included in the models, the ratios of predicted to measured scaling rates were plotted for each model against the following parameters: surface degree of supersaturation, surface absolute supersaturation, surface temperature, bulk degree of supersaturation, bulk absolute supersaturation, bulk temperature, bulk pH, and Reynolds Number.

\subsection{Empirical Constants Used in the Models}

All of the models except the two diffusion models (Baker Diffusion Model and Hasson Diffusion Model) contain empirical constants with values that are not well defined in the literature. Table 3.1 lists the various models and indicates the values of their empirical constants used in this research, with N/A meaning that the particular constant is not applicable to that model. The models are listed in order of decreasing accuracy of prediction as indicated by the standard deviation.

The Baker Combined Model and the Hasson Combined Model each include a secondorder surface-reaction rate term with an Arrhenius pre-exponential constant, $\mathrm{A}$, and an activation energy, $\mathrm{E}$, in the rate constant, $\mathrm{k}_{\mathrm{R}}$

$$
\mathrm{w}=\mathrm{k}_{\mathrm{R}}\left(\left[\mathrm{Ca}^{2+}\right]_{\mathrm{i}}\left[\mathrm{CO}_{3}^{2-}\right]_{\mathrm{i}}-\mathrm{K}_{\mathrm{SP}}^{\prime}\right)
$$




$$
k_{R}=A \exp \left(\frac{-E}{R T}\right)
$$

where equation 2.25 is repeated from the previous chapter. The values found in the literature for the activation energy vary between 36 and $87 \mathrm{~kJ} / \mathrm{mole}$. The Baker and Hasson Combined Models were each run for two cases, one with an activation energy of $43 \mathrm{~kJ} / \mathrm{mole}$ and the second with an activation energy of $75 \mathrm{~kJ} / \mathrm{mole}$. The pre-exponential constant was chosen for each case to minimize the model's standard deviation.

Both the Dalas Surface Model and the Dalas-Baker Combined Model contain an undefined pre-exponential constant, $A$, that is different from the Arrhenius pre-exponential constant

$$
\mathrm{w}=A \sigma_{v}{ }^{5 / 6} \exp \left(\frac{-\mathrm{B}}{\sigma_{v}}\right)
$$

where equation 2.33 is repeated from the previous chapter. This constant was also chosen to minimize each model's standard deviation.

All constants in the Baker and Hasson Diffusion Models had well defined values. This meant that there were no empirically determined constants that could be adjusted to eliminate bias by minimizing the standard deviation. In comparison, the other models all had empirical constants that were selected to minimize the model's standard deviation. As a result, it is not possible to make an accurate comparison and assessment of the diffusion models relative to the other models. Therefore, the Baker and Hasson Diffusion Models were each run for two cases, the first with no correction factor $(f=1)$ and the second with a correction factor chosen to minimize the standard deviation. These were found to be 0.6 and 0.65 , respectively. The correction factor, $\mathrm{f}$, was applied as a proportionality constant to the scaling rate

$$
\text { Rate }=f \times \text { Rate }_{o}
$$

where Rate and Rate $_{\mathrm{O}}$ are the corrected and reference scaling rates, respectively.

\subsection{Data Used in Comparison}

Initially, the diffusion and combined models were run using all of the data in Table 2.4. It was found that the errors for runs SS.1 - SS.8 (mild steel surface) and SF.1 - SF. 6 (finned mild steel surface) were significantly larger than for the other experimental runs. These runs were different from the others in that the scaling occurred on mild steel heat transfer surfaces and additionally, for runs SF.1 - SF.6 the scaling occurred on a finned surface. The experiments by Hasson et al. (1968) and Watkinson (1983) were performed on copper surfaces which exhibited 
scaling rates that increased monotomically with Reynolds Number. The rates on mild steel did not exhibit this monotomic increase with Reynolds Number, but instead initially increased and then decreased with Reynolds Number. Since it is expected that most heat transfer surfaces of interest will be made of copper, experimental runs SS.1 - SS.8 and SF.1 - SF.6 were not included in the subsequent analysis.

Morse and Knudsen (1977) did not indicate the material of their heat transfer surface. However, their data conformed well with that for copper heat transfer surfaces and were therefore included.

Dalas and Koutsoukos (1990) investigated scaling on aluminum, stainless steel, and borosilicate glass heat transfer surfaces and since they did not vary the Reynolds Number, the scaling rate's dependence on Reynolds Number could not determined. Inclusion of this data in the model comparison did not change the relative accuracies of the models. Therefore the data were assumed to conform well to that for scaling on copper surfaces and were included in the analysis.

\subsection{Results of Comparison}

Table 3.1 summarizes the results of the model comparisons, with the models being ranked from most to least accurate in terms of the standard deviation from the data. The table also includes the values of the constants used in the various models as discussed in Section 3.

\begin{tabular}{|l|c|c|c||c|}
\hline Model & $\mathbf{A}^{\mathbf{1}}$ & $\begin{array}{c}\mathbf{E}^{2} \\
\mathrm{~kJ} / \mathrm{mole}\end{array}$ & $\mathbf{f}^{\mathbf{3}}$ & $\begin{array}{c}\text { Standard } \\
\text { Deviation }\end{array}$ \\
\hline Baker Combined & $1.0 \mathrm{E}+13$ & 75 & N/A & $\mathbf{0 . 4 4}$ \\
Baker Combined & $5.0 \mathrm{E}+07$ & 43 & N/A & $\mathbf{0 . 4 5}$ \\
Hasson Combined & $1.0 \mathrm{E}+07$ & 43 & N/A & $\mathbf{0 . 5 5}$ \\
Dalas-Baker Combined & $1.0 \mathrm{E}-08$ & N/A & N/A & $\mathbf{0 . 5 6}$ \\
\hline Hasson Combined & $5.0 \mathrm{E}+11$ & 75 & N/A & $\mathbf{0 . 5 7}$ \\
Baker Diffusion (Corrected) & N/A & N/A & 0.6 & $\mathbf{0 . 5 7}$ \\
Hasson Diffusion (Corrected) & N/A & N/A & 0.65 & $\mathbf{0 . 6 0}$ \\
Hasson Diffusion (Uncorrected) & N/A & N/A & 1 & $\mathbf{0 . 7 3}$ \\
\hline Dalas Surface & 0.78 & N/A & N/A & $\mathbf{0 . 7 8}$ \\
Baker Diffusion (Uncorrected) & N/A & N/A & 1 & $\mathbf{0 . 7 9}$ \\
\hline
\end{tabular}

Notes: All data in Table 3.2 used except runs SS.1 - SS.8 and SF.1 - SF.6

N/A indicates the constant is not applicable to the model

'Arrhenius Pre-Exponential Constant for the Baker and Hasson Combined Models; Dalas Surface Model Pre-Exponential Constant for the Dalas-Baker Combined and Dalas Surface Models.

${ }^{2}$ Activation Energy

${ }^{3}$ Correction factor for the Baker and Hasson Diffusion Models

Table 3.1: Model Comparison Results 
There are several interesting points to note about these results. The combined models are more accurate than the diffusion models, with the Baker Combined Model being the most accurate. This suggests that the surface temperature dependency is important. However, the accuracy of the combined models showed little dependence on the value of the activation energy used. The diffusion models with the correction factors were significantly more accurate than the diffusion models without the correction factors. The Dalas-Baker Combined Model was significantly more accurate than the Dalas Surface Model, providing further evidence that the scaling rate has a large dependency on the diffusion rate and thus cannot be neglected. This is illustrated in Figure 3.1, which is a plot of the measured and predicted scaling rates versus Reynolds Number for the Dalas Surface Model.

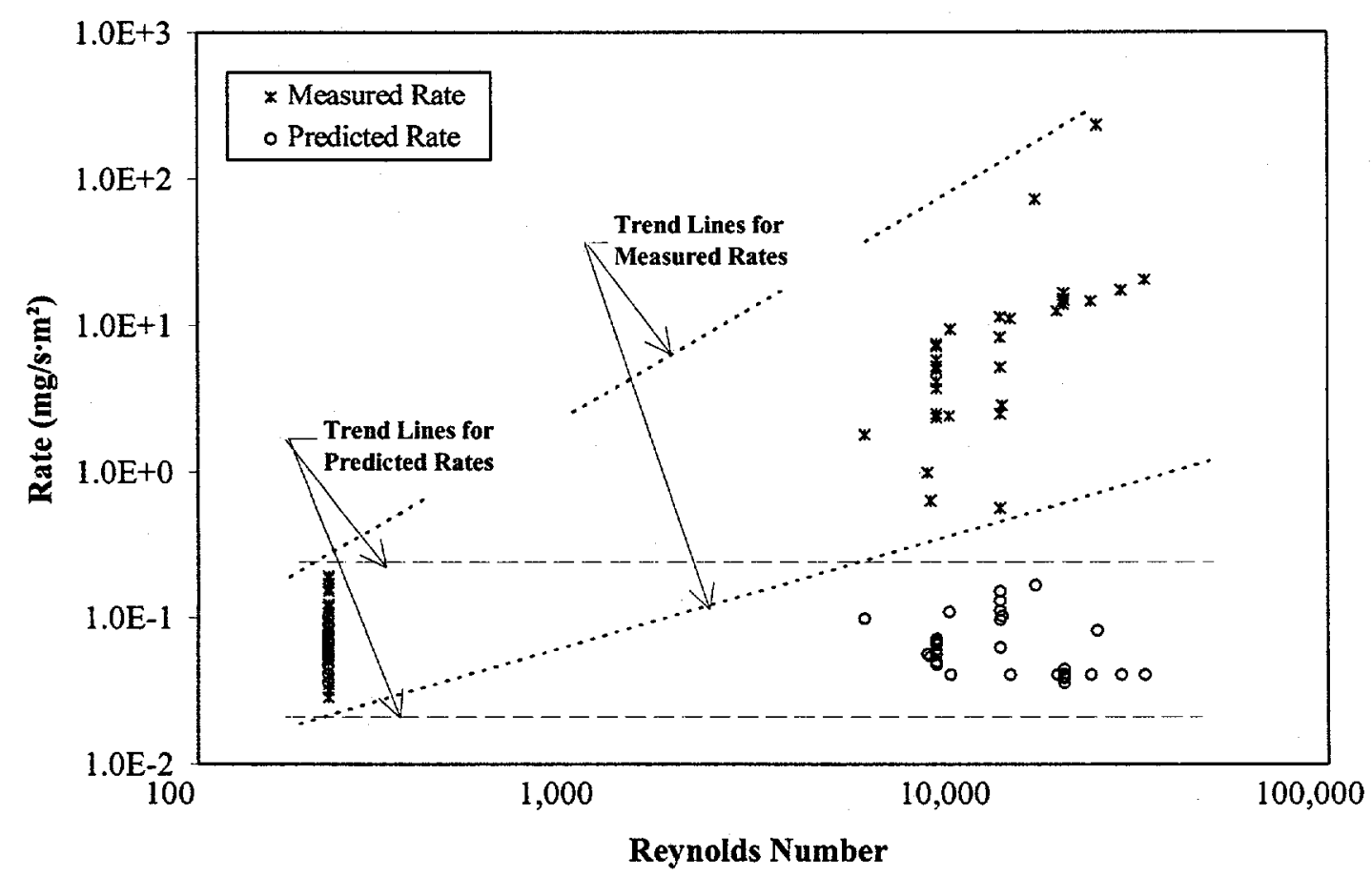

Figure 3.1: Measured and Predicted Scaling Rates versus Reynolds Number Dalas Surface Model

As can be seen, the measured scaling rate has a large Reynolds Number dependency that is not captured in the Dalas Surface model, making the model inadequate to predict rates over a range of Reynolds Numbers in the turbulent regime. On the other hand, the diffusion and combined models error's do not show a Reynolds Number dependency, suggesting that the Reynolds Number dependency was accurately captured in the diffusion rate in these models. The omission of the mass diffusion rate from the Dalas Surface Model may be because all of Dalas and 
Koutsoukos' (1990) experiments were in the laminar regime at constant velocity and bulk temperature. Therefore the diffusional resistance should have been relatively constant for all their experimental runs and accounted for in their model by the empirically determined constant $A$ in equation 2.33. It is not clear from their article if they only wanted to study the surface reaction and therefore wanted a constant mass transfer rate across the experiments, or if they merely did not consider the effect of the mass transfer rate.

The Baker and Hasson Diffusion Models assume that the interface approaches equilibrium conditions and therefore surface resistances can be neglected. If this assumption is erroneous and the surface reaction rate is important, the measured rates should show a surface temperature dependency not captured in the diffusion models. The Baker and Hasson Diffusion Models' standard deviations from the measured rates were larger than those for the Baker and Hasson Combined Models. This would indicate that the surface reaction rate is important. However, a visual inception of Figure 3.2, which is the predicted/measured scaling rates versus surface temperature for the Baker Diffusion Model with a 0.6 correction factor, does not show a strong surface temperature dependency. Although there is a small surface temperature dependency for the data of Hasson (1968) and Dalas (1990), the predicted/measured rate points are scattered both above and below unity across the full range of temperatures, with unity representing perfect agreement between predicted and measured rates. This graph is typical of the other diffusion models and would suggest that neglecting the surface reaction rate in the diffusion models is not their main source of error. Hasson et al. (1968) were the only researchers to assess the relative importance of Reynolds Number and surface temperature on scaling rates and they reported that the scaling rate does not have a large surface temperature dependency. Consequently they proposed a diffusion-controlled scaling rate model instead of a surface or combined model. 


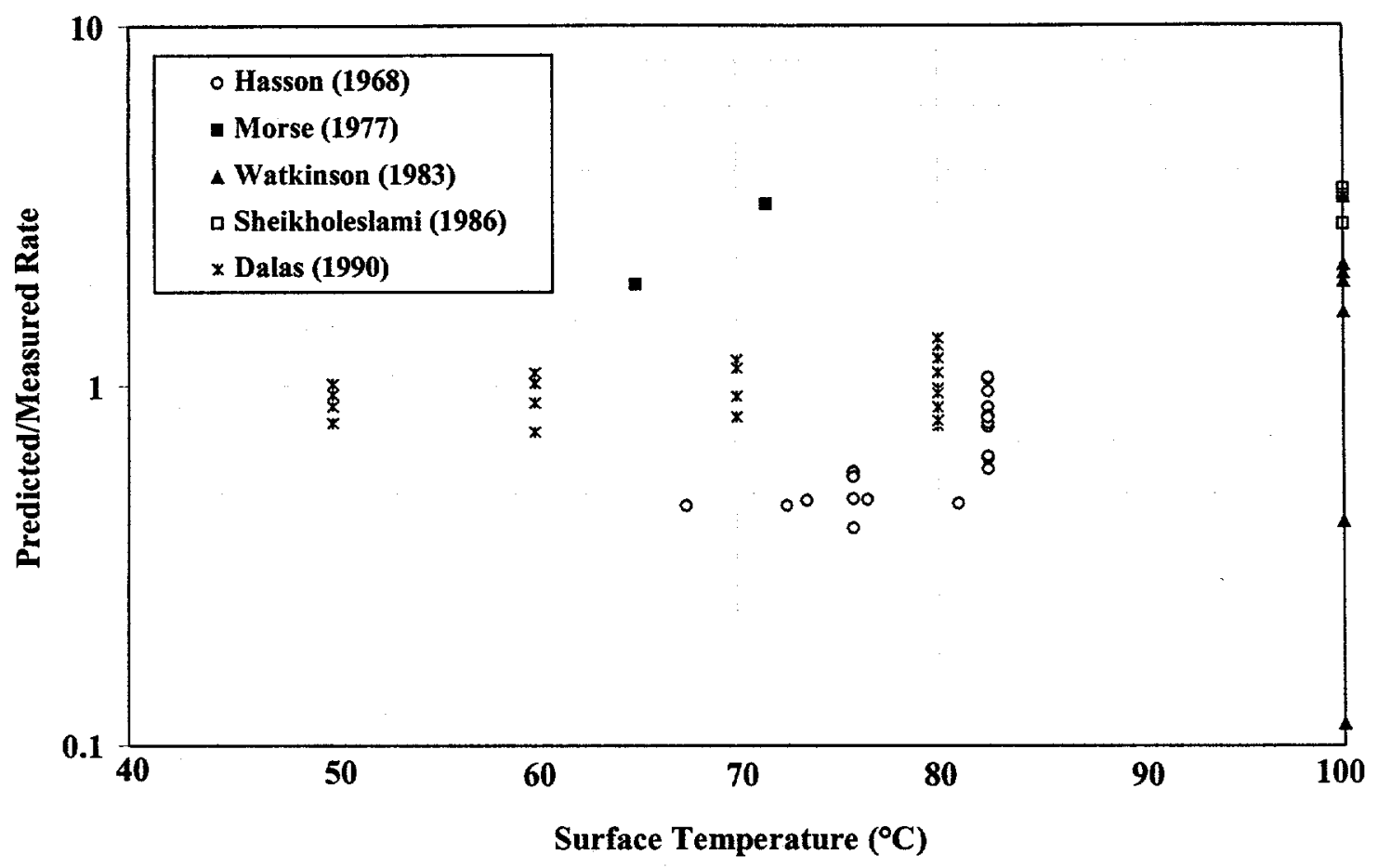

Figure 3.2: Predicted/Measured Scaling Rate versus Surface Temperature Baker Diffusion Model $(f=0.6)$

While the errors in the diffusion models did not show a large surface temperature dependency, the errors in all of the models (diffusion, combined, and surface) did show a large bulk temperature dependency. Using the Baker Combined Model with $E=43 \mathrm{~kJ} / \mathrm{mole}$ and $\mathrm{A}=5$ $x 10^{7}$, the effect of bulk temperature is discussed here, with the other models showing similar trends. Figures 3.3 and 3.4 are plots of the predicted/measured scaling rate versus bulk temperature for the data of Hasson et al. (1968) and Watkinson (1983), respectively, while Figure 3.5 is a similar plot using all the data. There is seen to be a consistent error trend for the model predictions with varying bulk temperature, which is seen both within and across experiments. 


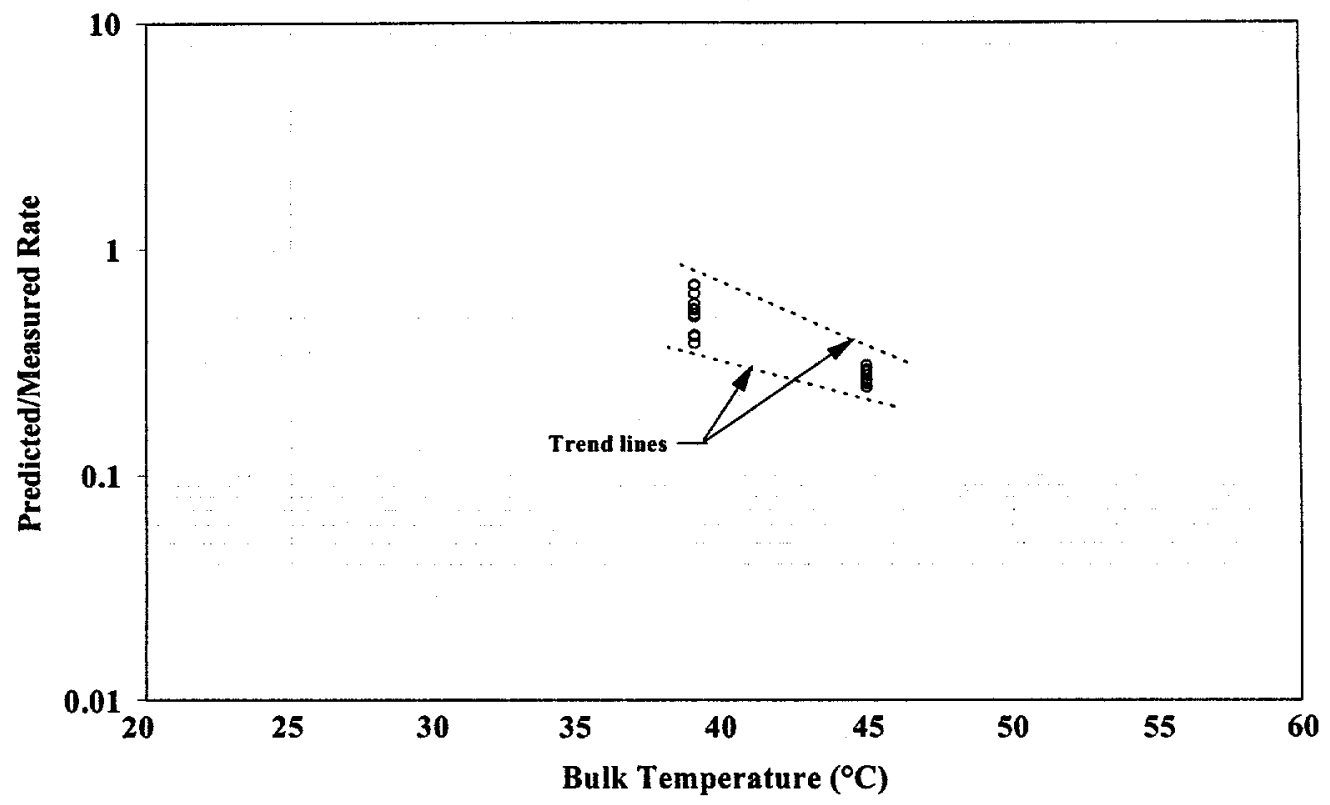

Figure 3.3: Predicted/Measured Scaling Rate versus Bulk Temperature Baker Combined Model ( $E=43 \mathrm{~kJ} / \mathrm{mole}, A=5 \times 10^{7}$ )

Hasson (1968) Data Only

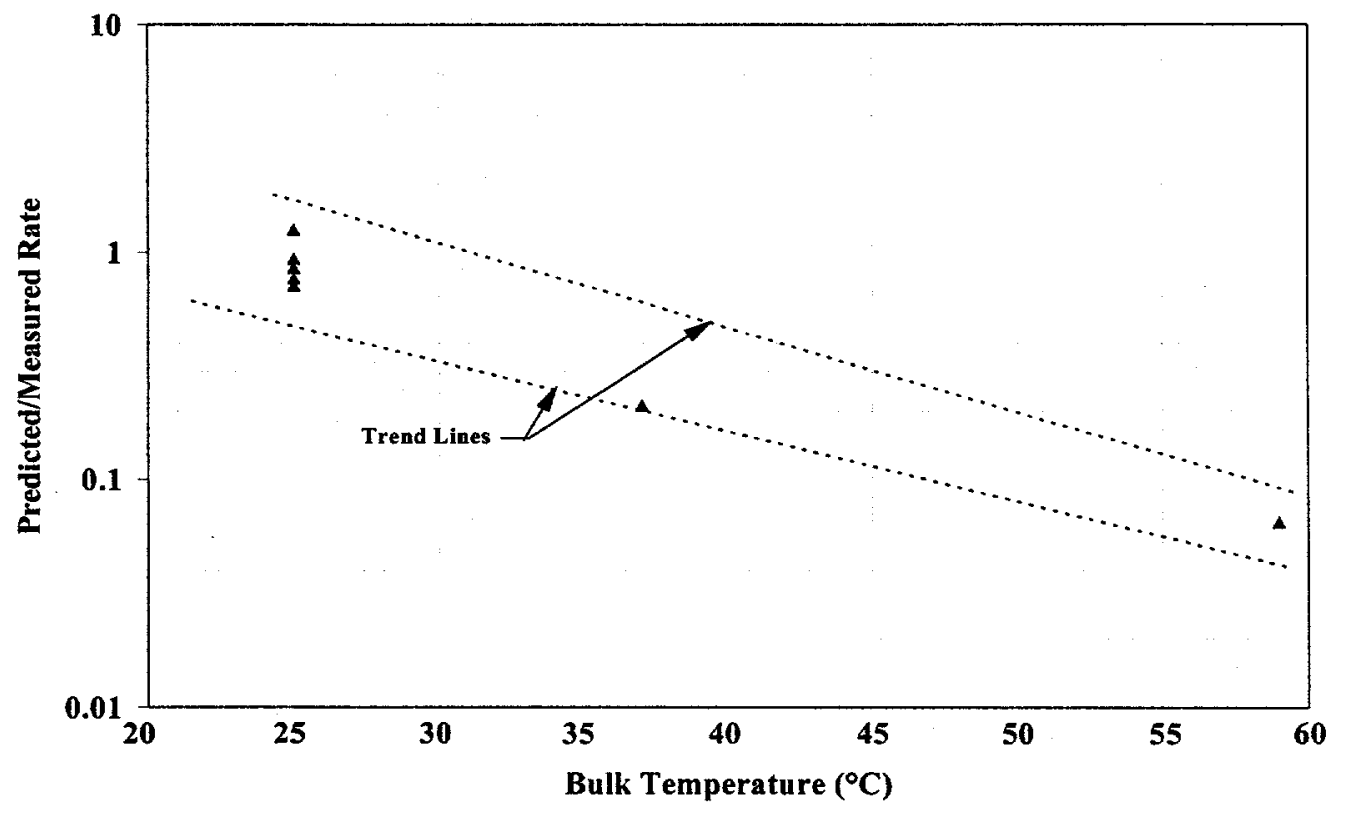

Figure 3.4: Predicted/Measured Scaling Rate versus Bulk Temperature Baker Combined Model $\left(E=43 \mathrm{~kJ} / \mathrm{mole}, A=5 \times 10^{7}\right)$ Watkinson (1983) Data 


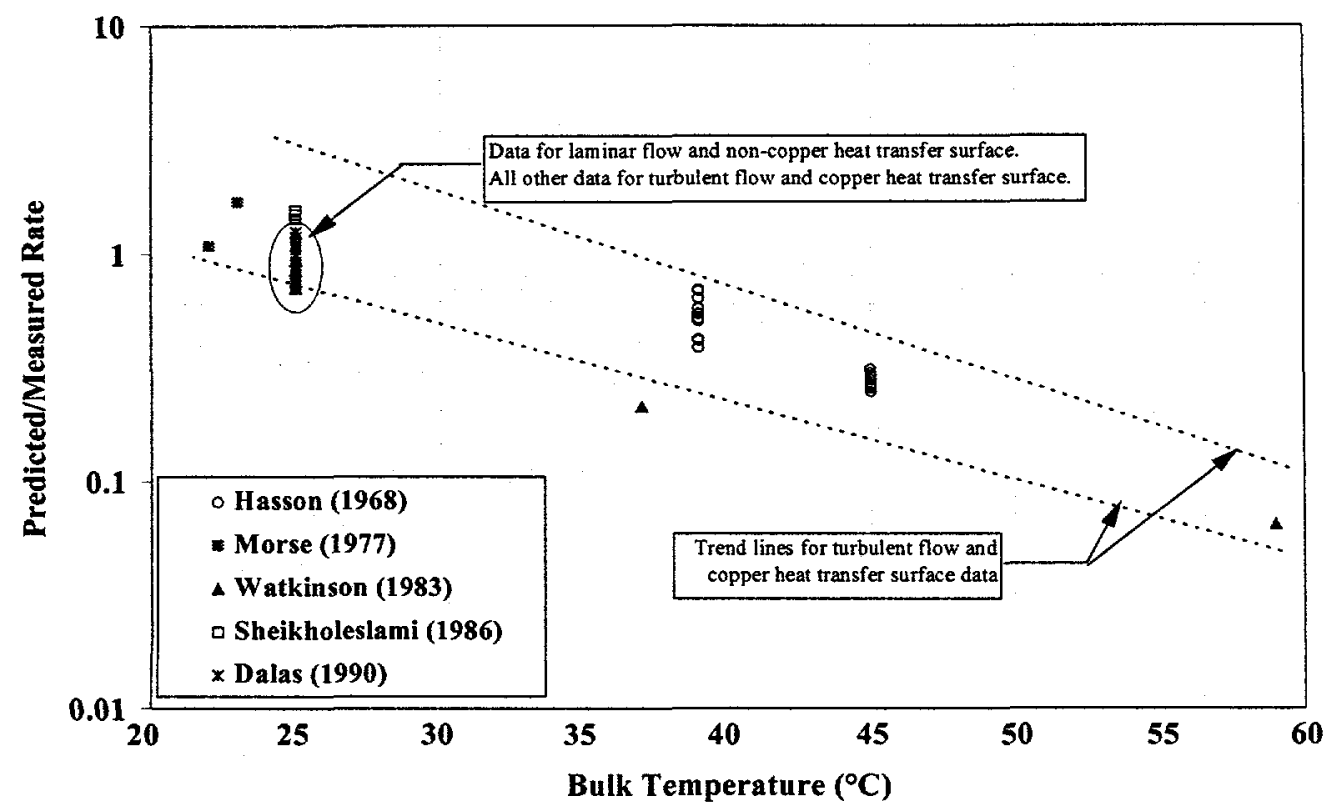

Figure 3.5: Predicted/Measured Scaling Rate versus Bulk Temperature Baker Combined Model $\left(E=43 \mathrm{~kJ} / \mathrm{mole}, A=5 \times 10^{7}\right)$

All Data

The strong scaling rate dependency on the bulk temperature is supported by the findings of Watkinson (1983), who compared the Hasson Combined Model's predictions to measured scaling rates. Watkinson used a bulk temperature of $25^{\circ} \mathrm{C}$ for most of the experimental runs and found scaling rates between approximately 0.6 and $12 \mathrm{mg} \mathrm{CaCO} / \mathrm{s} \cdot \mathrm{m}^{2}$. He also had two runs at elevated bulk temperatures $\left(37\right.$ and $\left.59^{\circ} \mathrm{C}\right)$ which resulted in the significantly larger scaling rates of 73 and $234 \mathrm{mg} \mathrm{CaCO} / \mathrm{s} \cdot \mathrm{m}^{2}$, respectively. These two runs did not differ drastically in their calcium concentrations, alkalinities, $\mathrm{pH}$ levels, or surface temperatures. Watkinson found that the Hasson Combined Model gave accurate predictions at bulk temperatures of $25^{\circ} \mathrm{C}$, but had errors of a similar order of magnitude as those reported here for the Baker Combined Model for the runs with bulk temperatures of 39 and $59^{\circ} \mathrm{C}$. Watkinson concluded that while the Hasson Combined Model was accurate at moderate scaling rates, it was inaccurate at high scaling rates. He did not suggest a bulk temperature dependency on the scaling rate.

Figure 3.6 is the predicted/measured scaling rate versus bulk temperature for the Baker Diffusion Model with a 0.6 correction factor, and as can be seen it is similar to Figure 3.5. However, the spread in the data is somewhat larger. 


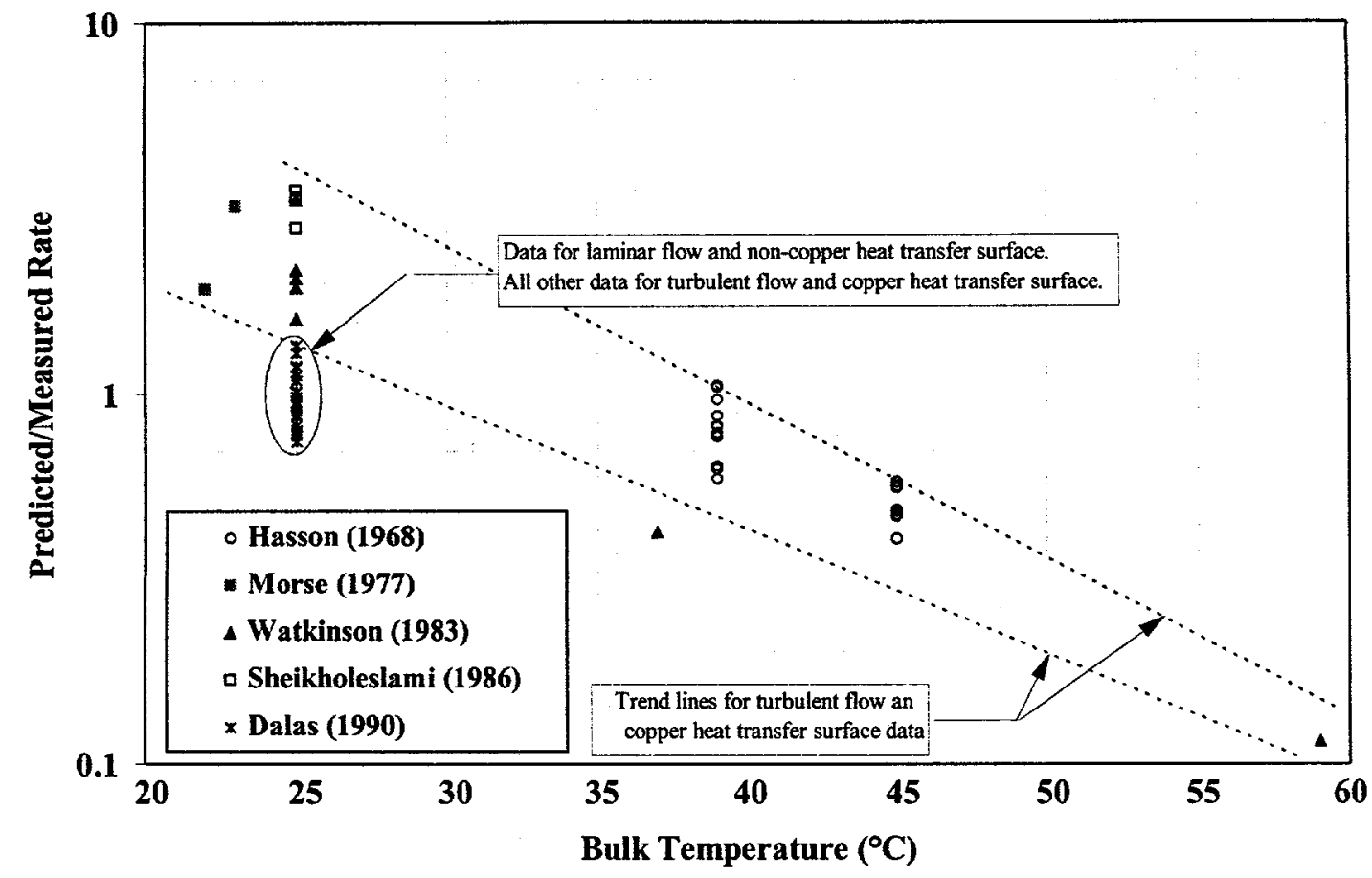

Figure 3.6: Predicted/Measured Scaling Rate versus Bulk Temperature Baker Diffusion Model $(f=0.6)$

Comparing Figures 3.2 and 3.6 (dependence on surface temperature and bulk temperature, respectively) the Baker Diffusion Model's error is seen to have a much larger bulk temperature dependency than surface temperature dependency. This suggests that the scaling rate is much more dependent on the bulk temperature than the surface temperature.

Further inadequacies in the current scaling models can be found by inspecting run W.7 in greater detail. This run had the highest bulk temperature and scaling rate of any run, $59^{\circ} \mathrm{C}$ and $234 \mathrm{mg} \mathrm{CaCO} 3 / \mathrm{s} \cdot \mathrm{m}^{2}$, respectively. The predicted scaling rate of the Baker Diffusion Model with no correction factor is $27 \mathrm{mg} / \mathrm{s} \cdot \mathrm{m}^{2}$, almost an order of magnitude smaller. The accuracy of the diffusion model was checked and also benchmarked against the results by Watkinson (1983) for run W.7 and no inconsistencies were found. Similar results were found for the other models. That the measured scaling rate is significantly larger than the diffusion rate indicates another fundamental problem with the models.

Plots for each of the models considered can be found in Vliet, Lawler and Baker (1997) of predicted/measured scaling rates against the following six parameters: supersaturation ratio, absolute supersaturation, $\mathrm{pH}$, Reynolds Number, surface temperature, and bulk temperature. However, the plots that were the most meaningful to the authors are those discussed above. 


\subsection{Semi-Empirical Scaling Rate Model Developed}

Based on the plot of predicted/measured scaling rates as a function of bulk temperature, a best-fit bulk-temperature dependent correction factor has been developed for the Baker Combined Model $\left(E=43 \mathrm{~kJ} / \mathrm{mole}, \mathrm{A}=5 \times 10^{7}\right)$ in the form of the Arrhenius rate constant

$$
\text { Rate }=\left\{1.8 \times 10^{11} \exp \left(\frac{-7,800}{T_{B}}\right)\right\} \text { Rate }_{o}
$$

where Rate is the corrected scaling rate, $T_{B}$ is the bulk temperature in Kelvin, and Rate $e_{O}$ is the uncorrected scaling rate.

When applied to the data, the model's predicted rates were within a factor of two of the measured rates, as shown in Figure 3.7. The model did not show any significant dependency on bulk degree of supersaturation, bulk absolute supersaturation, bulk pH, Reynolds Number, surface temperature, surface degree of supersaturation, or surface absolute supersaturation.

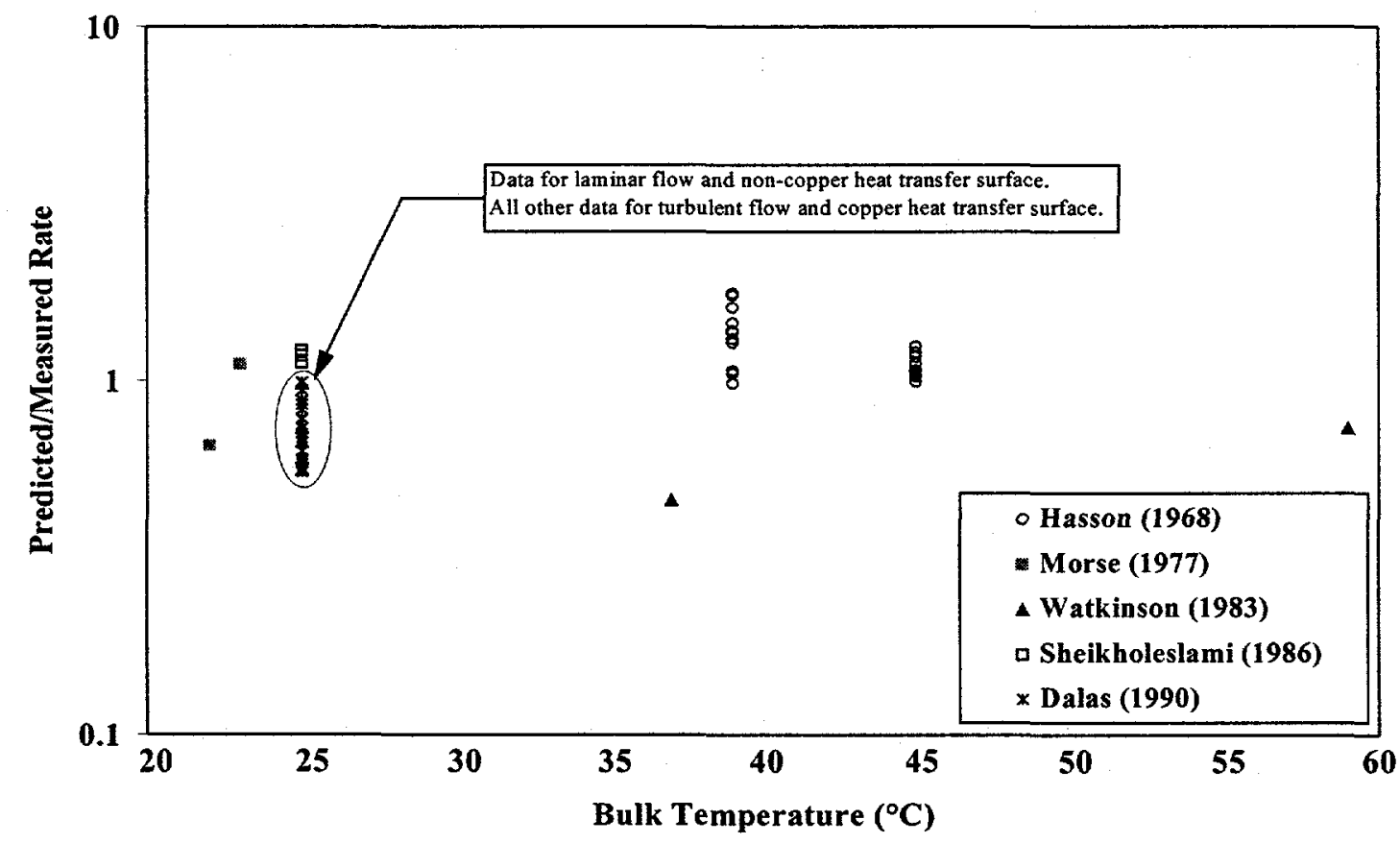

Figure 3.7: Predicted/Measured Scaling Rates versus Bulk Temperature Corrected Baker Diffusion Model

\subsection{Discussion}

All the models are based on the assumption that the precipitating ions diffuse as ions from the bulk to the interface and then integrate into the crystal lattice. The authors claim that no bulk precipitation or particulate fouling occurred in their experiments based on the stability of 
the solutions, strength of the foulant deposited, and/or the use of filters to remove any suspended solids. However, the precipitation rates for the experiments at elevated bulk temperatures exceed predicted diffusion rates by almost an order of magnitude. Unfortunately, bulk temperature dependencies have not been investigated before and conclusions are difficult to draw based on the available information. The following are two possible explanations.

The bulk temperature may affect the quality of the scale being deposited, in particular the scale's porosity. Scaling rates were measured based on fouling resistances while the models predict scaling rates based on mass deposition rates. To compare measured and predicted scaling rates, a density and conductivity of calcium carbonate scale were assumed based on measured experimental data from Table 2.3. It may be possible that at elevated temperatures the porosity of the scale increases, which would decrease the effective conductivity and density of the scale, both of which would increase the fouling resistance for a given mass of scale deposited.

Bulk precipitation may have occurred in these experiments. The bulk precipitation may have occurred in a classical sense, with the particles growing in the bulk and then depositing as particulate fouling. Or calcium carbonate may exist as a stable complex (i.e., not growing) consisting of more than one calcium carbonate molecule for solutions with large degrees of supersaturations. These stable complexes may be physically small enough that they are not seen using standard measures for solids, such as filters, and may not result in a loose foulant thought typical of particulate fouling. Calcium carbonate is known to exist as the complexes $\mathrm{CaCO}_{3}{ }^{\circ}$ and $\mathrm{CaHCO}_{3}{ }^{+}$in the bulk, but the possibility of these complexes combining to form larger complexes was not mentioned in the literature reviewed.

Investigating the dependence of calcium carbonate scaling rates on bulk temperature will be the initial thrust of the proposed research. 


\section{Chapter 4}

Proposed Research

\subsection{Introduction}

Based on the comparison of the scaling rate models proposed in the literature contained in Chapter 3, all the scaling rate models appear to have fundamental problems. Two results from this comparison are most striking. The first is the apparently strong dependence of the [experimentally] measured scaling rate on the bulk temperature that is not captured in any of the models. The second is that, at high bulk temperatures, the measured scaling rate is approximately an order of magnitude higher than the predicted bulk diffusion rate, which is the rate at which the precipitating species diffuse from the bulk to the scaling surface. This result is, of course, physically impossible since the scaling rate cannot be faster than the bulk diffusion rate of the precipitation ions. Neither of these phenomena have been identified in the literature nor are they suggested based on the current theory of the mechanisms by which scaling occurs.

Past scaling rate experiments have measured scaling rates based on either the change in the heat transfer resistance, the change in the bulk water chemistry, or the mass of scale deposited, with most experiments measuring the change in heat transfer resistance. All of the reviewed scaling rate models predict scaling rates based on a mass deposition rate. It seems reasonable that a scale's porosity, and therefore its effective density and thermal conductivity, may vary under different scaling conditions. If this variation really occurs, then the same mass of scale deposited could lead to different thermal fouling resistances. Little research has been performed to compare these different methods of measuring scaling rates or how different parameters may affect the quality, porosity, and thermal resistance of a deposited scale.

The experimental conditions of most scaling rate experiments are such that their results may not be applicable to scaling rates outside the laboratory. Most previous scaling rate experiments have focused on pure calcium carbonate scaling without significant concentrations of other scaling salts being present in the bulk. While it appears that calcium carbonate is the dominant scale in most domestic situations, other ions may be present in solution that could affect calcium carbonate's scaling rate. Texas waters, for example, often have more magnesium than waters in other parts of the United States, and magnesium has been shown to inhibit calcium carbonate scaling. In commercial and industrial situations scales are often mixed and may consist of at least calcium, magnesium, carbonate, phosphate, and chloride. Another problem is that most previous scaling experiments have used carefully prepared water with high saturations 
to obtain high scaling rates, short run times and water chemistries that are simple to model. It is possible that the mechanisms that control the scaling rate under these laboratory conditions are different from those found outside the laboratory, where in general the waters have a lower saturation level, slower scaling rate, and more complex chemistry. Little work has been done to determine how scaling rates measured under controlled laboratory conditions can be generalized to those in actual domestic, commercial, and industrial situations.

\subsection{Proposed Research}

The purpose of the proposed research is to develop a deeper understanding of the mechanisms that control scaling rates under a variety of conditions. The research will focus on conducting experiments to elucidate the parameters that exert the largest influence on scaling rates and developing scaling rate models validated by the experimental results. It is proposed to experimentally investigate the following areas initially, with later experiments possibly being performed based on these results:

(1) Compare scaling rates as measured by changes in bulk water chemistry, changes in fouling resistance, and mass of scale deposited.

(2) Investigate the influences of different parameters on calcium carbonate scaling rates, focusing on bulk temperature.

(3) Investigate scaling rates from untreated water, such as City of Austin tap water and/or cooling water for electric power plants, using long term experiments.

(4) Investigate scaling rates from water containing significant concentrations of calcium and magnesium ions, which in some cases may result in a mixed scale.

This experimental research is divided into five phases, and intermittent summary reports will be generated as necessary. Additionally, these summary reports will form the basis for the author's dissertation. The scaling salt being investigated, anticipated time period when the research will occur and major tasks to be completed for each of the five phases of the experimental research are summarized in Table 4.1. More detailed explanations of the proposed experimental research for each phase are given below. 


\begin{tabular}{|c|c|c|c|}
\hline $\begin{array}{l}\text { Research } \\
\text { Phase }\end{array}$ & $\begin{array}{l}\text { Scaling } \\
\text { Salt }\end{array}$ & Dates & Tasks to be Completed \\
\hline \multirow[t]{2}{*}{ One } & \multirow{2}{*}{$\mathrm{CaCO}_{3}$} & $2 / 98-5 / 98$ & Design and construct initial experimental set-up using single test section \\
\hline & & $6 / 98-8 / 98$ & $\begin{array}{l}\text { Gain experience measuring scaling rates } \\
\text { Compare different methods for measuring scaling rates } \\
\text { Make tentative conclusion on effects of bulk temperature }\end{array}$ \\
\hline \multirow[t]{2}{*}{ Two } & \multirow[t]{2}{*}{$\mathrm{CaCO}_{3}$} & $8 / 98-9 / 98$ & Modify experimental set-up to include multiple test sections \\
\hline & & $10 / 98-1 / 99$ & $\begin{array}{l}\text { Investigate and compare effects of bulk and surface temperature, } \\
\text { fluid velocity, and water supersaturation on } \mathrm{CaCO}_{3} \text { scaling rates }\end{array}$ \\
\hline \multirow[t]{2}{*}{ Three } & \multirow[t]{2}{*}{$?$} & $11 / 99-12 / 99$ & $\begin{array}{l}\text { Design and construct simple test sections to investigate City of } \\
\text { Austin tap water and/or electric power plant cooling water }\end{array}$ \\
\hline & & $1 / 99-8 / 99$ & Investigate scaling from these waters using long-term experiments \\
\hline \multirow[t]{2}{*}{ Four } & \multirow{2}{*}{$\begin{array}{l}\mathrm{CaCO}_{3} / \\
\text { Mixed }\end{array}$} & $12 / 99-1 / 99$ & Experimental design for bulk water with $\mathrm{Ca}^{2+}$ and $\mathrm{Mg}^{2+}$ \\
\hline & & $2 / 99-6 / 99$ & Run experiments \\
\hline \multirow[t]{2}{*}{ Five } & \multirow[t]{2}{*}{$?$} & $5 / 99-6 / 99$ & If time permits, design experiments based on previous results \\
\hline & & $7 / 99-9 / 99$ & Run experiments \\
\hline
\end{tabular}

Table 4.1: Phases of Experimental Research and Major Tasks to be Completed

\subsubsection{Phase One: Initial Experimental Set-up and Calibration}

Phase One will use the experimental set-up described in Section 4.3 to investigate pure calcium carbonate scaling. The main purpose of this phase will be to compare the different methods for measuring scaling rates (mass deposited, change in chemistry, and fouling resistance), to make a preliminary conclusion as to the effect of bulk temperature on scaling rates, and to gain experience in acquiring reliable experimental data. Care must be taken to avoid or account for precipitation occurring outside the test section, which will confound the comparison of the scaling rates measured based on changes in water chemistry with those measured based on mass deposited and fouling resistance. It is anticipated that data will be obtained for bulk temperatures of approximately 25,40 , and $10^{\circ} \mathrm{C}$, with identical bulk water chemistries, flow velocities, and surface temperatures. Experiments at a bulk temperature of approximately $25^{\circ} \mathrm{C}$ will be performed in a normal room. Elevating the bulk temperature to approximately $40^{\circ} \mathrm{C}$ will be done by heating the feed tank and insulating the pipes. For the experiments with a bulk temperature of approximately $10^{\circ} \mathrm{C}$ the experimental set-up will be placed in a $4^{\circ} \mathrm{C}$ cold room in ECJ. Additional runs may be necessary to refine the experimental technique and optimize the scaling rate so that conclusions are possible. A statistical and error analysis of the data will be performed to elucidate any weaknesses in the experimental design and will form the basis for modifications implemented in Phase Two. 


\subsubsection{Phase Two: Pure Calcium Carbonate Scaling}

Phase Two will also investigate pure calcium carbonate scaling. Once the initial data from Phase One is analyzed, the second phase of experiments will be begin. In addition to making modifications to the experimental set-up suggested by the experience gained in Phase One, the equipment will be modified so that a single tank feeds 4 - 5 test sections simultaneously, allowing the effects of flow velocity and surface temperature to be studied using the same bulk water.

The main focus of these experiments will be to check repeatability, further investigate the effect of bulk temperature, and investigate the effects of water chemistry, flow velocity, and surface temperature. However, the variables actually investigated will ultimately be determined based on the results of Phase One.

\subsubsection{Phase Three: Long Term Experiments using Unprepared Water}

Phase Three will investigate scaling from uncontrolled waters sources. A simple experimental set-up will be constructed to run long-term experiments using tap water and/or cooling water from electric power plants. Such an experiment could be performed in ECJ or ETC, while one using cooling water may be located at an electric power plant. The final design of the test sections and experimental method will be heavily dependent on the results from the first two phases, but it is currently envisioned that water will be drawn from the source, flow through the test section, and then be dumped without being recirculated. The test section will consist of a concentric tube, constant-heat-flux heat exchanger, with the tube being a heater and the scaling water flowing through the annulus. Thermocouples will be placed on the scaling surface and periodically the temperature manually read to estimate scaling rates. At the end of each run the mass of scale deposited will be determined. Water samples will be drawn periodically to assess any changes in water chemistry. Although these experiments will be much simpler than the ones using prepared water, they will be essential in understanding to what extent the scaling rates from prepared water can be generalized to real-life applications.

\subsubsection{Phase Four: Water with Dissolved Calcium and Magnesium Ions}

Phase Four will investigate scaling from water containing both calcium and magnesium ions. The resulting scale may be pure calcium carbonate, or a mixed scale containing both calcium and magnesium. It appears that little quantitative research has been performed on scaling rates from water containing both magnesium and calcium ions in significant 
concentrations. One possible reason is that a loose mixed scale may form if both calcium and magnesium precipitate that is more likely to have significant scale removal rates due to fluid shear forces. Significant removal rates make rate data difficult to interpret and adds another layer of complexity to scaling rate models. Additionally, the water chemistry becomes more complex, not only because there may be multiple scaling salts precipitating, but also because it appears that the presence of magnesium ions inhibits the precipitation of calcium carbonate; the reverse may also true. However, these conditions probably simulate those found in industry more closely than the previous conditions.

\subsubsection{Phase Five: Undefined Additional Experiments}

If time permits additional experiments will be performed investigating areas suggested by the experimental results to date. The direction of this final phase may be strongly influenced by the results of Phase Three, where scaling rates from untreated water are investigated, in an attempt to generalize the scaling rates measured under controlled laboratory conditions to those in uncontrolled environments.

\subsubsection{Modeling Work}

In parallel with the experimental work, scaling rate models will be developed based on precipitation theory. Based on the literature review on precipitation theory completed thus far, there are large gaps in precipitation theory that make it difficult to apply directly to scaling rate models. The literature on precipitation will be further reviewed, although it is believed that the experimental results will be instrumental in elucidating the mechanisms of precipitation that are important in scaling. The theory on precipitation as it applies to scaling will be extended and applied to develop scaling rate models, which will be validated using the experimental results. These models will be incorporated into software.

\subsubsection{Writing of Dissertation}

The author will write his dissertation during the fall of 1999 and the proposed graduation date is December, 1999.

\subsection{Experimental Set Up}

It is envisioned that a relatively simple experimental set-up will be initially used to compare the different methods of measuring scaling rates (rate of change of fouling resistance and water chemistry, and mass deposited) and provide tentative conclusions on the effects of 
bulk temperature on scaling rates. The set-up will consist of a tank which feeds a single test section where the scaling occurs. The test section will be followed by a pump, flow meter, and a heat exchanger, used to cool the stream before it is returned to the tank. An automatic titrator will be used to titrate calcium and carbonate compounds back into the feed tank to replace precipitated calcium carbonate. This is shown schematically in Figure 4.1.

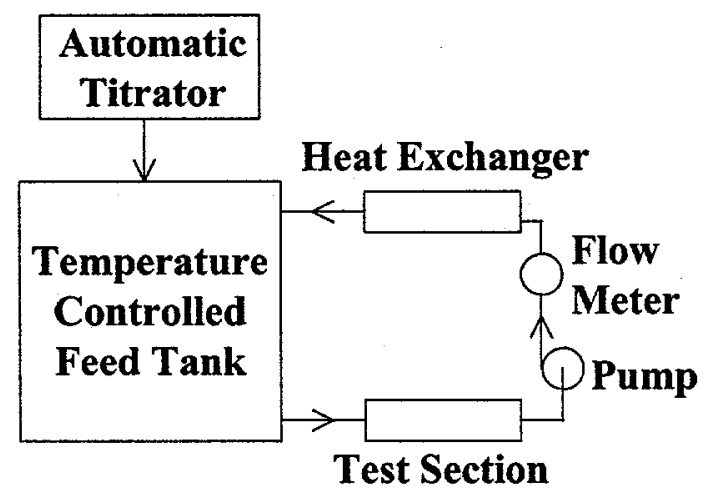

Figure 4.1: Initial Experimental Set-up

After Phase One the experimental set-up will be modified so that a single tank simultaneously feeds multiple test sections. The surface temperature and flow velocity for each test section will be independently controlled so that their effects on scaling rates can be tested using the same bulk water. The automatic titrator will still be used in Phase Two to maintain a constant water chemistry. However, since a single tank will be feeding multiple test sections, the titration rate can no longer be directly correlated to a scaling rate in a single test section. In Phase Four both calcium and magnesium scaling may be occurring, and it may not be possible to use the automatic titrator. In this case it may be necessary to use a larger feed tank to maintain a constant water chemistry.

Details of each part of the initial set-up are given below.

\subsubsection{Feed Tank}

The feed tank will hold a reservoir of water at a constant temperature. The $\mathrm{pH}$ will be constantly measured and a drop in the $\mathrm{pH}$ from a set value, indicating calcium carbonate precipitation has occurred, will trigger an automatic titrator to add calcium and carbonate compounds, such as calcium chloride and sodium carbonate, to return the bulk water to the initial conditions based on the measured $\mathrm{pH}$. The rate of titration will be measured and this will be used as one measure of the rate of scaling. 


\subsubsection{Test Section}

The scaling water will flow through the annulus of a heat exchanger. The inner tube of the heat exchanger will consist of an unheated entry region, a heated test section, and an unheated exit region. The unheated sections will be separated from the heated section using an appropriately chosen thermally insulating material. The surface of the unheated test sections will be a material similar to Teflon, which should inhibit nucleation and keep these sections free of scale. The heated section will consist of a cylindrical heater with variable heat output. During an experimental run, a constant heat flux will be used so that the scale-water interface remains at a constant temperature, assuming the convection coefficient stays relatively constant.

Thermocouples will be placed along the length of the heater and the rise in temperature at the heater surface as scaling occurs will be used as a second measure of the scaling rate. A thin walled copper cylinder will slide over the cylindrical heater and provide the scaling surface. A thermally conductive gel will be placed between the heater and cylinder to minimize the thermal contact resistance between the two. If in the future if it is decided to investigate other heat transfer surfaces, this design will allow other materials to be easily substituted for the copper sleeve. The outer tube of the heat exchanger will be an appropriately chosen clear material that allows visual inspection of the scaling process and that inhibits nucleation, which should keep this surface from scaling. Figure 4.2 schematically shows the construction of the heated portion of the test section.

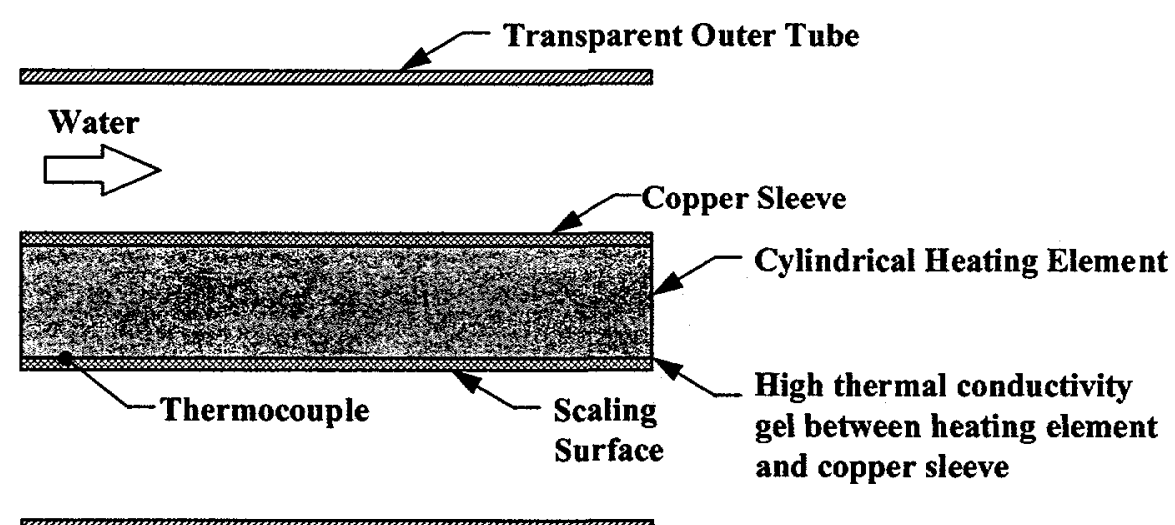

Figure 4.2: Cross Sectional View of the Heated Portion of the Test Section

Either the whole center section or only the section that is heated will be removable so that the scale can be analyzed after a run. Also, it will be possible to circulate an acidic solution 
through the test section after an experimental run to dissolve the deposited calcium carbonate scale, and the acidic solution can then be analyzed to determine the dissolved calcium carbonate, allowing a third measure of the scaling rate based on mass deposited. After the scale has been dissolved from the test section, the test section will be returned to the experimental apparatus. An acidic solution will then be circulated through the entire experimental apparatus and the acid analyzed to determine the precipitation that occurred outside the test section.

\subsubsection{Other}

Following the test section the water will be cooled using a second heat exchanger before being returned to the feed tank. A peristaltic pump will be used to circulate the fluid and a flow meter will measure the flow rate. For select runs, in addition to the scaling rate, the scale's phase, density, porosity, thermal conductivity, and the strength of the scale's adhesion to the heat transfer surface may also be determined.

\subsection{Applied Research on Scaling}

Applied research on scaling that will be performed in parallel to the proposed research, but which is not considered to form a significant portion of the dissertation research, includes work on scaling in solar hot water systems and electric power plants. Under a continuing grant from the Department of Energy through the National Renewable Energy Laboratory, the development of software to predict scaling rates in solar hot water systems will be completed over the next year (Vliet, Lawler, and Baker, 1995, 1997; and Baker, 1996a, 1996b). Major tasks include a proposed joint research project with the Florida Solar Energy Center to collect quantitative field data on scaling in solar hot water systems in Florida. These data will be used to validate the software developed. Work will also be performed to assess the consequences of scaling for different solar hot water designs and determine how this knowledge can be applied to design systems that are resistant to scaling problems. Finally, the scaling rate models developed as part of the dissertation research will be incorporated into the software. Additionally, software similar to that developed for solar hot water systems will be developed for the Lower Colorado River Authority and the American Public Power Association to predict scaling rates in the condensers of electric power plants. 


\section{References}

Andritsos, N., M. Kontopoulou, A.J. Karabelas, and P.G. Koutsoukos, Caclium Carbonate Deposit Formation Under Isothermal Conditions, The Canadian Journal of Chemical Engineering, Vol. 74, p. 911, (1997).

Baker, D.K., Development of Software to Predict Calcium Carbonate Scaling in Solar Domestic Hot Water Systems, Masters Thesis, Department of Mechanical Engineering, The University of Texas at Austin, (1996a).

Baker, D.K., G.C. Vliet, and D.F. Lawler, SOLSCALE: Software to Predict Scaling in Solar Domestic Hot Water Systems, Proceedings of the 1996 Annual Conference, American Solar Energy Society, Asheville, NC, April (1996b).

Baker, J.S., and S.J. Judd, Review Paper: Magnetic Amelioration of Scale Formation, Water Research, Vol. 30, No. 2, p. 247, (1996c).

Burch, J., N. Egrican, and N. Carlisle, Calcium Carbonate Scaling in Solar Domestic Hot Water Systems, Proceedings of the 1990 Annual Conference, American Solar Energy Society, Austin, TX, March 19-22, p. 261, (1990).

Chan, S.H., and K.F. Ghassemi, Analytical Modeling of Calcium Carbonate Deposition for Laminar Falling Films and Turbulent Flow in Annuli: Part I - Formulation and Single Species Model, Journal of Heat Transfer, Vol. 113, p. 735, (1991a).

Chan, S.H., and K.F. Ghassemi, Analytical Modeling of Calcium Carbonate Deposition for Laminar Falling Films and Turbulent Flow in Annuli: Part II - Multispecies Model, Journal of Heat Transfer, Vol. 113, p. 741, August, (1991b).

Christoffersen, J., and M.R. Christoffersen, Kinetics of Spiral Growth of Calcite Crystals and Determination of the Absolute Rate Constant, Journal of Crystal Growth, Vol. 100, p. 203, (1990).

Dalas, E., and P.G. Koutsoukos, Calcium Carbonate Scale Formation and Prevention in a FlowThrough System at Various Temperatures, Desalination, Vol. 78, p. 403, (1990).

Epstein, N, Fouling in Heat Exchangers, Heat Transfer 1978, Proceedings of the Sixth International Heat Transfer Conference, Vol. 6, (1978), as published in Fouling of Heat Transfer Equipment, Proceedings of the International Conference on the Fouling of Heat Transfer Equipment 1979, Rensselaer Polytechnic Institute, Hemisphere Publishing Corporation: Washington, DC, p. 701, (1981a).

Epstein, N, Fouling: Technical Aspects (Afterward to Fouling in Heat Exchangers), Fouling of Heat Transfer Equipment, Proceedings of the International Conference on the Fouling of Heat Transfer Equipment 1979, Rensselaer Polytechnic Institute, Hemisphere Publishing Corporation: Washington, DC, p. 31, (1981b). 
Epstein, N, Fouling of Heat Exchangers, Heat Exchangers: Theory and Practice by J. Taborek, G.F. Hewitt, N. Afgan, Proceedings from the 14th International Center for Heat and Mass Transfer Symposium, 1981, Dubrovnik, Croatia, Hemisphere Publishing Corporation: Washington, p. 795, (1983).

Epstein, N, General Thermal Fouling Models, Fouling Science and Technology edited by L.F. Melo, T.R. Bott, and C.A. Bernardo, Proceedings of the NATO Advanced Study Institute on Advances in Fouling Science and Technology, 1987, Alvor, Portugal, Kluwer Academic Publishers: Dordecht, The Netherlands, p. 15, (1988).

Franke, J., and A. Mersmann, The Influence of the operational conditions on the Precipitation Process, Chemical Engineering Science, Vol. 50, No. 11, p. 1737, (1995).

Gomez-Morales, J., J. Torrent-Burgues, R. Rodriguez-Clemente, Nucleation of Calcium Carbonate at Different Initial pH Conditions, Journal of Crystal Growth, Vol. 169, p. 331, (1996).

Hasson, D., M. Avriel, W. Resnick, T. Rozenman, and S. Windreich, Mechanisms of Calcium Carbonate Scale Deposition on Heat-Transfer Surfaces, I \& EC Fundamentals, Vol. 7, No. 1, p. 59, (1968).

Hasson, D., H. Sherman, and M. Biton, Prediction of Calcium Carbonate Scaling Rates, Proceedings of the 6th International Symposium Fresh Water from the Sea, Vol. 2, p. 193, (1978).

Hasson, D., and I. Perl, Scale Deposition in a Laminar Falling-Film System, Desalination, Vol. 37, p. 279 (1981a).

Hasson, D., Precipitation Fouling, Fouling of Heat Transfer Equipment, Proceedings of the International Conference on the Fouling of Heat Transfer Equipment 1979, Rensselaer Polytechnic Institute, Hemisphere Publishing Corporation: Washington, DC, p. 527, (1981b).

Ishiguro, R., H. Sakashita, K. Sugiyama, and Y. Takamura, Microscopic Study of $\mathrm{CaCO}_{3}$ Scaling on Heat Transfer Surfaces, JSME International Journal, Vol. 36, No. 4, p. 644, (1993).

Keysar, S., R. Semiat, D. Hasson, and J. Yahalom, Effect of Surface Roughness on the Morphology of Calcite Crystallizing on Mild Steel, Journal of Colloid and Interface Science, Vol. 162, p. 311, (1994).

Kralj, D., L. Brecevic, and A.E. Nielsen, Vaterite growth and dissolution in aqueous solution: I. Kinetics of crystal growth, Journal of Crystal Growth, Vol. 104, p. 793, (1990).

Lawler, D.F., Personal conversations, Department of Civil Engineering, The University of Texas at Austin, (1997).

Loewenthal, R.E., and G.V.R. Marais, Carbonate Chemistry of Aquatic Systems, Ann Arbor Science Publishers: Ann Arbor, MI, (1976).

Meyer, H., The Influence of Contaminants on the Growth Rate of Calcite, Journal of Crystal Growth, Vol. 66, p. 639, (1984). 
Morse, R.W., and J.G. Knudsen, Canadian Journal of Chemical Engineering, Vol. 55, p. 272 (1977).

Nancollas, G.H., M.M. Reddy, The Crystallization of Calcium Carbonate: II. Calcite Growth Mechanism, Journal of Colloid and Interface Science, Vol. 36, No. 2, June, p. 824, (1971).

Nielsen, A.E., Kinetics of Precipitation, Pergamon Press: New York, (1964).

Nielsen, A.E., Electrolyte Crystal Growth Mechanisms, Journal of Crystal Growth, Vol. 67, p. $289,(1984)$.

Nielsen, A.E. and J.M. Toft, Electrolyte Crystal Growth Kinetics, Journal of Crystal Growth, Vol. 67, p. 278, (1984).

Reddy, M.M., and G.H. Nancollas, The Crystallization of Calcium Carbonate: I. Isotopic Exchanger and Kinetics, Journal of Colloid and Interface Science, Vol. 36, No. 2, June, p. $166,(1971)$.

Roques, $\mathrm{H}$. and A. Girou, Kinetics of the Formation Conditions of Carbonate Tarters, Water Research, Vol. 8, p. 907, (1974).

Sheikholeslami, R., and A.P. Watkinson, Scaling of Plain and Externally Finned Heat Exchanger Tubes, Journal of Heat Transfer, American Society of Mechanical Engineers (ASME), Vol. 108, p. 147, (1986).

Snoeyink, V.L., and D. Jenkins, Water Chemistry, John Wiley \& Sons: New York, (1980).

Somerscales, E.F.C., and J.G. Knudsen, Fouling of Heat Transfer Equipment, Proceedings of the International Conference on the Fouling of Heat Transfer Equipment 1979, Rensselaer Polytechnic Institute, Hemisphere Publishing Corporation: Washington, DC (1981).

Suitor, J.W., W.J. Marner, and R.B. Ritter, The History and Status of Research in Fouling of Heat Exchangers in Cooling Water Service, The Canadian Journal of Chemical Engineering, Vol. 55, p. 374 (1977).

Taborek, J., T. Aoki, R.B. Ritter, and J.W. Palen, Fouling: The Major Unresolved Problem in Heat Transfer, Chemical Engineering Progress, Vol. 68, No. 2, p. 59, (1972a).

Taborek, J., T. Aoki, R.B. Ritter, and J.W. Palen, Predictive Methods for Fouling Behavior, Chemical Engineering Progress, Vol. 68, No. 7, p. 69, (1972b).

Thompson, J.D., White, M.C., Harrington, G.W., and Singer, P.C., Enhanced Softening: Factors Influencing DBP Precursor Removal, Journal of the American Water Works Association, Vol. 89, Issue 6, p. 94, (1997).

Vliet, G.C., D.F. Lawler, and D.K. Baker, Validation of SOLSCALE: Software to Predict Scaling in Solar Domestic Hot Water Systems, DE-FG36-94 G010034, Year End Report to the National Renewable Energy Laboratory, CO, Oct. (1997). 
Vliet, G.C., D.F. Lawler, and D.K. Baker, Software to Predict Scaling in Solar Domestic Hot Water Systems, DE-FG36-94 G010034, Year End Report to the National Renewable Energy Laboratory, CO, Nov. (1995).

Vliet, G.C., Design of Solar Hot Water Systems for Scale Prevention/Remeditation, Proceedings of the ASME International Solar Energy Conference, Maui, Hawaii, April (1992).

Watkinson, A.P., O. Martinez, Scaling of Heat Exchanger Tubes by Calcium Carbonate, Journal of Heat Transfer, Vol. 97, p. 504, (1975)

Watkinson, A.P., Water Quality Effects on Fouling from Hard Waters, Heat Exchangers: Theory and Practice, Hemisphere Publishing Corporation, Washington, DC, p. 853, (1983).

Weijden, R.D. van der, A.E. van der Heijden, G.J. Witkamp, G.M. van Rosmalen, The Influence of Total Calcium and Total Carbonate on the Growth Rate of Calcite, Journal of Crystal Growth, Vol. 71, p. 190, (1997)

Wiechers, H.N.S., P. Sturrock, and G.v.R. Marais, Calcium Carbonate Crystallization Kinetics, Water Research, Vol. 9, p. 835, (1975). 


\section{Derek K. Baker}

\section{Education:}

Ph.D., Mechanical Engineering, Thermal/fluid systems

December 1999

The University of Texas at Austin, Austin, Texas

(Anticipated)

- Passed Doctorial Qualifying Exam: Passed written and oral exams in heat transfer, thermodynamics, and fluid mechanics.

- DEED Scholarship Recipient, American Public Power Association, 1998

- Presidential Centennial Fellowship Recipient, The University of Texas at Austin, 1996-7

M.S., Mechanical Engineering, Thermal/fluid systems

August 1996

The University of Texas at Austin, Austin, Texas

- Master's Thesis: Development of software to predict calcium carbonate scaling in the heat exchangers of solar hot water systems.

B.S., Mechanical Engineering

Virginia Polytechnic Institute and State University (VA Tech), Blacksburg, Virginia

May 1992

\section{Academic Experience:}

The University of Texas at Austin, Austin, Texas

Development of software to predict scaling rates in solar hot water (SHW) systems

Sept. 1994 - Present

Software is being developed that will allow field personnel to predict if a SHW system will scale a priori. This will allow appropriate measures to be taken proactively, increasing the reliability of these systems. Water chemistry, scaling rate, and SHW system temperature models were developed and incorporated into windows based software using Visual Basic.

Validation is currently in progress including validating the scaling rate models using published scaling rate data, collecting scaling data from SHW systems, and assessing the susceptibility of different SHW system designs to scaling problems.

Development of software to predict scaling rates in electric power plants

Sept. 1997 - Present

Software similar to that developed for SHW systems will be developed to predict scaling rates in electric power plants.

Development of a Web Site to Assist in the Teaching of Thermodynamics

Jan. 1998 - Present

The web site will compliment existing introductory thermodynamic textbooks by using the strengths of the web, such as animation and interactivity, as a learning resource.

\section{Teaching Assistant}

Thermodynamics I Taught weekly 2 hour discussion session

Aug. - Dec. 1996

Thermodynamics II

Substitute teacher and grader

June - Aug. 1996

Solar Energy

Grader

June - Aug. 1996

Thermal/Fluids Lab

Taught weekly 3 hour labs

Aug. - Dec. 1994 


\section{Industry Experience:}

New England Electric Systems (NEES), Westborough, Massachusetts April 1993 - July 1994 Contract Engineer

Technology Demonstration Programs: Assisted in demonstration projects to determine the effectiveness of ground source heat pumps (GSHP) and solar domestic hot water (SDHW) systems in the New England region.

Monitoring: Managed a monitoring program of controlled residential water heaters and analyzed data to determine the program's cost effectiveness.

Computer Modeling: Refined a computer program to model variable-speed-drive savings in HVAC applications.

Siv. Ing. Gaute Flatheim, Stavanger, Norway

Mechanical Engineer, HVAC consulting

Sept. - Nov. 1992

Computer modeling: Computer modeled the monthly thermal house load and the monthly thermal output of solar collectors for a solar heated house. Created a video presentation of the house for the 1993 International Solar Energy Conference.

ABB, Gas Turbine Power Division, Chester, Virginia

May - Aug. 1992

Mechanical Engineer Summer Intern, Gas Turbine Manufacturing

- Reliability Research: Researched rotor settling in gas turbines due to high temperatures.

- Failure Analysis: Analyzed performance data leading up to a gas turbine failure.

Duke Power Company, Mt. Holly, NC

Aug. 1988 - Aug. 1990

Mechanical Engineer Co-op, Fossil Power Plant Maintenance Center

- Control Panel Design: Designed, constructed, and installed control panel for a heat treat oven.

\section{Publications and Reports:}

Baker, D.K. and G.C. Vliet, Designing for Scaling in Solar Domestic Hot Water Systems, Proceedings of the 1998 Annual Conference, American Solar Energy Society, Albuquerque, NM, June (1998).

Vliet, G.C., D.F. Lawler, and D.K. Baker, Validation of SOLSCALE: Software to Predict Scaling in Solar Domestic Hot Water Systems, DE-FG36-94 G010034, Year End Report to the National Renewable Energy Laboratory, CO, Oct. (1997).

Baker, D.K., Development of Software to Predict Calcium Carbonate Scaling in Solar Domestic Hot Water Systems, Masters Thesis, Department of Mechanical Engineering, The University of Texas at Austin, (1996).

Baker, D.K., G.C. Vliet, and D.F. Lawler, SOLSCALE: Software to Predict Scaling in Solar Domestic Hot Water Systems, Proceedings of the 1996 Annual Conference, American Solar Energy Society, Asheville, NC, April (1996).

Vliet, G.C., D.F. Lawler, and D.K. Baker, Software to Predict Scaling in Solar Domestic Hot Water Systems, DE-FG36-94 G010034, Year End Report to the National Renewable Energy Laboratory, CO, Nov. (1995). 